UNIVERSIDADE DE SÃO PAULO

ESCOLA DE ENGENHARIA DE SÃO CARLOS

DEPARTAMENTO DE ENGENHARIA MECÂNICA

\title{
Sistema de laser de diodo de cavidade estendida para padrões de frequência
}

JAIR DE MARTIN JUNIOR

Orientador: Prof. Dr. Daniel Varela Magalhães

São Carlos 



\section{Sistema de laser de diodo de cavidade estendida para padrões de frequência}

Dissertação apresentada à Escola de Engenharia de São Carlos da Universidade de São Paulo, com parte dos requisitos para a obtenção do título de Mestre em Engenharia Mecânica . Área de concentração: Dinâmica de Máquinas e Sistemas.

Orientador: Prof. Dr. Daniel Varela Magalhães

São Carlos

2013
ESTE EXEMPLAR TRATA-SE

DA VERSÃO CORRIGIDA. A VERSÃO ORIGINAL ENCONTRA-SE DISPONÍVEL JUNTO AO DEPARTAMENTO DE ENGENHARIA MECÂNICA DA EESC-SP 
AUTORIZO A REPRODUÇÃO TOTAL OU PARCIAL DESTE TRABALHO, POR QUALQUER MEIO CONVENCIONAL OU ELETRÔNICO, PARA FINS DE ESTUDO E PESQUISA, DESDE QUE CITADA A FONTE.

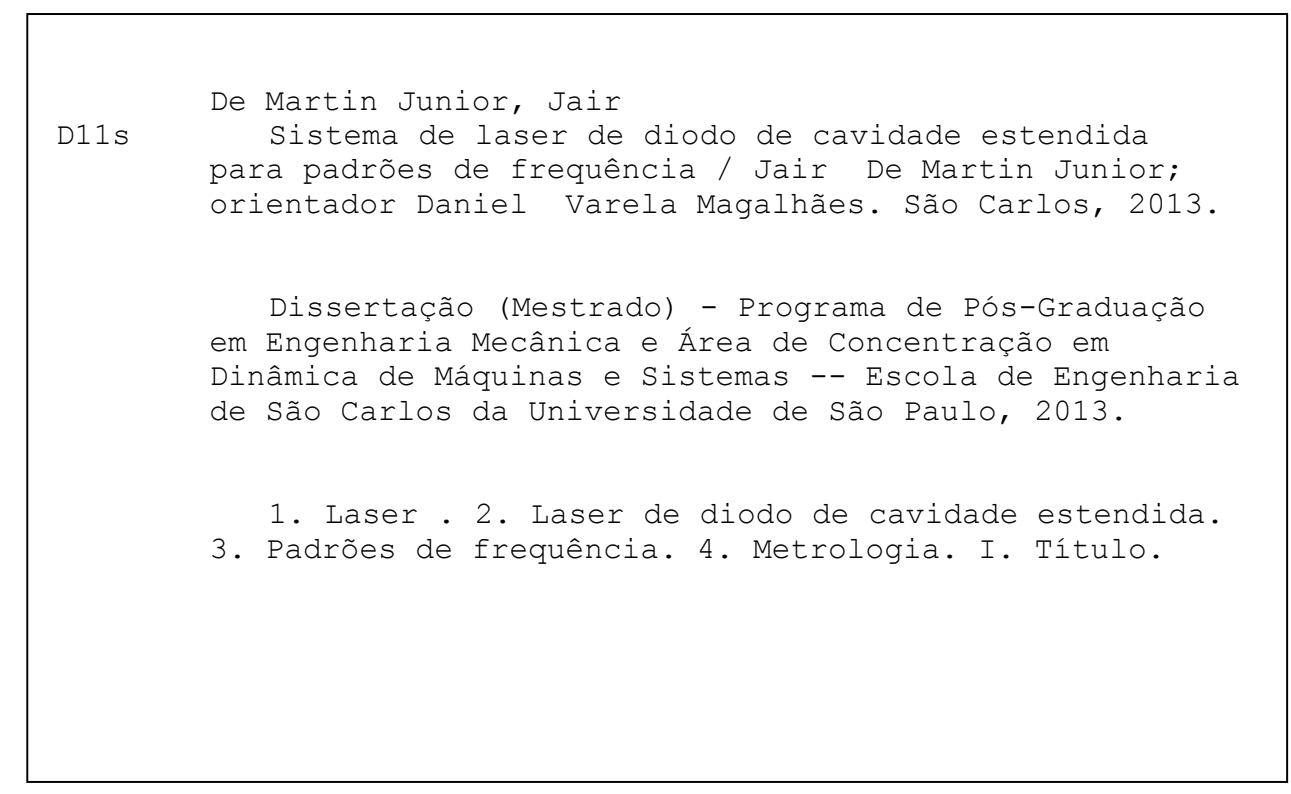




\section{FOLHA DE JULGAMENTO}

Candidato: Engenheiro JAIR DE MARTIN JÚNIOR.

Título da dissertação: "Sistema de laser de diodo de cavidade estendida para padrões de frequência".

Data da defesa: 10/05/2013

\section{Comissão Julgadora:}

Prof. Dr. Daniel Varela Magalhães (Orientador)

(Escola de Engenharia de São Carlos/EESC)

Prof. Dr. Rodrigo Nicoletti

(Escola de Engenharia de São Carlos/EESC)

Drª . Kilvia Mayre Farias

(Instituto de Física de São Carlos/IFSC)

\section{Resultado:}

Apuovano

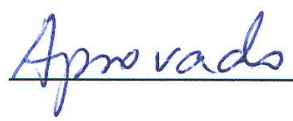

APROUADO

Coordenador do Programa de Pós-Graduação em Engenheira Mecânica:

Prof. Associado Marcelo Areias Trindade

Presidente da Comissão de Pós-Graduação:

Prof. Titular Denis Vinicius Coury 
Dedico este trabalho à minha familia e à Deus 


\section{Agradecimentos}

À Deus, por iluminar meu caminho todos os dias, ajudando-me a conquistar essa grande vitória.

Ao meu orientador Prof. Dr. Daniel Varela Magalhães pela confiança em mim depositada durante os 2 anos de mestrado, além da orientação tornou-se um grande amigo.

Aos meus colegas de laboratório, pelo companherismo e bom ambiente de trabalho.

A pesquisadora Stella Müller pelo apoio no desenvolvimento do meu projeto.

Aos meus amigos do LIEPO e LAT pelo grande apoio no desenvolvimento do meu projeto e pela grande amizade.

Aos meus amigos do Grupo de Óptica pela ajuda e companherismo.

Aos meus amigos da oficina mecânica do Institudo de Física pelo bom trabalho realizado na caixa do laser.

Ao Cloves, pelo grande apoio na formatação da minha dissertação.

Ao Andrez, pelas aulas de física quântica.

Aos meus pais Jair De Martin e Susette de Cassia Beil De Martin e irmãos: João Paulo De Martin e Michelle De Martin, pela confiança, amor e apoio nos momentos mais difíceis.

A meus avós Evilásio De Martin(in memoriam) e Antônia Galiardi De Martin (in memoriam) pelo carinho e valor que em mim depositava.

A minha futura esposa Silmara da Silva Dias e meu filho Miguel Dias De Martin pela confiança, amor, inspiração e motivação, nos quais foram essênciais para meu mestrado.

À Fundação de Amparo à Pesquisa do Estado de São Paulo (FAPESP) pelo apoio financeiro pessoal.

Ao apoio financeiro das agências, CAPES, CNPq e CePOF-FAPESP ao projeto. 
Talvez não tenha conseguido fazer o melhor, mas lutei para que o melhor fosse feito. Não sou o que deveria ser, mas Graças a Deus, não sou o que era antes. 


\section{Resumo}

MARTIN JR, J. (2013). Sistema laser de diodo de cavidade estendida para padrões de frequência. Dissertação de Mestrado, Escola de Engenharia de São Carlos, Universidade de São Paulo, São Carlos.

Este trabalho tem como objetivo principal desenvolver uma nova fonte de laser de diodo compacta e robusta, além de um novo drive de controle para serem utilizados em padrões primário de tempo e frequência tipo chafariz de átomo de Césio e padrões compacto baseados em átomos frios. Um dos requisitos para utilização de laser de diodo em padrões primários de tempo e frequência é sua estabilidade em frequência e baixíssimo ruído espectral. Além disto, dada à aplicação embarcada, o laser deve ser extremamente robusto com relação às condições adversas: mecânicas, térmicas e elétricas. Tanto a parte optomecânica, quanto os controles eletrônicos do novo laser foram desenvolvidos neste trabalho. Vale salientar que tal sistema, em sua concepção, é de grande interesse para diversos outros tipos de aplicação, como espectroscopia de gases (LIDAR), referências em outras frequências e experimentos de física atômica e molecular, que possuem elevados níveis de exigência com relação a ruídos espectrais.

Palavras chaves: Laser, Laser de diodo de cavidade estendida, Padrões de frequência, Metrologia. 


\begin{abstract}
MARTIN JR, J. (2013). Extended cavity diode laser system for primary frequency standards. Master's Dissertation, Escola de Engenharia de São Carlos, Universidade de São Paulo, São Carlos.
\end{abstract}

This work has as main objective to develop a new source of diode laser compact and robust, beyond a new drive control for use in primary of time and frequency standards type cesium atom fountain and compact standards-based cold atoms. One of the requirements for the use of diode laser in primary of time and frequency standards are their stability in frequency and are very low spectral noise. Furthermore, given the embedded application, the laser must be extremely robust with respect to adverse conditions: mechanical, thermal and electrical. Both opto-mechanical part, as the electronic controls of the new laser were developed in this work. It is noteworthy that such a system, in its conception, is of great interest to many other types of applications such as spectroscopy of gases (LIDAR), references in other frequencies and experiments of atomic and molecular physics, which have high levels of demand with respect to spectral noise.

Key word: Lasers, External Cavity Diode Laser, Frequency Standards, Metrology. 


\section{Lista de Figuras}

Figura 1: Diagrama genérico para um Padrão de frequência atômico. 35

Figura 2: Sistema de vácuo de um padrão de frequência tipo chafariz...................................36

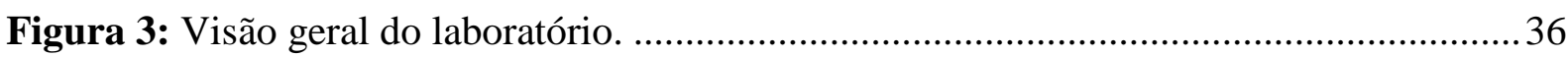

Figura 4: Mesa óptica do padrão de frequência tipo chafariz. .............................................. 37

Figura 5: Diagrama da mesa óptica do chafariz atômico (Alves, 2012)............................... 38

Figura 6: Diferença entre um esquema espacial e temporal de um padrão de tempo e frequência (Müller, 2010).

Figura 7: Esquema de funcionamento de um padrão de frequência compacto (Müller, 2010).

Figura 8: Mesa óptica do padrão compacto.

Figura 9: Diagrama da mesa óptica do padrão compacto.

Figura 10: Comparação do tamanho de um laser com uma moeda (WIKIPÉDIA). 43

Figura 11: Cavidade de um laser de diodo 44

Figura 12: Princípio de funcionamento de um laser de diodo (Cepof - IFSC). 44

Figura 13: Potência de saída versus corrente elétrica. 45

Figura 14: Modos Longitudinais de laser de diodo. 1 - Curva do ganho do laser; 2 - Modos longitudinais de um laser de diodo livre; 3 - Modos longitudinais de um laser de diodo montado em uma cavidade estendida; 4 - Resposta espectral de um elemento seletor de

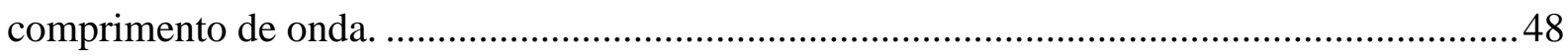

Figura 15: Laser com cavidade estendida em configuração de Littrow (Rp-Photonics) ........ 49

Figura 16: Laser com cavidade estendida em configuração de Littman (Rp-Photonics)........50

Figura 19: Cavidade estendida com filtro de interferência (Baillard et al., 2006).................50

Figura 17: Configuração Littrow. 1- Laser de diodo; 2 - Lente de colimação; 3 - Rede de

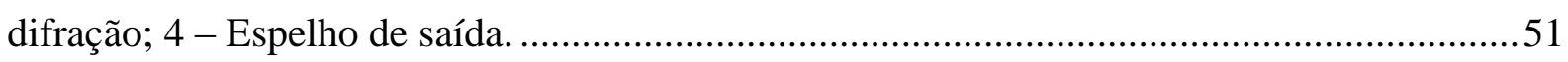

Figura 18: Absorção Saturada do átomo de césio (TUBOY, 1996) .....................................52

Figura 20: Diagrama de blocos do sistema de laser de diodo, 1-Amplificador Lock-in.........53

Figura 21: (a)Sinal de absorção saturada de uma célula de vapor de Cs133 com destaque para a transição a ser usada como referência para o travamento do laser; (b) Sinal de saída do demodulador síncrono usado para gerar o sinal de erro para o circuito de controle. ...............54

Figura 22: Curva característica de potência de saída versus corrente de injeção ....................56 
Figura 23: Laser de diodo, SDL 5422 H1 em encapsulamento TO-3 ................................. 56

Figura 24: Esquema da vista lateral da montagem do elemento sensor (termistor) e de atuação (peltier) base do laser. 57

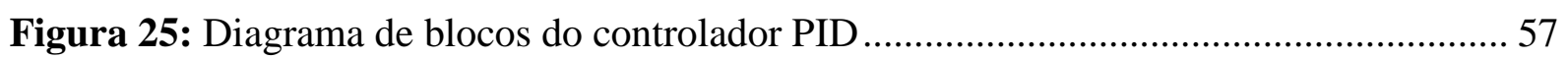

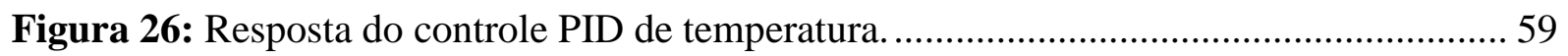

Figura 27: Diagrama de bloco do controle de temperatura do laser..................................... 59

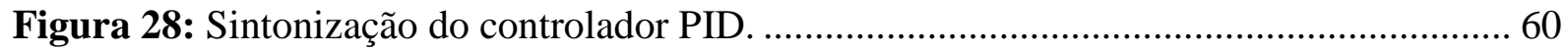

Figura 29: Medida do sinal de erro para a operação no limite de estabilidade do sistema (ganho crítico).

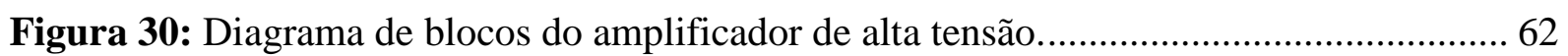

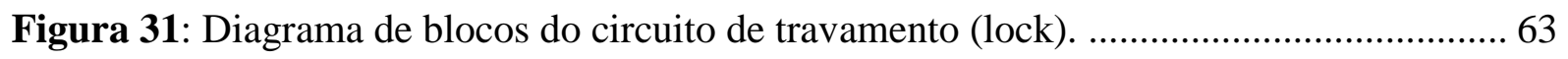

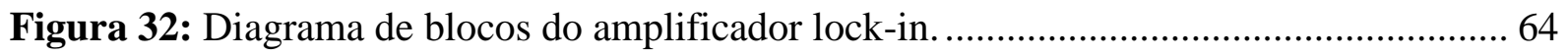

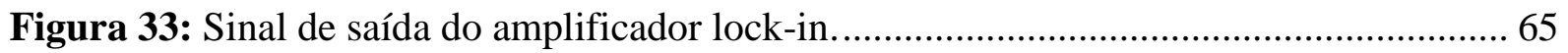

Figura 34: Sistema de referência de absorção saturada (Alves, 2012)................................. 65

Figura 35: Perfil Doppler do átomo de Césio (Magalhães, 2004)......................................... 66

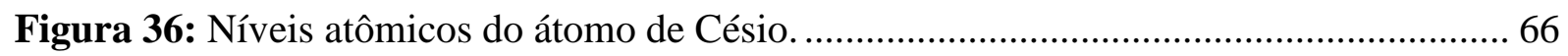

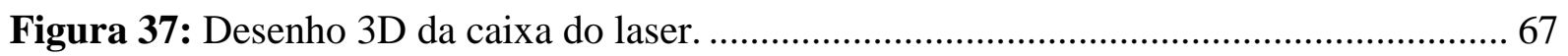

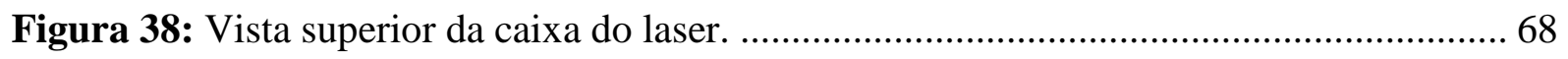

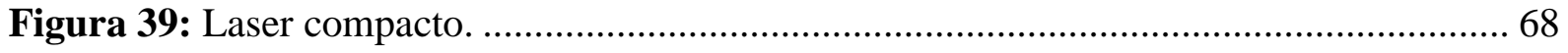

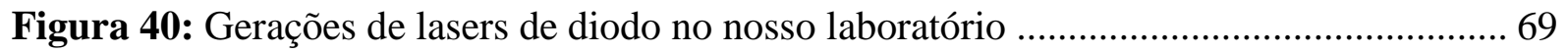

Figura 41: Estabilidade do controle PID de temperatura da caixa do laser.......................... 71

Figura 42: Estabilidade do controle PID de temperatura do laser ....................................... 72

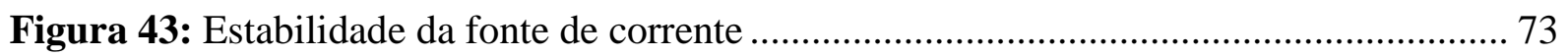

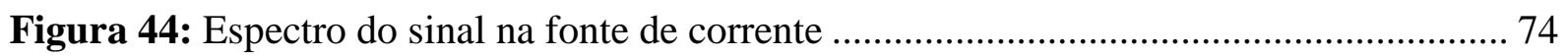

Figura 45: Configuração do sistema para avaliação de ruído nos resistores. ......................... 75

Figura 46: Sinais espectrais do ruído nos resistores............................................................ 75

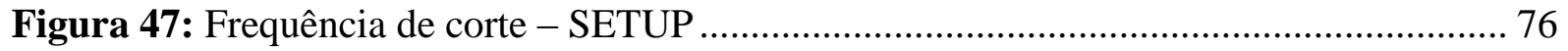

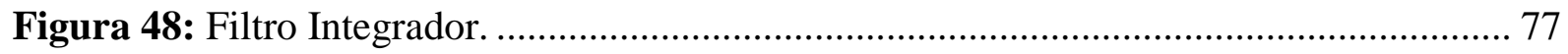

Figura 49: Sinal utilizado para fazer o travamento do laser (Zhao, et. al. 2004). ................. 78

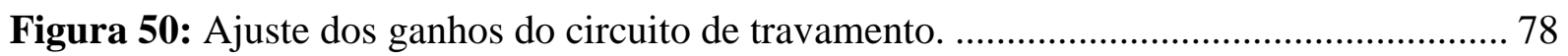

Figura 51: Esquemático da análise de ruído na fonte de alimentação .................................... 79

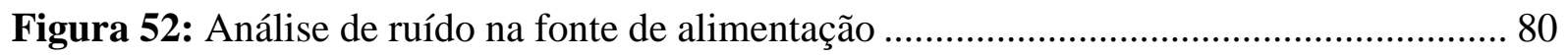

Figura 53: Modos na transmissão da cavidade externa do laser.......................................... 81

Figura 54: Seleção do modo em aproximadamente 852nm.................................................. 82 
Figura 55: Sistema de absorção saturada montado para servir de referência para o laser de cavidade estendida...... 82

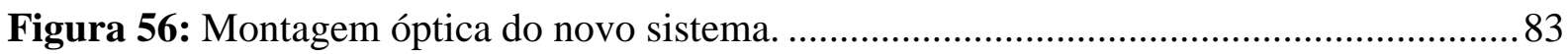

Figura 57: Perfil Doppler (laranja) e o sinal utilizado para fazer o travamento (azul).......... 84

Figura 58: Diferença entre o primeiro vale da absorção e o segundo.................................... 84

Figura 59: Sinal de saída lock-in, utilizado para fazer o travamento do laser. ...................... 85

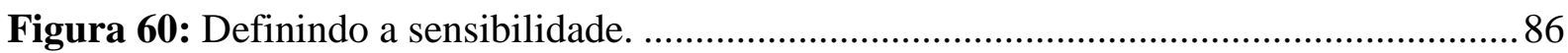

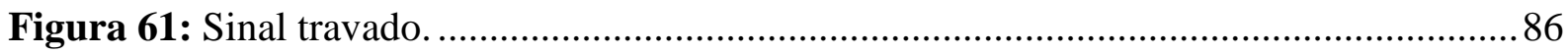

Figura 62: Configuração para a avaliação do sinal de ruído do laser. ...................................87

Figura 63: Espectros dos sinais de ruído dos lasers de diodo, utilizado para fazer a

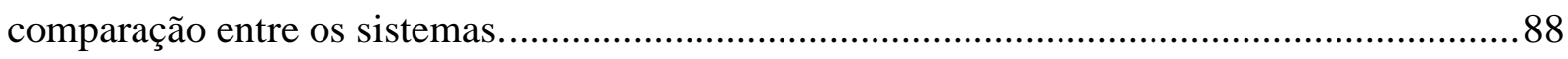

Figura 64: Caixa dos controles eletrônicos do sistema de laser de diodo desenvolvido nesse

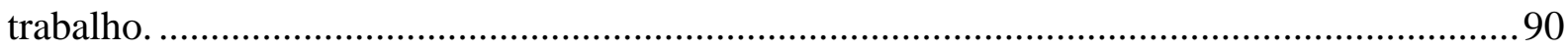

Figura 65: Topologias de conexão entre diversos controles de lasers interligados a um controle central. . 91 
xviii 


\section{Lista de Tabelas}

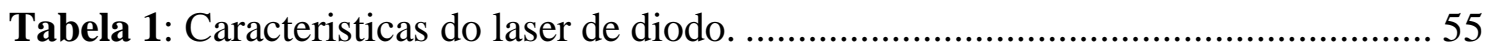

Tabela 2: Frequência de corte do amplificador de alta tensão...................................... 76 


\section{Lista de abreviatura e siglas}

$\begin{array}{ll}\text { BIPM - } & \text { International Bureau of Weights and Measures } \\ \text { CepoF - } & \text { Centro de Pesquisa em Óptica e Fotônica } \\ \text { DL } & \text { Diode Laser } \\ \text { FFT - } & \text { Fast Fourier Transform } \\ \text { FI } & \text { Filtro de interferência } \\ \text { GE } & \text { General Electric } \\ \text { IFSC - } & \text { Instituto de Física de São Carlos } \\ \text { LASER } & \text { Light Amplification by Stimulated Emission of Radiation } \\ \text { LC } & \text { Lente Colimadora } \\ \text { LED } & \text { Light Emitting Diode } \\ \text { LIDAR } & \text { Light Detection And Ranging } \\ \text { MOT } & \text { Magneto Optical Trap } \\ \text { NBS } & \text { National Bureau of Standards } \\ \text { NIST } & \text { National Institute for Standards and Technology } \\ \text { OC } & \text { Output couple } \\ \text { PID } & \text { Proporcional Integral e Derivativo } \\ \text { PZT } & \text { Piezoelectric Transducer } \\ \text { SI - } & \text { Sistema Internacional de Unidades } \\ \text { SMD } & \text { Surface Mount Device } \\ \text { TAC } & \text { Tupiniquim Atomic Clock } \\ \text { TAI } & \text { Temps atomique international } \\ \text { UTC } & \text { Universal Time Coordinated } \\ \end{array}$


xxii 


\section{Nomeclatura}

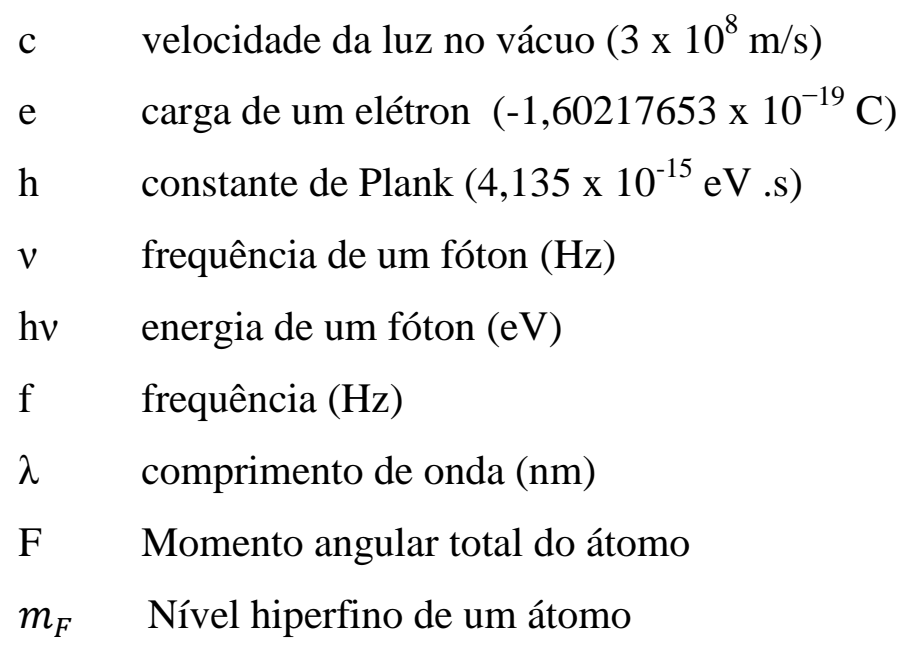


xxiv 


\section{Sumário}

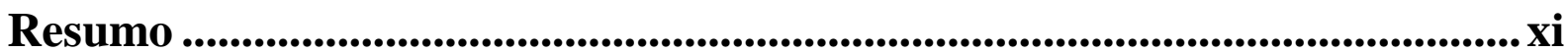

Abstract .................................................................................................................

Lista de Figuras ........................................................................................................

Lista de Tabelas .................................................................................................. xix

Lista de abreviatura e siglas ............................................................................xi

Nomeclatura....................................................................................................xxiii

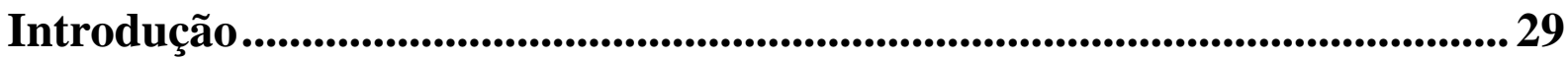

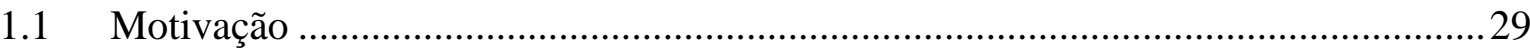

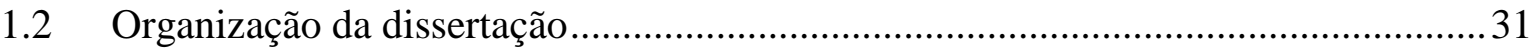

Revisão Bibliográfica ....................................................................................................33

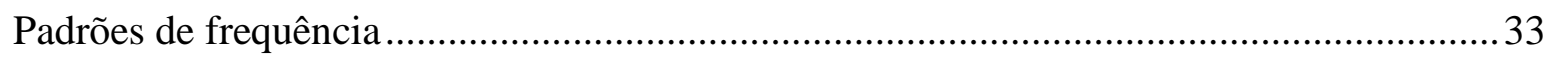

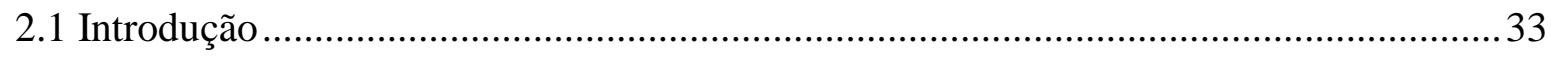

2.2 Visão geral de um padrão de frequência ................................................................. 34

2.3 Relógio Atômico tipo Chafariz............................................................................. 35

2.4 Montagem óptica do padrão de frequência tipo chafariz .............................................. 37

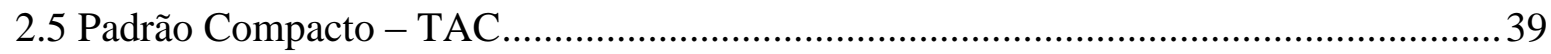

2.6 Montagem óptica do padrão de frequência compacto .............................................. 40

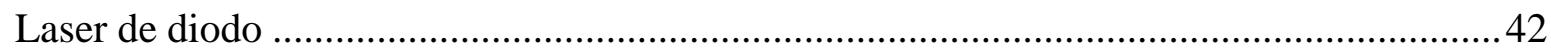

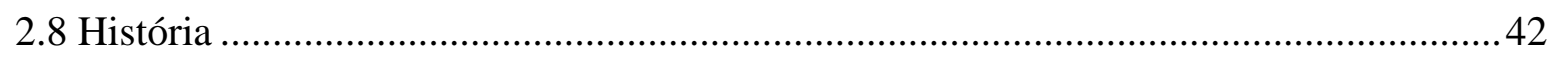

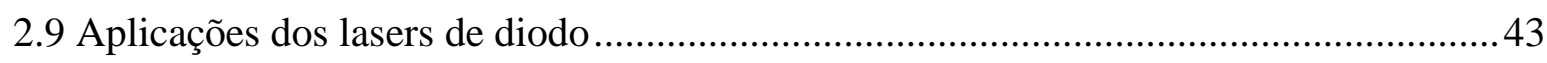

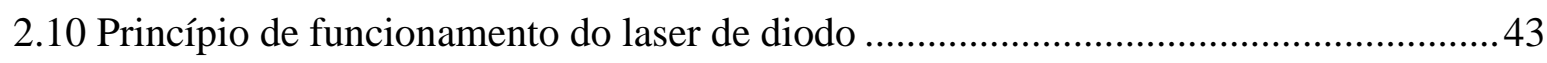

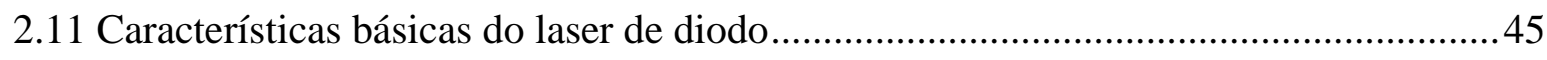

2.11.1 Corrente limiar e Potência de saída ................................................................ 45

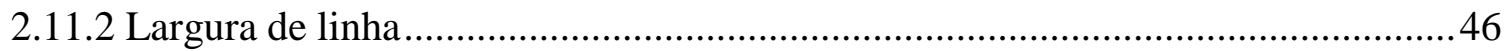


2.12 Laser Diodo de Cavidade Estendida para padrões de tempo e frequência

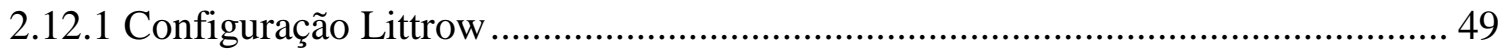

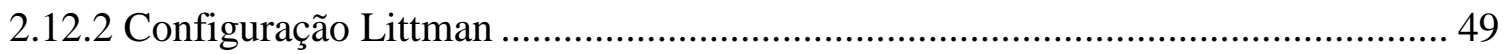

2.12.3 Laser de Cavidade Estendida com filtro de interferência ................................... 50

2.13 Largura de linha com relação ao tamanho da cavidade externa ................................. 51

Projeto do sistema laser de diodo............................................................53

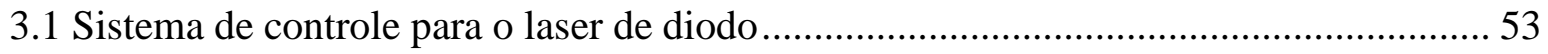

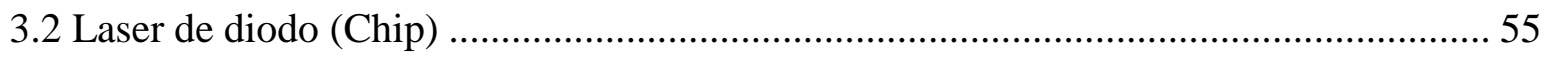

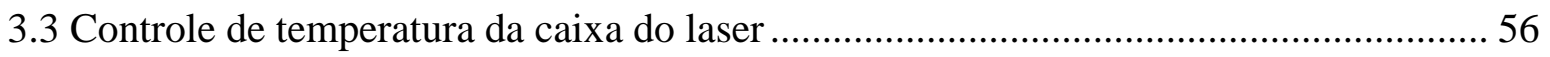

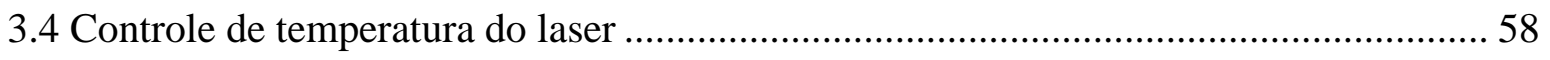

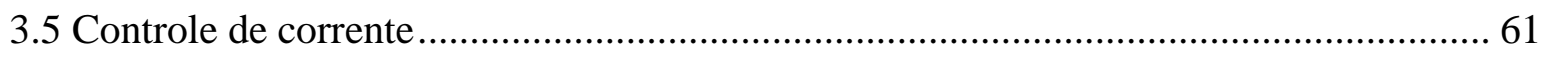

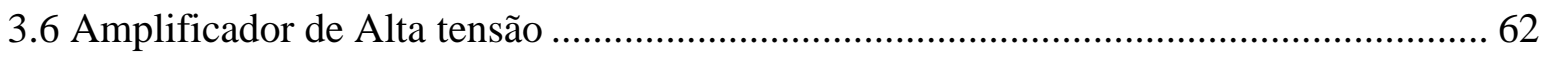

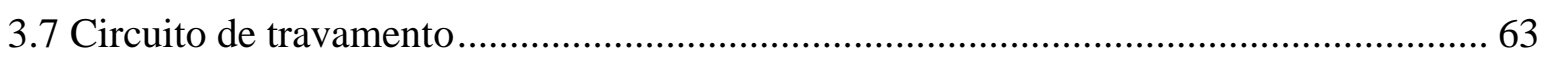

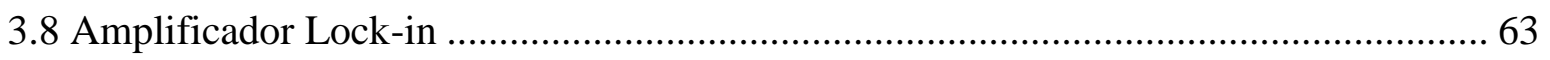

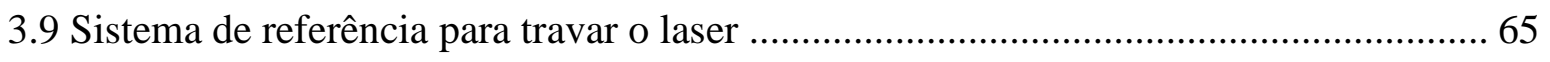

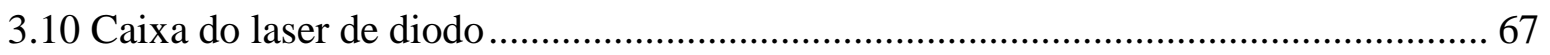

Caracterização de subsistemas...................................................................71

4.1 Estabilidade dos controles de temperatura ........................................................ 71

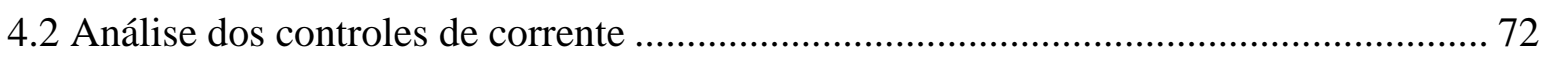

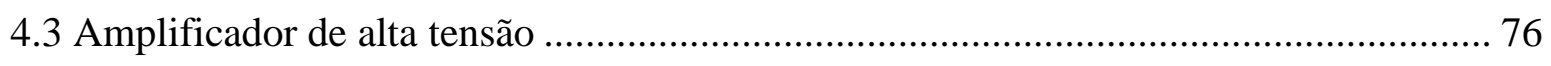

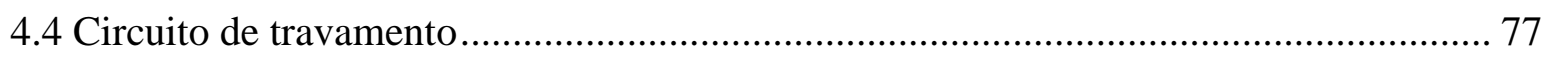

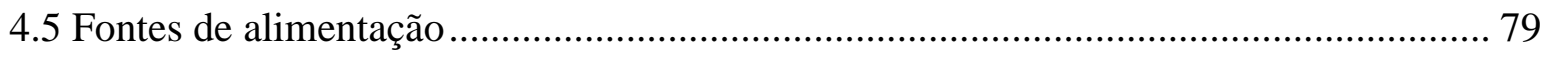

Caracterização em operação do laser de diodo ...........................................81

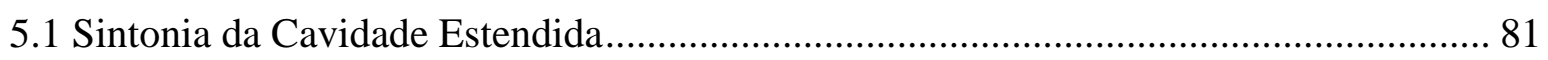

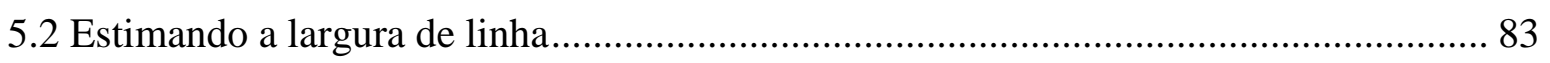

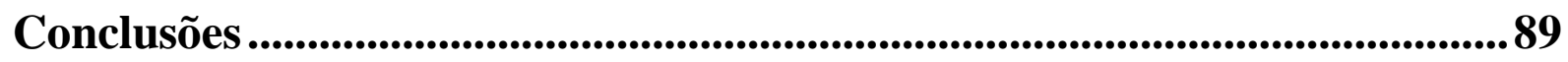

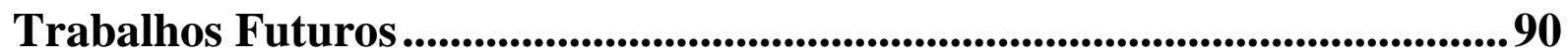


Referências bibliográficas .....................................................................................................93

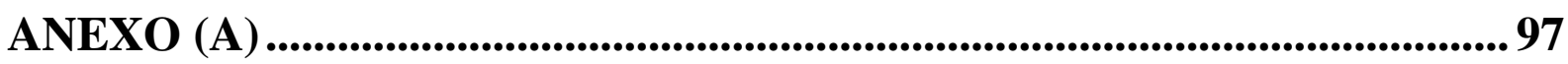

ANEXO (B) .................................................................................................................... 105

ANEXO (C)

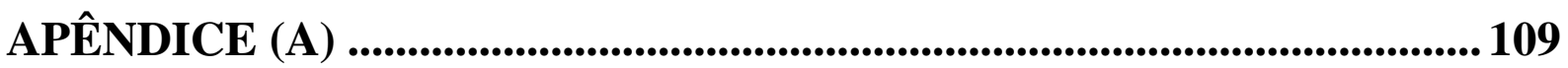

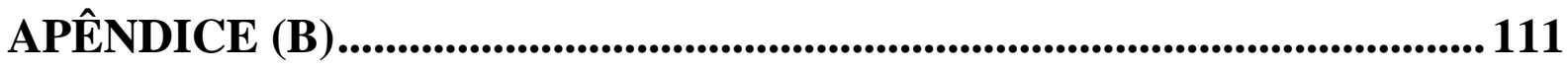

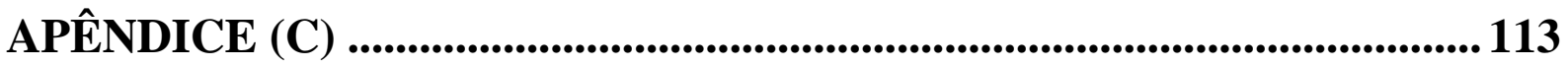

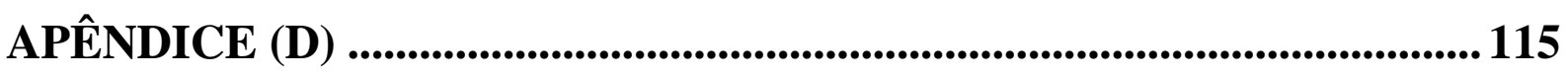

APÊNDICE (E) 
xxviii 


\section{Capítulo 1}

\section{Introdução}

\subsection{Motivação}

A grande necessidade em medir o tempo com maior precisão em metrologia, tanto científica como industrial, deu origem aos relógios baseados em propriedades atômicas. $\mathrm{O}$ primeiro experimento deste tipo utilizando propriedades atômicas ocorreu em 1949, quando o National Institute for Standards and Technology (NIST, na época National Bureau of Standards - NBS), construiu um padrão de tempo e frequência baseado na transição atômica da amônia. Porém, o relógio de amônia não teve bons resultados comparado aos relógios convencionais da época e foi, de certo modo, deixado de lado. Em 1955 o National Physical Laboratory (NPL) na Inglaterra construiu o primeiro padrão de tempo e frequência utilizando átomos de césio, com resultados mais promissores (Ahmed et al., 2007). A partir daí numa reunião do comitê consultivo de Tempo e Frequência, ocorrida em Paris no dia 8 de outubro de 1964, o Bureau International des Poids et Mesures (BIPM) adotou a definição de um padrão atômico temporário, definindo-se um novo padrão a ser investigado para o segundo:

"The standard to be employed is the transition between the two hyperfine levels $\mathrm{F}=4, \mathrm{~m}_{\mathrm{f}}=0$ and $\mathrm{F}=3, \mathrm{~m}_{\mathrm{f}}=0$ of the fundamental state $6 \mathrm{~S}_{1 / 2}$ of the atom of cesium 133, undisturbed by external fields, and the value 9192631770 hertz is assigned" (NBS Technical New Bulletin, 1964).

Durante a $13^{\text {a }}$ Conferência Geral de Pesos e Medidas, realizada em outubro de 1967 em Paris, confirmou-se uma nova definição para o segundo:

“La seconde est la durée de 9192631770 périodes de la radiation correspondant à la transition entre les deux niveaux hyperfins de l'état fondamental de l'atome de ${ }^{133} \mathrm{Cs}$ " (Conférence Générale Des Poids Et Mesures, 1967-1968). 
Após essa decisão os laboratórios de tempo e frequência do mundo direcionaram suas pesquisas para desenvolver sistemas capazes de reproduzir tal definição com mais e mais estabilidade e exatidão.

No Brasil, o Instituto de Física de São Carlos da Universidade de São Paulo, iniciou um programa de metrologia de tempo e frequência com o intuito de reduzir a diferença entre o Brasil e os países desenvolvidos, tais como: Estados Unidos com o NIST e a França com a Agência Nacional de Metrologia (BNM).

O laboratório de Sistemas de Refência faz parte de um seleto grupo de grupos de pesquisa que possuem relógios atômicos tipo chafariz. Um dos principais objetivos do grupo é contribuir com o Tempo Atômico Universal (TAI) e com o Tempo Universal Coordenado (UTC). Sendo assim, o grande desafio atualmente está relacionado à robustez e à estabilidade de cada parte do sistema. Uma descrição mais detalhada de um relógio atômico será abordada nos capítulos seguintes.

Além disso, está sendo desenvolvido um padrão de tempo e frequência móvel. Em vista disso, a necessidade de compactar cada componente do sistema é fundamental e, dada a aplicação móvel, o sistema deverá ser extremamente robusto com relação as condições adversas.

Em quase todos os tipos de padrão de frequências atualmente, sistemas de laser de diodo de baixa largura espectral são de extrema importância. Tais lasers são utilizados em processos de bombeamento e detecção óptica (padrão de feixe térmico operado opticamente) ou nos processos de resfriamento, manipulação e detecção óptica (chafariz atômico). Além disso, as fontes de lasers de diodo ocupam um papel fundamental em outras áreas científicas, principalmente em espectroscopia atômica. Com o avanço tecnológico, essas fontes tornaramse mais estáveis, com largura de linha reduzida e sintonia mais fina, permitindo diversos avanços no estudo da interação atômica com radiação eletromagnética. 
No mercado, atualmente, há vários tipos de sistemas de laser de diodo, porém, raramente encontramos algum que seja capaz de atender aos requesitos desejados no nosso sistema, em relação à largura de linha, robustez mecânica e banda de modulação do laser. Por essas razões, decidimos desenvolver um sistema de laser de diodo com cavidade estendida para ser utilizado nos relógios atômicos de átomos frios ou em outros experimentos e aplicações que necessitem de uma fonte laser com alta resolução espectral.

Como pontos mais específicos temos:

- O sistema de laser de diodo é de cavidade estendida, utilizando um filtro de interferência como elemento de seleção do modo intracavidade;

- O comprimento de onda do laser é de 852,1 nm, referente à linha D2 do átomo de Cs133.

- Utilização de componentes eletrônicos de montagem de superfície (Surface Mount Device - SMDs), para compactação das placas de circuitos impressos e redução de ruído eletrônico.

\subsection{Organização da dissertação}

Será apresentada no próximo capítulo uma revisão bibliográfica dos temas pertinentes a este projeto, com respeito ao estado da arte dos lasers de diodo, lasers de diodo com cavidade estendida, filtro de interferência e padrões de frequência (Capítulo 2). No Capítulo 3, será apresentada uma descrição mais completa sobre o projeto, descrevendo cada componente utilizado. Análise de ruído e estabilidade de cada componente do sistema será visto no Capítulo 4. A caracterização do laser de diodo com cavidade estendida será apresentada no Capítulo 5 e por fim o Capítulo 6 apresenta as conclusões obtidas e perspectivas futuras do trabalho. 


\section{Capítulo 2}

\section{Revisão Bibliográfica}

\section{Padrões de frequência}

\subsection{Introdução}

Os padrões de tempo e frequência são sistemas em que trava-se um oscilador local em uma referência atômica, sua precisão pode chegar na ordem de $10^{-18}$. Utilizando-se um padrão de frequência com um contador tem-se os chamados relógios atômicos, que desde 1964 são utilizados para definir o segundo (Alves, 2012).

Para associar um átomo a um bom oscilador, sendo que, bons osciladores têm que fornecer um sinal periódico e constante ao longo do tempo, utiliza-se dois níveis de energia E1 e E2 de um átomo, onde E2 > E1. Em meados de 1910, Bohr descobriu que os níveis de energia dos átomos são quantizados e a diferença de energia que separa os seus níveis é dado pela relação de Bohr, $h v_{o}=E 2$ - E1 (Bebeachibuli,2003). Sempre que os átomos são submetidos à radiação eletromagnética correspondente à diferença de energia E2E1, eles interagem com o campo, de forma a modificar a distribuição de cargas do sistema, promovendo uma transição entre os estados atômicos, do ponto de vista energético.

Quando a frequência da radiação à qual os átomos estão expostos for a frequência de Bohr, a probabilidade da transição entre os estados atômicos ocorrer é máxima. Essa relação entre frequência e energia sugere que os átomos podem ser usados como osciladores de referência e a frequência de ressonância, absorvida ou emitida é uma propriedade intrínseca do átomo (Bebeachibuli, 2007).

Num sistema de referência os átomos são empregados para definir um padrão de frequência. Para tanto eles são interrogados, sendo submetidos a uma determinada radiação, e verificados com relação à eficiência da transição excitada pela radiação. Há dois métodos que se pode utilizar para a interrogação atômica, o primeiro é conhecido como Método de Rabi, 
em que a amostra atômica é exposta a um único pulso de interrogação e o segundo é o método de Ramsey, em que a amostra atômica interage duas vezes com a radiação eletromagnética, com uma separação dada por uma região livre de qualquer perturbação oscilatória. Nesse segundo método os átomos interagem com a primeira região durante um tempo $\tau$, passam por uma região livre de radiação por um tempo $T$ e então a amostra interage novamente com o campo de micro-ondas por um tempo $\tau$.

Há diversos tipos de padrões de frequência em operação, porém, distinguem-se entre o tipo de átomos utilizados para servir de referência ou pelo tipo de mecanismo para detectar a transição relógio escolhida. Dentre dos padrões de frequência em operação em nossos laboratórios, pode-se citar: Padrões de frequência tipo feixe térmico de ${ }^{133} \mathrm{Cs}$, chafariz atômico de ${ }^{133} \mathrm{Cs}$ e padrões compactos.

\subsection{Visão geral de um padrão de frequência}

Um padrão de frequência pode ser entendido como um sistema em que temos um oscilador muito preciso realimentado por uma transição atômica, seguindo um modelo clássico de controle em malha fechada.

Temos um oscilar local, no caso de um padrão de Cs133 uma cadeia de microondas, que irá gerar um sinal elétrico a ser comparado com uma transição atômica. A figura 1 ilustra o esquemático desse sistema.

Começando pelo oscilador, ele irá alimentar e excitar um modo do campo eletromagnético em uma cavidade de micro-ondas, por sua vez, os átomos quando passarem nessa cavidade irão sofrer uma mudança em seu estado (referência atômica). Essa mudança será detectada e o ponto ótimo do padrão de frequência é quando ocorre o máximo de transição na amostra atômica. O sinal de erro produzido será então utilizado como sinal de realimentação na malha de controle.

Por fim, a malha de controle alterará a frequência do oscilador de forma que ele esteja sempre próximo do ponto máximo. Para que esse sistema funcione como um relógio atômico, a rigor, é preciso utilizar um contador na saída do oscilador com um dispositivo que mostre essa contagem. 


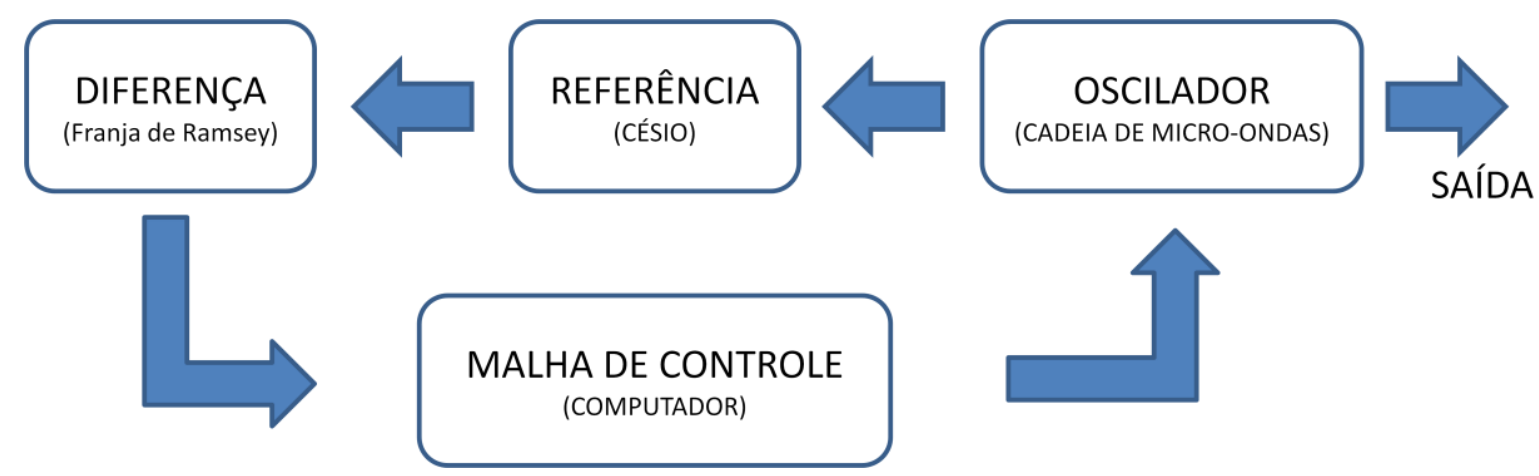

Figura 1: Diagrama genérico para um Padrão de frequência atômico.

\subsection{Relógio Atômico tipo Chafariz}

O padrão de frequência tipo chafariz de átomos frios utiliza a técnica de resfriamento, aprisionamento e manipulação de átomos de ${ }^{133} \mathrm{Cs}$ para operar. Na primeira etapa os átomos são aprisionados utilizando a técnica de aprisionamento magneto-óptico (Magneto Optical Trap - MOT). Após o aprisionamento os átomos são resfriados para aumentar a resolução espectral e lançados verticalmente, através da técnica de melado óptico em movimento, e passam duas vezes por uma cavidade de micro-ondas, utilizando o método de interrogação de Ramsey. Por fim, após o voo balístico, os átomos atingem a zona de detecção, por fluorescência. Assim como no relógio de feixe, é verificada a distribuição de átomos em cada nível de energia do estado fundamental. Novamente, a partir da resposta obtida pelo fotodetector, um sinal de correção é elaborado e realimenta a cadeia de microondas, que é travada na frequência que maximiza o sinal medido na zona de detecção.

A figura 2 ilustra as partes que compõem o sistema de vácuo que contém os átomos de Cs e é utilizado no padrão de frequência tipo chafariz e a figura 3 ilustra uma visão geral do laboratório. 


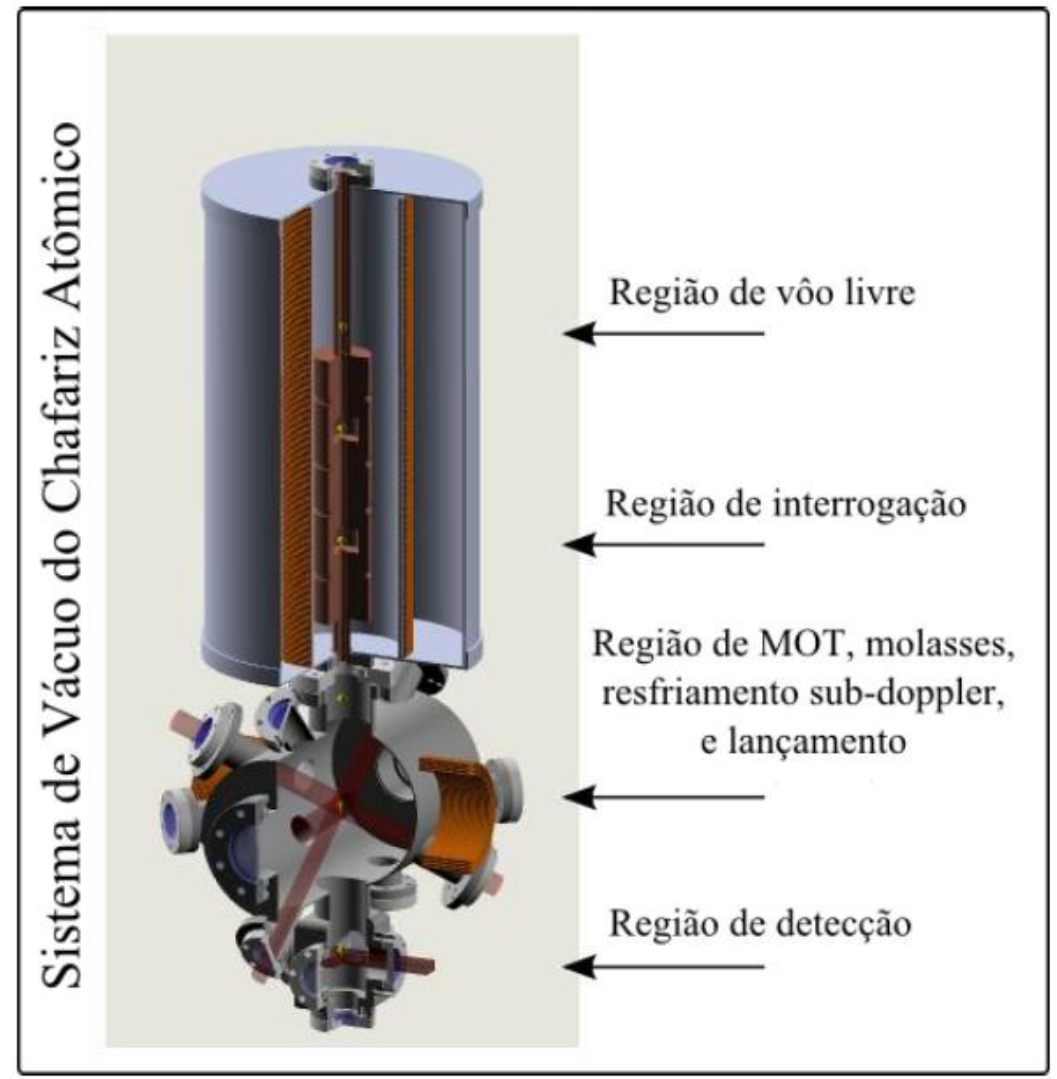

Figura 2: Sistema de vácuo de um padrão de frequência tipo chafariz.

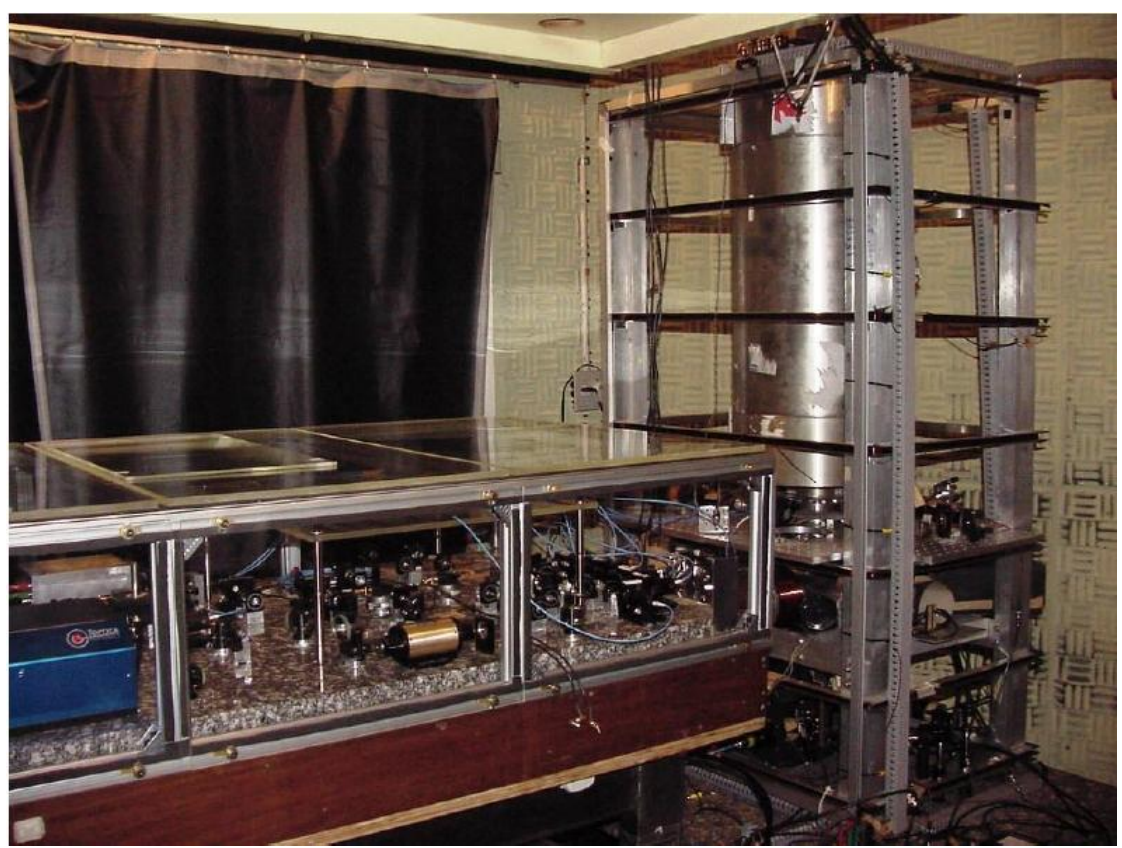

Figura 3: Visão geral do laboratório. 


\subsection{Montagem óptica do padrão de frequência tipo chafariz}

Todo o conjunto óptico do padrão de frequência tipo chafariz encontra-se montados em uma mesa óptica, como mostra a figura 4 e 5, com isolação mecânica, de modo a minimizar as vibrações do solo. Os feixes são gerados, travados em uma determinada linha atômica do Césio, passam por moduladores acusto-ópticos e por fim são acoplados em fibras ópticas que os levam para o sistema de vácuo a fim de interagirem com os átomos de Césio.

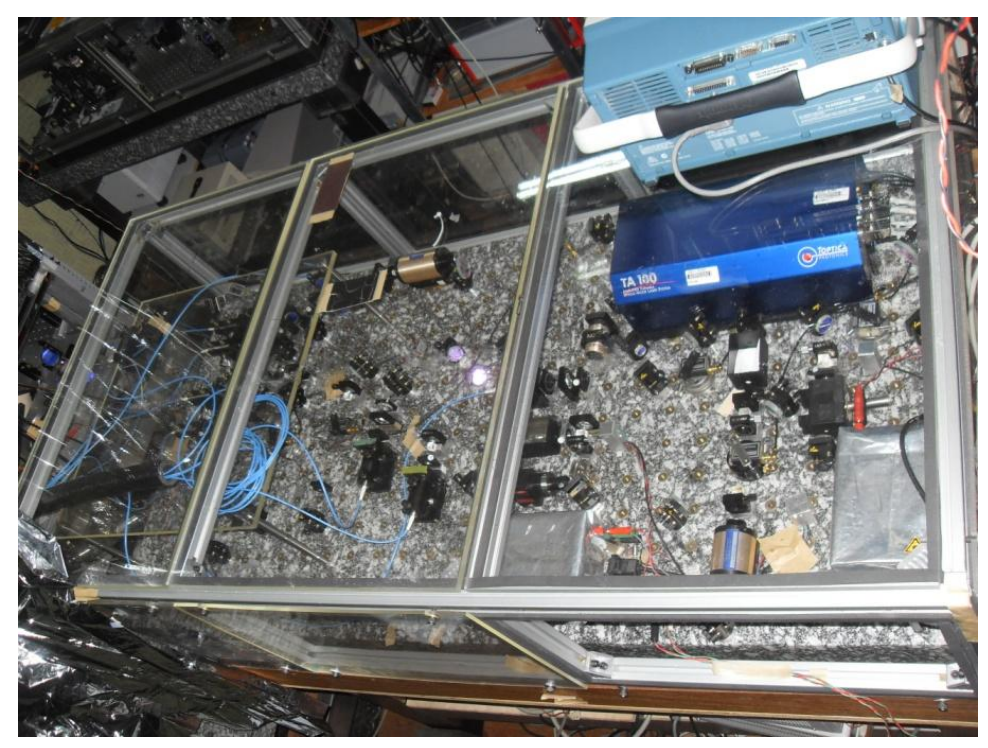

Figura 4: Mesa óptica do padrão de frequência tipo chafariz. 


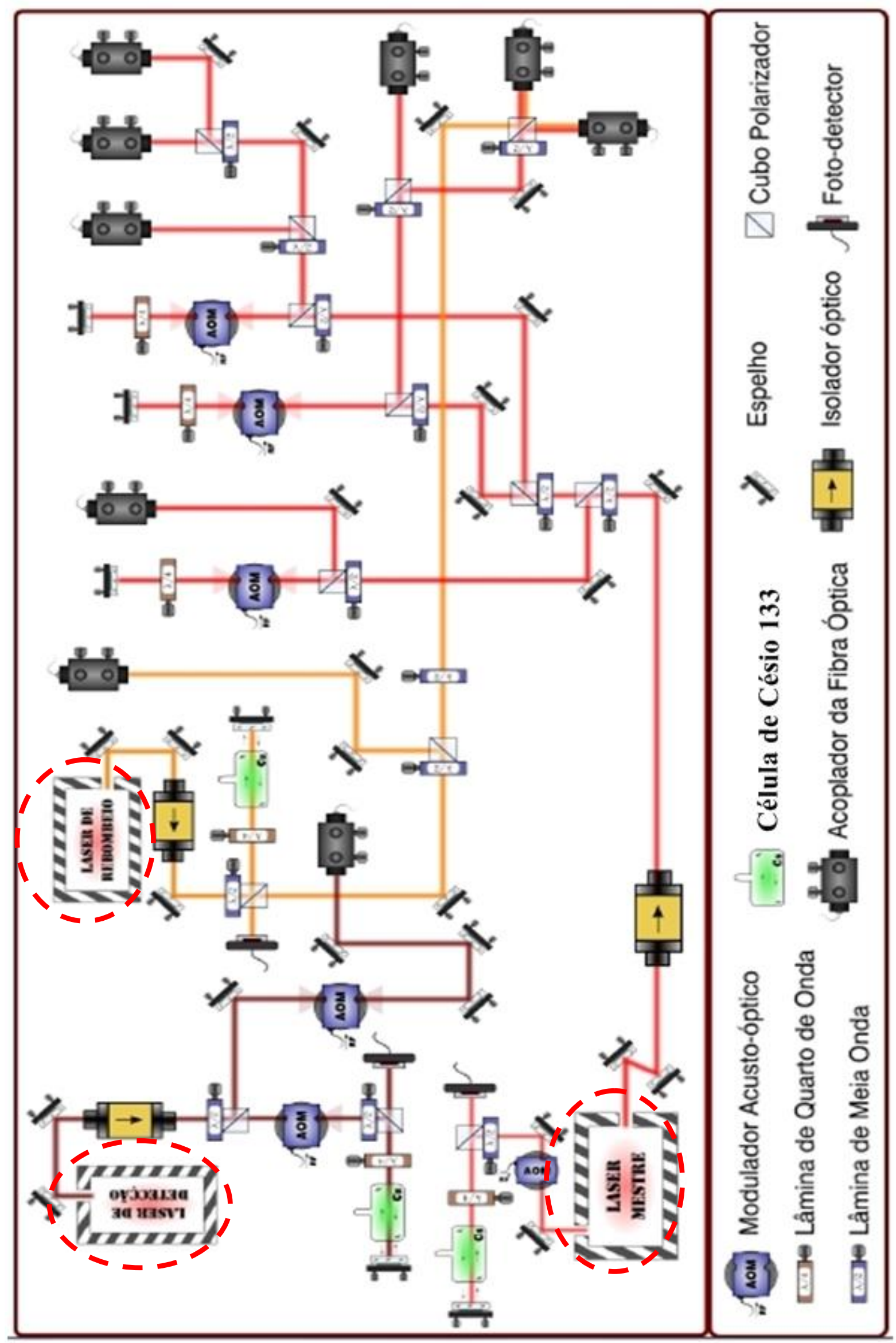

Figura 5: Diagrama da mesa óptica do chafariz atômico (Alves, 2012). 
Como mostrado no diagrama da figura 5, no chafariz atômico são utilizados três lasers de diodo, um laser denominado "laser mestre", laser de detecção e por fim o laser de rebombeio.

O laser mestre é um laser comercial modelo TA-100 de 500mW fabricado pela TOPTICA, que é um conjunto de laser de diodo com cavidade estendida e um sistema de amplificação. Este laser de diodo, juntamente com um par de bobinas, tem a função de realizar a armadilha magneto-óptica e lançar a nuvem de átomos frios para a região de interrogação, onde serão aplicados os pulsos de Ramsey.

O laser de rebombeio tem a função de recuperar os átomos que venham a decair para o nivel F=3 devolvendo-os ao ciclo de aprisionamento, este laser é utilizado tanto no processo de aprisionamento quanto na detecção dos átomos

E por fim o laser de detecção é utilizado para detectar os átomos que sofreram a transição relógio, determinando assim o número de átomos no estado $\mathrm{F}=4$ e o número total de átomos $\mathrm{F}=4+\mathrm{F}=3$.

\subsection{Padrão Compacto - TAC}

Diferentemente do chafariz atômico, em que cada zona (aprisionamento, preparação, interrogação e detecção) é feita em locais diferentes, ou seja, seguem um esquema espacial, um padrão compacto tem como característica um esquema temporal. Sendo assim, todas as etapas de preparação, interrogação e detecção são feitas dentro da cavidade de microondas (Figura 6). Uma das vantagens desse sistema é a redução do tamanho do padrão.

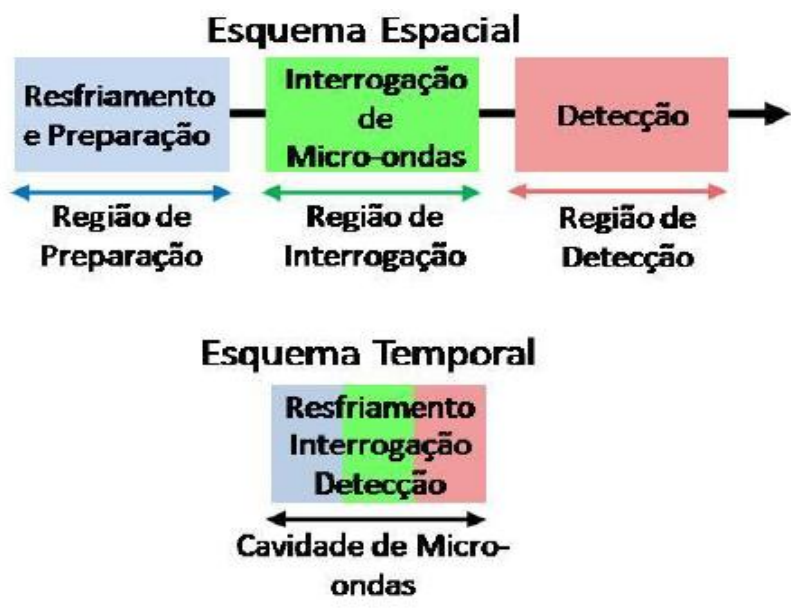

Figura 6: Diferença entre um esquema espacial e temporal de um padrão de tempo e frequência (Müller, 2010). 
O funcionamento desse padrão segue a mesma lógica de um chafariz atômico. Porém, os átomos não são lançados em um voo balístico. A figura 7 ilustra o ciclo de funcionamento de um padrão de frequência compacto.

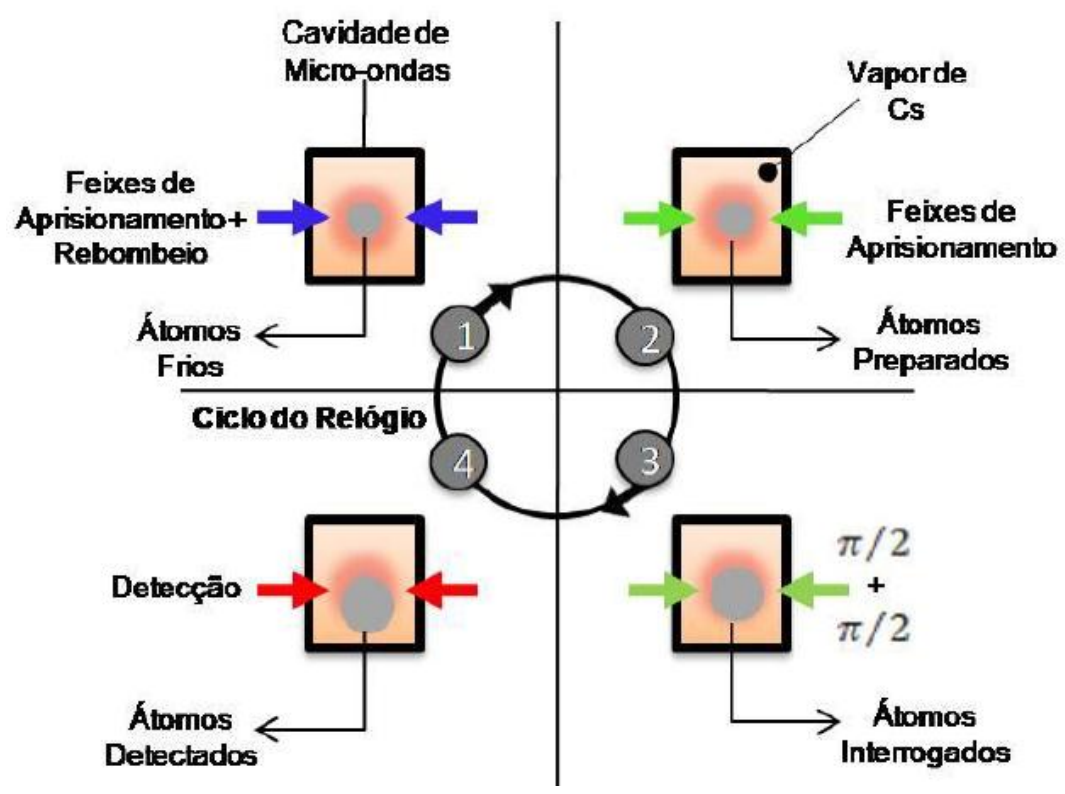

Figura 7: Esquema de funcionamento de um padrão de frequência compacto (Müller, 2010).

Primeiramente os átomos são aprisionados por uma armadilha magneto-óptica. Logo a seguir essa armadilha é desligada e os átomos começam a se expandir livremente. Nessa fase de expansão, dois pulsos de micro-ondas de 9,2 GHz gerados por uma cadeia de micro-ondas são aplicados para que o modo eletromagnético da cavidade interaja com os átomos.

Após interagirem com o campo eletromagnético, os átomos que sofreram a transição relógio são detectados e o sinal é utilizado para travar um oscilador local (Müller, 2010).

\subsection{Montagem óptica do padrão de frequência compacto}

A montagem óptica do padrão de frequência compacto, representada na figura $8 \mathrm{e}$ figura 9, tem o mesmo intuito da montagem óptica do chafariz atômico, no entanto são utilizados apenas dois lasers de diodo para o funcionamento do padrão. 
O laser denominado "Mestre" é montado com uma cavidade estendida e alimenta um sistema de amplificação de luz (Master Oscillator Power Amplifier - MOPA). Este laser é utilizado na etapa de aprisionamento dos átomos e na detecção.

O laser de rebombeio é utilizado na etapa de aprisionamento dos átomos bombeando os átomos para o estado $F=3 \rightarrow F^{\prime}=4$, assim como no chafariz.

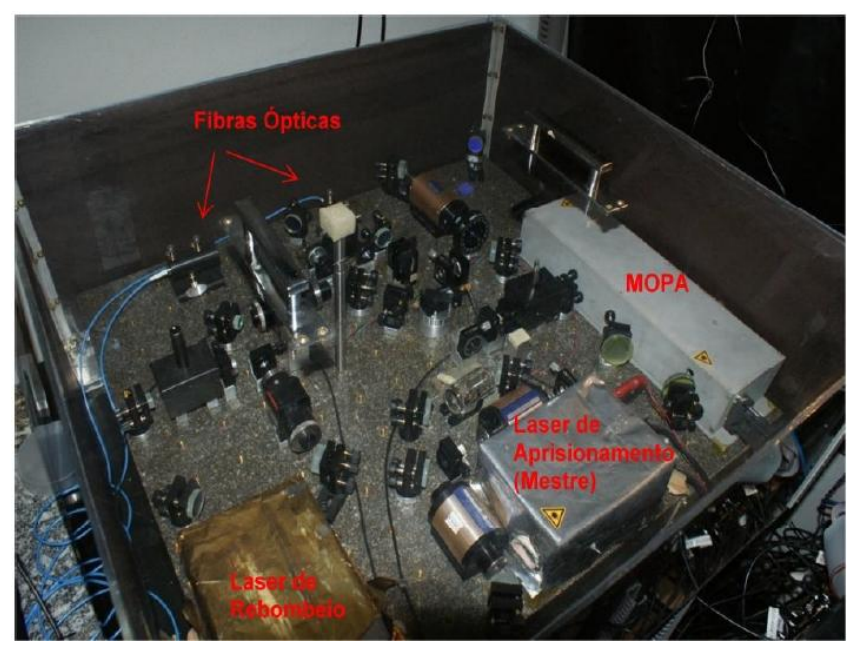

Figura 8: Mesa óptica do padrão compacto.

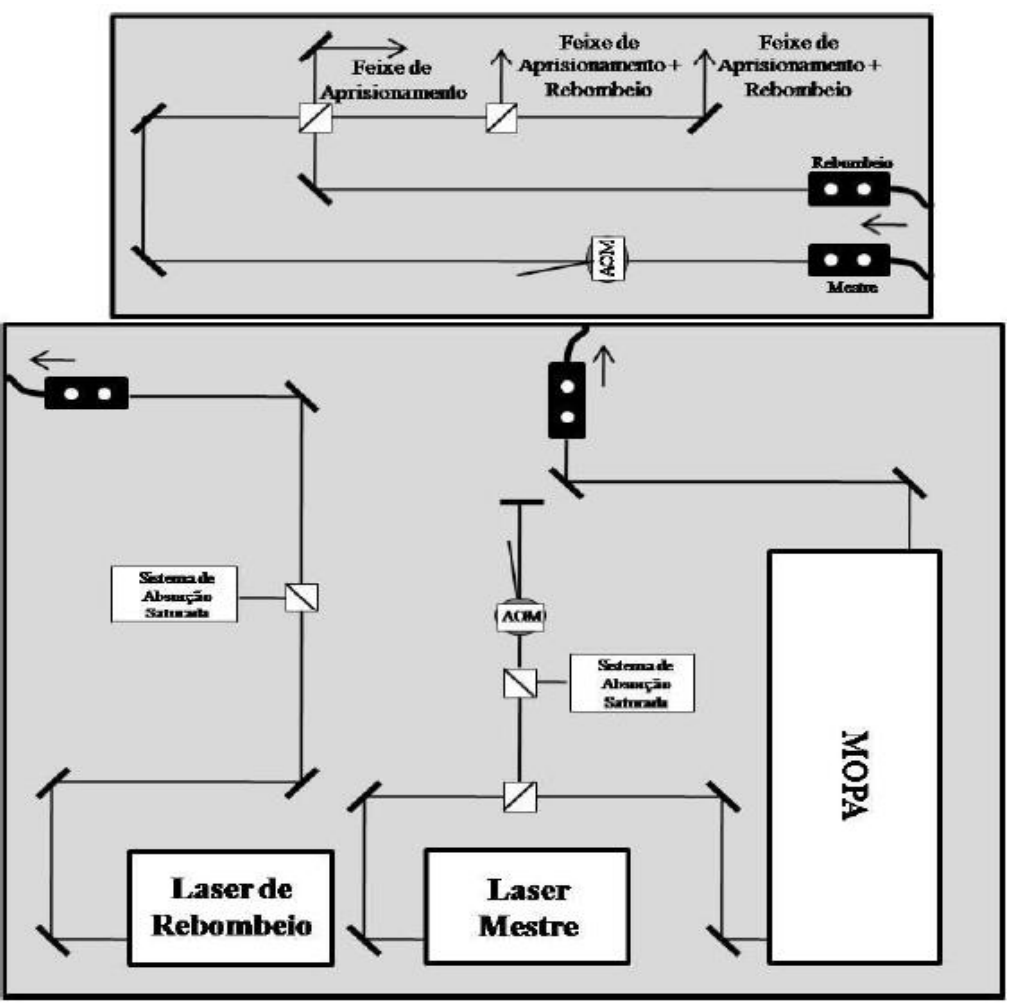

Figura 9: Diagrama da mesa óptica do padrão compacto. 


\section{Laser de diodo}

\subsection{História}

Os lasers semicondutores ou lasers de diodo recebem este nome devido à sua semelhança com diodos comuns, cuja estrutura básica é do tipo p-n. Estes dispositivos tiveram um desenvolvimento rápido, pois o grande interesse em sua aplicação era em comunicação por fibras ópticas.

Após uma publicação teórica escrita por Jonh Von Neumann, em 1953, surgiram discussões sobre a possibilidade de obter luz amplificada por emissão estimulada (Tuboy,1990), e começaram a investigação e demonstração sobre essa teoria. Em 1962 o centro de pesquisas da General Electric (GE) chefiado por Robert N. Hall e pela sua equipe demonstraram pela primeira vez a amplificação da luz por emissão estimulada em semicondutores.(Silfvast, 2004).

Os primeiros lasers de diodo eram constituídos por semicondutores do tipo (GaAs ou $\operatorname{GaP}_{x} A s(1-x)$ ), por isso eram chamados se lasers homoestruturas, porém sua aplicação foi limitada, pois necessitava-se de uma densidade de corrente muito alta à temperatura ambiente, o que impedia a operação em regime contínuo e sua utilização começou a decair a partir de 1965 (Catalani, 1997).

Neste mesmo período, uma nova classe de lasers, chamados de lasers heteroestruturas, começou a chamar a atenção. Conforme proposto por Kroemer e Alferov no início de 1963, foi possível a construção de um laser através de uma camada de semicondutor entre dois outros semicondutores diferentes e com gaps de energia maiores (Kroemer e Alferov, 1963). Observou-se que a junção de dois semicondutores diferentes originava uma barreira de potencial que confinava os elétrons injetados nessa região. Dentre outras observações, concluíram que com esses resultados era possível operar com esse laser em regime contínuo à temperatura ambiente.

Com essa nova tecnologia de lasers heteroestruturados, sua utilização aumentou devido às seguintes características: fácil sintonia operacional do sistema, baixo custo, tanto do laser quanto dos controles, por ter um tamanho muito pequeno em relação aos outros tipos de laser, seu transporte acaba sendo facilitado, sintonia de frequência muito simples e largura de linha relativamente estreita. 
Os lasers de diodo por serem componentes muito pequenos, tem uma aplicabilidade que abrange diversas áreas do mercado, desde leitores de DVDs até aplicações médicas. A figura 10 ilustra o tamanho de um laser de diodo comercial típico em relação a uma moeda de cinco centavos de dólar.

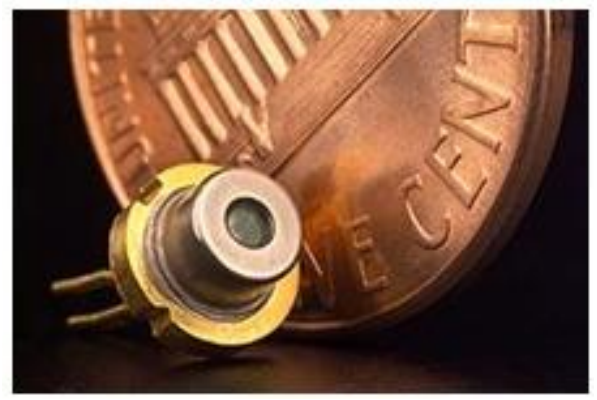

Figura 10: Comparação do tamanho de um laser com uma moeda (WIKIPÉDIA).

\subsection{Aplicações dos lasers de diodo}

Diversas áreas utilizam o laser de diodo como ferramenta funcional, sendo assim podemos citar, por exemplo, processos de qualidade industrial, como medição de rugosidade, na área médica em tratamentos não invasivos, na área odontológica para detecção e remoção de cáries, em sistemas de detecção de gases(LIDAR), sistemas de comunicação por fibra ópticas, etc. Neste trabalho o objetivo será focado na interação luz-matéria onde uma das aplicações é a espectroscopia de alta resolução.

O estreitamento espectral do laser de diodo utilizando cavidade estendida, que será abordado mais detalhadamente nos próximos capítulos, permite a utilização desse tipo de laser em sistemas onde a largura de linha estreita é um dos principais requisitos, como é o caso da espectroscopia de alta resolução. (Wieman e Hollberg, 1990).

\subsection{Princípio de funcionamento do laser de diodo}

Um laser de diodo é constituído por uma cavidade óptica ressonante (cavidade Fabry-Pérot), formada por dois espelhos paralelos entre si, separados por uma região ativa, como ilustrado na figura 11. 


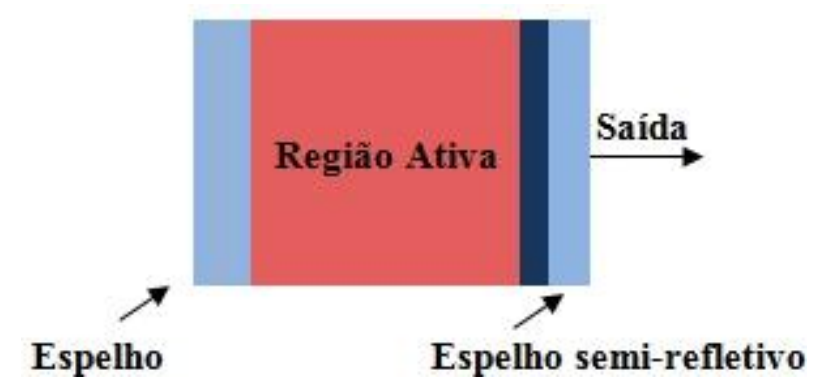

Figura 11: Cavidade de um laser de diodo

A figura 11 representa uma forma genérica de um laser de diodo, o espelho semirefletivo é utilizado para fornecer a realimentação óptica, formando assim uma cavidade ressonante. Para que ocorra a ação laser é necessária a inversão de população no meio ativo do laser, ou junção p-n no caso de um laser semicondutor, ou seja, a população no estado excitado deverá ser maior que a população no estado fundamental. Essa inversão é conseguida através da injeção de corrente elétrica na região ativa do laser.

As etapas ilustrativas do ciclo de funcionamento de um laser de diodo são mostradas na figura 12 .

1
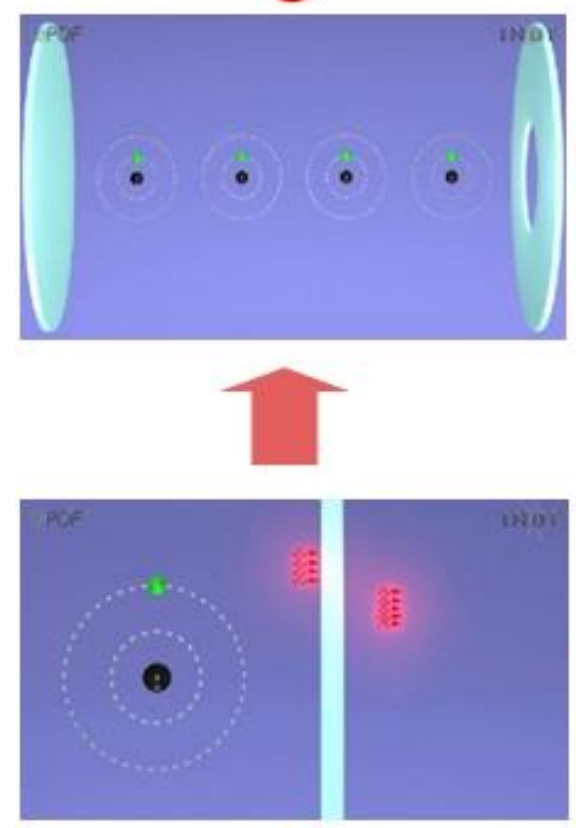

4
2
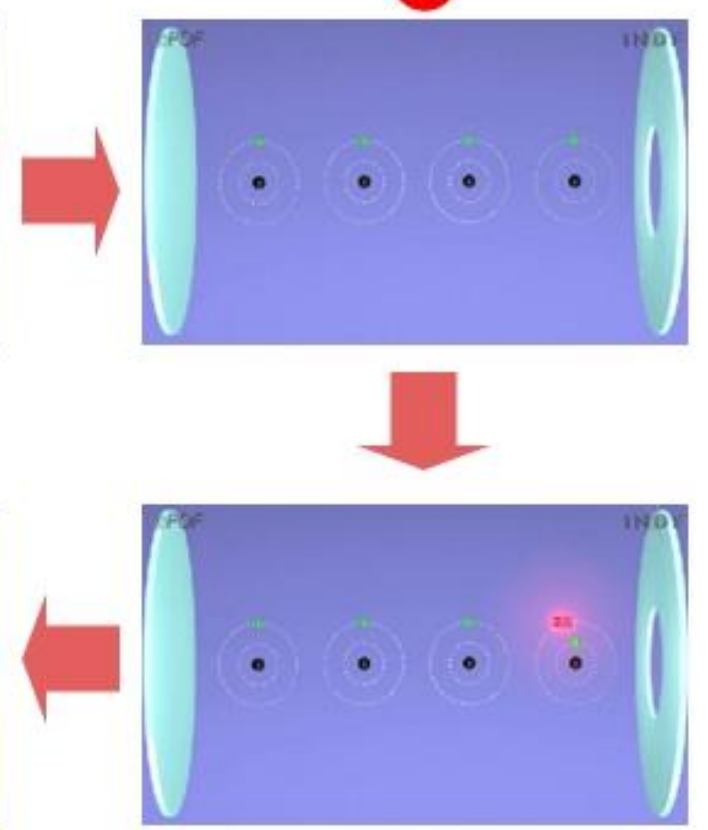

3

Figura 12: Princípio de funcionamento de um laser de diodo (Cepof - IFSC).

O funcionamento pode ser divido em quatro etapas: $\mathrm{Na}$ primeira os elétrons encontram-se no estado fundamental (Laser Off), após a injeção de corrente na região ativa, 
os elétrons absorvem essa energia e passam para um nível de energia excitado (Absorção Etapa 2). O decaimento espontâneo de um dos elétrons para o estado fundamental origina um fóton, adicionando assim luz à cavidade. A porção de luz gerada por esses elétrons é refletida no espelho da cavidade e interage novamente com os elétrons (Etapa 3). Quando um fóton interage com um elétron no estado excitado, esse elétron passa para o estado fundamental e origina dois fótons com mesma fase, frequência, polarização e direção (Emissão Estimulada). Esse processo proporciona a amplificação da luz por emissão estimulada na cavidade do laser. Uma parcela dessa luz gerada é refletida para dentro da cavidade do laser por um espelho semi-refletor, que também permite a saída de luz para utilização (Etapa 4).

\subsection{Características básicas do laser de diodo}

\subsubsection{Corrente limiar e Potência de saída}

Quando pretende-se utilizar lasers de diodo em experimentos, um dos parâmetros importantes é a potência de saída do laser. A figura 13 ilustra o comportamento de um laser de diodo em função da corrente elétrica.

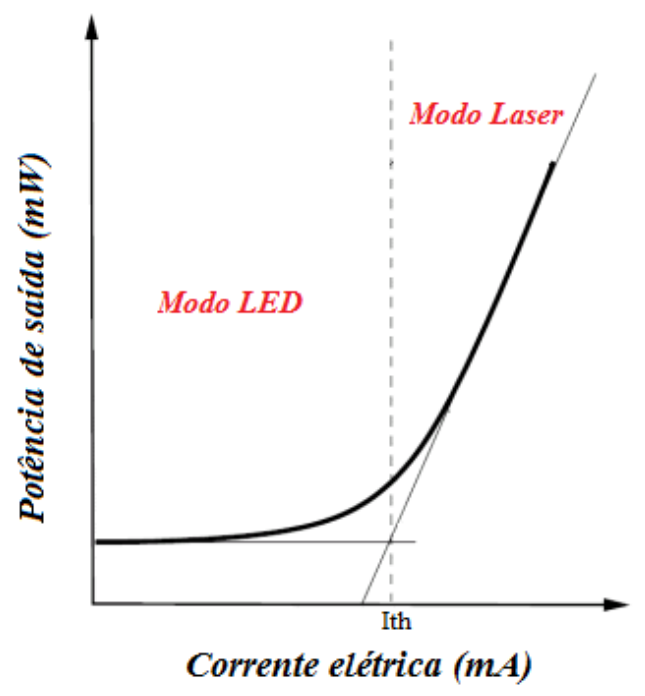

Figura 13: Potência de saída versus corrente elétrica.

Observando-se no gráfico da figura 13, observa-se que até a corrente limiar um laser de diodo comporta-se como um LED, ou seja, a população no estado fundamental é maior em relação a população do estado excitado e a emissão espontânea predomina. Acima 
da corrente de limiar ocorre a inversão da população, a população no estado excitado aumenta e predomina agora a emissão estimulada.

A potência de saída de um laser é dada pela seguinte expressão:

$$
P=n_{\text {in }} \frac{h v}{e} \frac{\alpha_{m}}{\alpha_{\text {total }}}\left(I-I_{t h}\right)
$$

onde

nin é a eficiência quântica, $\alpha_{m}$ e $\alpha_{\text {total }}$ são a perda por modo e a perda total através da saída de fótons pelo espelho do laser, hv é a energia de um fóton, $e$ é a carga do elétron, I é a corrente de injeção e $\mathrm{I}_{t h}$ é a corrente de limiar ou corrente de threshold (Catalani, 1997).

\subsubsection{Largura de linha}

A largura de linha de um laser de diodo é outra característica bastante importante que deve ser observada, pois a relação sinal-ruído de um padrão de tempo e frequência depende diretamente desse parâmetro (Bize, 2001).

Os lasers de diodo, comparados com outros tipo de lasers (gás e estado sólido), tem uma largura de linha maior, devido, principalmente, ao tamanho de sua cavidade. (Mooradian, 1985).

Segundo (Schawlow and Townes, 1958), a largura de linha à meia altura (FWHM - Full Width on Half Maximum) de um laser de diodo pode ser formulada como:

$$
\Delta v_{L}=\left(\frac{h v_{0} \eta_{s p}}{4 \pi}\right) \frac{1+\alpha_{H}^{2}}{P_{o p t} \tau_{c}^{2}}
$$

onde $\eta_{s p}$ é o fator de emissão espontânea ( 2), $P_{o p t}$ é a potência útil emitida, $\alpha_{H}$ é o fator de correção de largura de linha ( $\sim 5$ em um laser de diodo) e $\tau_{c}$ é o tempo de vida de um fóton dentro de uma cavidade;

O tempo de vida de um fóton é dado por:

$$
\frac{1}{\tau_{c}}=\frac{c}{\mu_{G}} \cdot \frac{\alpha_{i} L-\ln \sqrt{R_{1} R_{2}}}{L}
$$


onde $\mu_{G}$ é o índice de grupo ( 4 para AlGaAs), $c$ é a velocidade da luz, $\alpha_{i}$ é o coeficiente de perdas intra-cavidade, L é o comprimento da cavidade e R1 e R2 são os coeficientes de reflexão das faces da cavidade.

Para um laser de diodo SDL5422- H1, os coeficientes R1 e R2 valem respectivamente 0.95 e 0.02 e $\mathrm{L}=300 \mu \mathrm{m}$. Assim o tempo de vida de um fóton é:

$$
\frac{1}{\tau_{c}}=79,84.10^{9} 1 / \mathrm{s}
$$

Assim,

$$
\tau_{c}=1,2 \times 10^{-12} \mathrm{~s}
$$

Para uma corrente de injeção de $100 \mathrm{~mA}$ e uma potência útil de $70 \mathrm{~mW}$, a largura de linha é de aproximadamente $\Delta v_{L}=10 \mathrm{MHz}$.

\subsection{Laser Diodo de Cavidade Estendida para padrões de tempo e frequência}

Um dos cuidados na utilização de lasers de diodo na manipulação atômica é a necessidade de redução de largura de linha espectral. Os feixes de laser são utilizados em um chafariz atômico para aprisionar, lançar e detectar os átomos na linha D2 do átomo de ${ }^{133} \mathrm{Cs}$, particularmente na transição $F=4 \rightarrow F^{\prime}=5$, cuja largura de linha natural é de 5,3 MHz. Desse modo, a largura espectral do laser em questão deve ser estreita o suficiente para "resolver" a linha atômica a ser observada. O apêndice 1 mostra o diagrama de níves de energia para o átomo de ${ }^{133} \mathrm{Cs}$.

O ruído de detecção dos átomos também está relacionado diretamente com a estabilidade de frequência do relógio atômico, implicando na deterioração no sinal de frequência medido. Uma das maneiras de diminuir a largura espectral do laser de diodo e, consequentemente, melhorar sua capacidade de baixo ruído, é aumentar o comprimento da cavidade do diodo (Laurent,2001).

A configuração de um laser com cavidade estendida consiste em um laser de diodo acoplado com um selecionador de comprimento de onda, que pode ser uma rede de 
difração ou um filtro de interferência. Ambos são responsáveis pela realimentação óptica e pela seleção do comprimento de onda.

A utilização de uma cavidade estendida faz com que as distâncias dos modos longitudinais de uma cavidade ressonante sejam reduzidas, por exemplo, uma cavidade externa de $10 \mathrm{~cm}$ faz com que os modos longitudinais fiquem espaçados entre si de 1,5 $\mathrm{GHz}$, a figura 14(a) representa os modos longitudinais de um laser livre e a figura 14(b) representa os modos longitudinais de um laser de cavidade estendida.

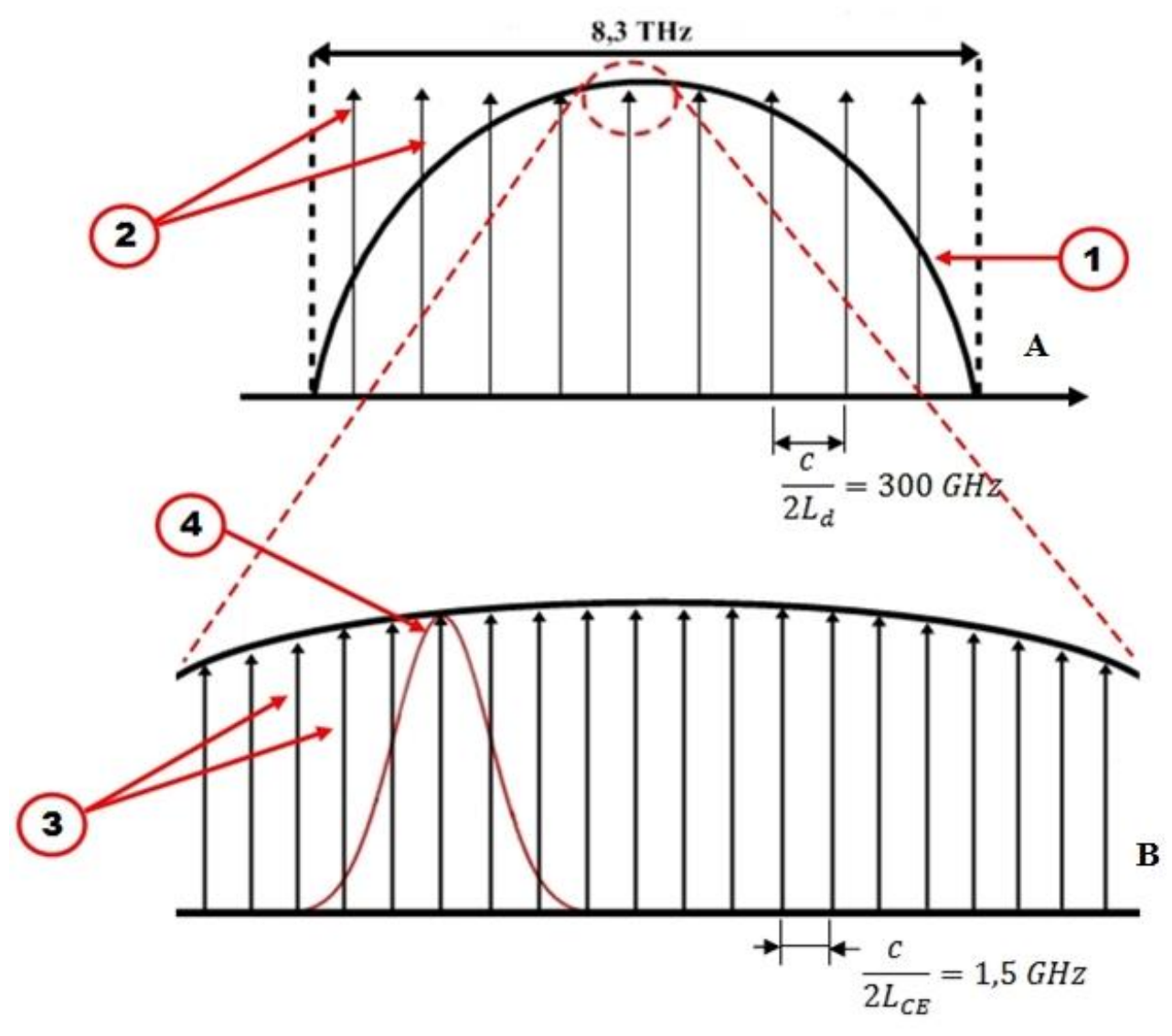

Figura 14: Modos Longitudinais de laser de diodo. 1 - Curva do ganho do laser; 2 - Modos longitudinais de um laser de diodo livre; 3 - Modos longitudinais de um laser de diodo montado em uma cavidade estendida; 4 - Resposta espectral de um elemento seletor de comprimento de onda.

A escolha da configuração da cavidade externa é fundamental, pois a mesma influência na estabilidade de um padão de frequência. A seguir será abordado as três configurações mais utilizadas pela comunidade científica, são elas: Configuração Littrow, Configuração Littam e Filtro de Interferência. 


\subsubsection{Configuração Littrow}

A configuração Littrow, mostrada na figura 15 , é constituída por uma lente de colimação, uma rede de difração e uma espelho. $\mathrm{O}$ feixe difratado de primeira ordem fornece a realimentação óptica para o laser, assim formando uma cavidade externa ressonante, o feixe de ordem zero é utilizado no experimento (feixe de saída). A sintonização do comprimento de onda desta configuração é feita pelo posicionamento da rede de difração (rotação), consequentemente a desvantagem desta configuração é o desalinhamento do feixe de saída (Hawthorn et al., 2001).

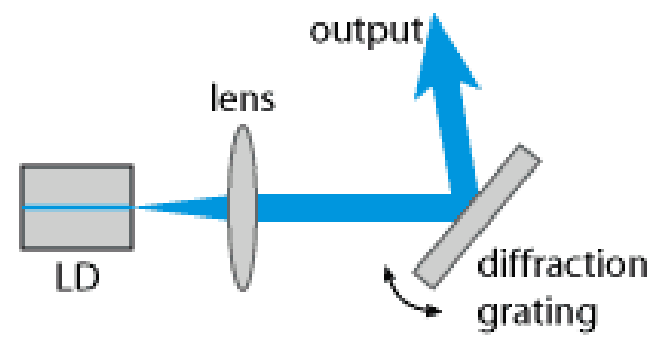

Figura 15: Laser com cavidade estendida em configuração de Littrow (Rp-Photonics)

\subsubsection{Configuração Littman}

Em uma configuração Littman, mostrada na figura 16, a orientação da rede de difração é fixa, sendo assim, é adicionado um espelho utilizado para refletir a primeira ordem, assim fechando a cavidade ressonante. O comprimento de onda é sintonizado pelo posicionamento do espelho, ao contrário da configuração Littrow, consequentemente o feixe de saída não é desalinhado com a sintonização do comprimento de onda, no entanto, uma desvantagem é que a ordem zero é perdida nesta configuração, com isso, a potência de saída é menor com relação à configuração Littrow. 


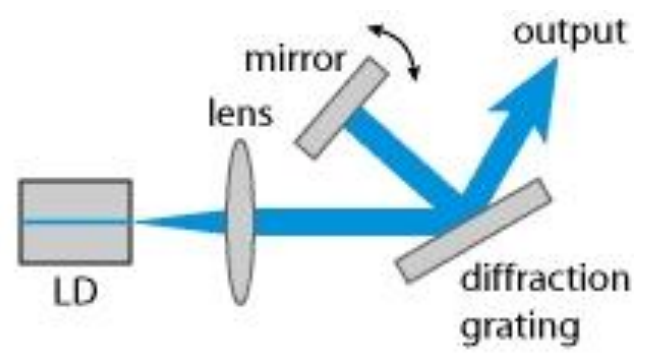

Figura 16: Laser com cavidade estendida em configuração de Littman (Rp-Photonics)

\subsubsection{Laser de Cavidade Estendida com filtro de interferência}

Como já ressaltado, um laser com alta resolução espectral em um padrão de tempo e frequência é fundamental, tornando a utilização de laser com cavidade externa essencial.

A escolha do tipo de cavidade é importante, pois, implicará na estabilidade do sistema. Estudos prévios mostram que um laser de cavidade estendida com filtro de interfêrencia como seletor de comprimento de onda mostra-se mais estável em condições adversas, principalmente com relação ao ruído mecânico (Baillard et al., 2006).

Um filtro de interferência ou étalon, nada mais é, que um interferômetro de FabryPerot com espelhos fixos (Zilio,2009).

O feixe proveniente do laser (DL) é colimado por uma lente objetiva (LC) e um espelho semi refletor (OC) fornece a realimentação para o laser de diodo. Esse espelho é fixado em um elemento piezoelétrico (PZT) para variar o comprimento da cavidade. O filtro (FI) tem a finalidade de favorecer apenas um dos muitos modos ressonantes da cavidade formada externamente pelo semi-espelho (OC). A figura 17 ilustra o desenho esse sistema.

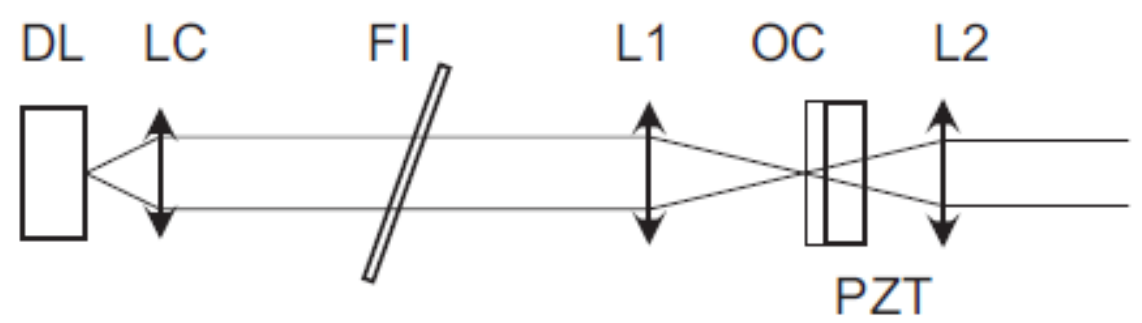

Figura 177: Cavidade estendida com filtro de interferência (Baillard et al., 2006).

A discriminação do comprimento de onda do filtro é baseada nas múltiplas reflexões dentro do filtro comportando-se como uma cavidade de Fabry-Perot, com índice de refração $n_{\text {eff. }}$ O comprimento de onda transmitido é dado por: 


$$
\lambda=\lambda_{\max } \cdot \sqrt{1-\frac{\sin ^{2} \theta}{\eta_{e f f}^{2}}}
$$

onde, $\theta$ é o angulo de incidência e $\lambda_{\max }$ é o comprimento de onda nominal.

Com essa configuração, podem-se citar como principais vantagens a maior estabilidade, robustez, largura de linha estreita com relação à rede de difração e fácil sintonia.

\subsection{Largura de linha com relação ao tamanho da cavidade externa}

Como discutido anteriormente, à largura de linha é inversamente proporcional ao tamanho da cavidade externa de um laser. Para exemplificar isso, reporta-se a figura 18.

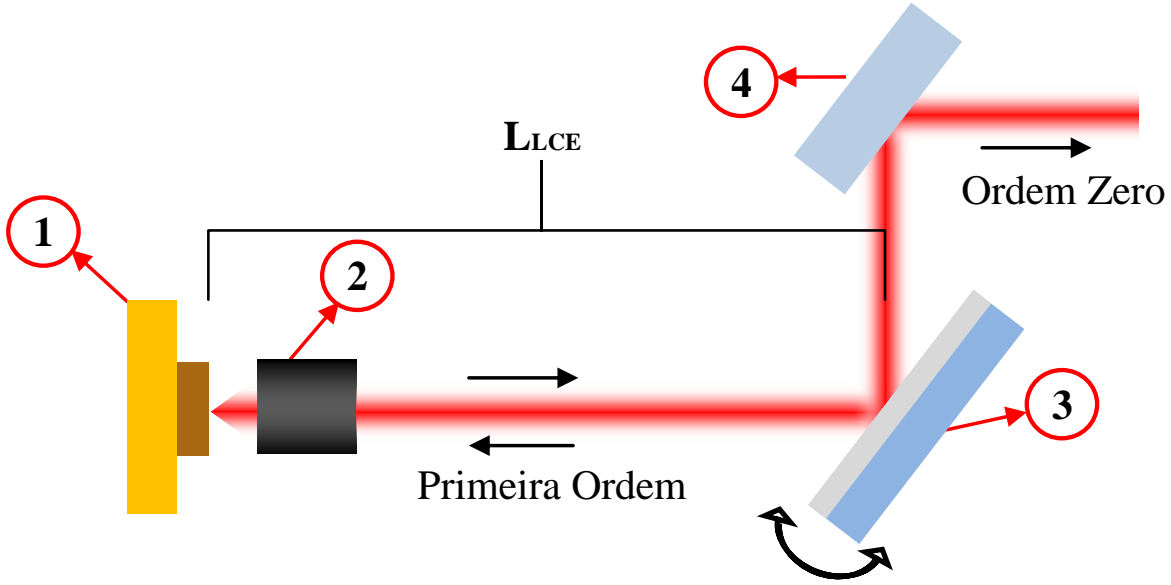

Figura 18: Configuração Littrow. 1- Laser de diodo; 2 - Lente de colimação; 3 - Rede de difração; 4 - Espelho de saída.

O tamanho da cavidade externa é medido da rede de difração até a face de saída do laser (LLCE), caso a face não tenha um tratamento anti-reflexo, essa distância deve ser razoável, por exemplo, numa relação de $\left(\mathrm{LLCE}_{\mathrm{L}} / \mathrm{LD}\right) \approx 200$.

O tempo de vida do fóton na cavidade é dado por:

$$
\frac{1}{\tau_{\mathrm{c}}}=\frac{c}{\mu} \cdot \frac{\alpha_{\mathrm{i} .} \operatorname{LD}-\ln \sqrt{R 1 \cdot R 3}}{\operatorname{LLCE}}
$$


onde LLCE é o comprimento da cavidade externa, LD é o comprimento da cavidade interna do laser e R3 é o coeficiente de reflexão do espelho de saída do laser.

Dessa forma, utilizando uma cavidade externa com comprimento LLCE $=10 \mathrm{~cm}$ com um laser de diodo com largura de linha na ordem $\sim 10 \mathrm{MHz}$ e $\mathrm{LD}_{\mathrm{D}}=500 \mu \mathrm{m}$ a largura de linha do laser com cavidade estendida é de aproximadamente $50 \mathrm{kHz}$.

Para o aprisionamento e detecção dos átomos de ${ }^{133} \mathrm{Cs}$ é necessário minimizar as flutuações na frequência do laser, para não haver flutuações na eficiência da interação luzátomo. A figura 19 ilustra dois espectros de absorção saturada dos átomos de césio, o espectro (a) representa a utilização de um laser livre ou seja, sem cavidade externa, o espectro (b) representa a utilização de um laser de cavidade estendida.

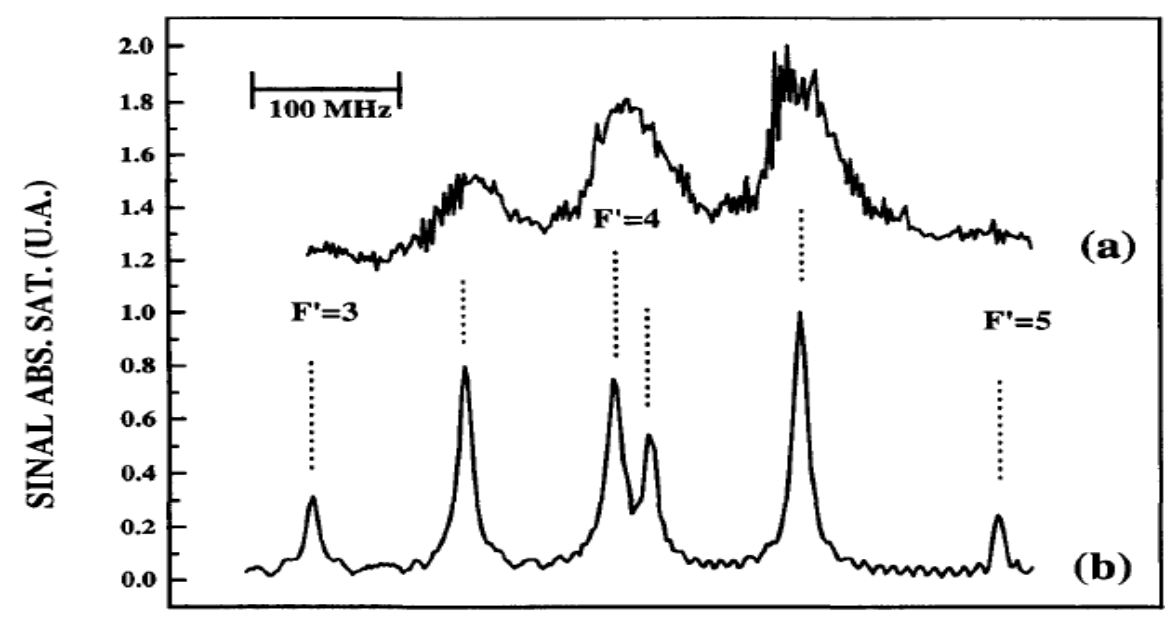

FREQUENCIA DO LASER

Figura 19: Absorção Saturada do átomo de césio (TUBOY, 1996)

Pode-se enumerar assim as principais vantagens do laser de diodo montado em uma configuração de cavidade estendida:

- Diminuição de ruído espectral;

- Redução da largura de linha;

- Sintonia fina do comprimento de onda. 


\section{Capítulo 3}

\section{Projeto do sistema laser de diodo}

Um sistema de laser de diodo é constituído por: Chip Laser de Diodo, Cavidade Externa e Circuitos de Controle. Este capítulo apresentará o detalhamento de cada componente de um sistema de laser de diodo e suas caracteristicas.

\subsection{Sistema de controle para o laser de diodo}

Para o controle de cada componente de um sistema de laser diodo com cavidade estendida, foi necessário o desenvolvimento de circuitos eletrônicos, a discussão de cada componente será representada por diagramas de blocos, visando simplificar o entendimento, como mostrado na figura 20.

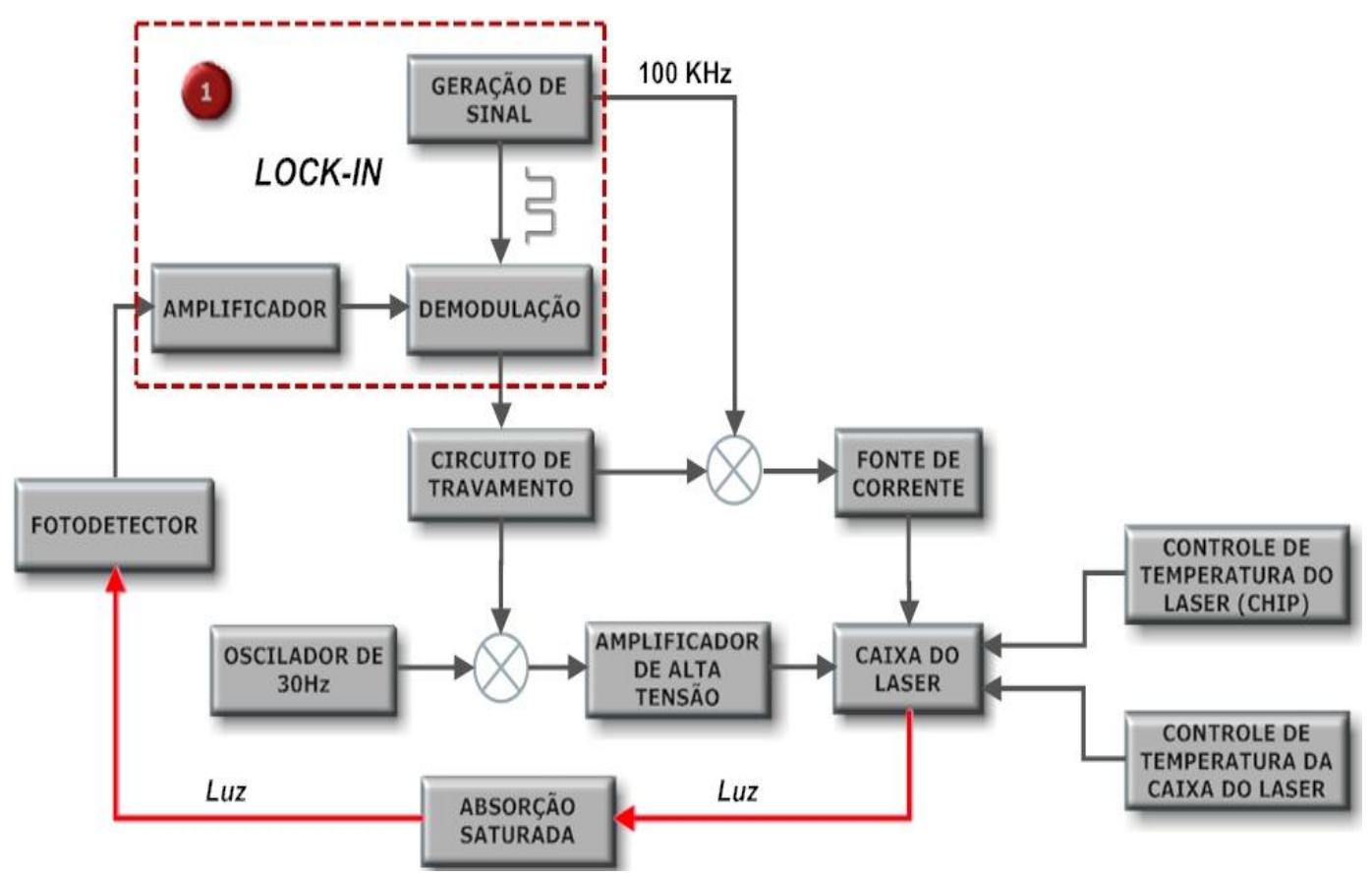

Figura 18: Diagrama de blocos do sistema de laser de diodo, 1-Amplificador Lock-in. 
O sistema de controle para os lasers de diodo tem como objetivo a correção, sintonia e travamento da frequência de interesse. No entanto, a frequência de um laser de diodo é proporcional à temperatura do laser e à corrente de injeção, ou seja, se um desses parâmetros flutuar a frequência flutuará. Outro fator importante é o controle de temperatura da caixa do laser, pois, o comprimento da cavidade externa varia com a temperatura.

No controle ilustrado na figura 20, um dos blocos é um sistema de absorção saturada utilizado como referência para fazer a correção e o travamento dos lasers. O sinal de fluorescência dos átomos da absorção saturada é detectado por um fotodetector e amplificado. Uma das dificuldades no travamento nessa referência é que o sinal desejado é um vale ou um pico, como ilustrado na figura 21(a). A tentar "travar" a frequência do sinal nessa referência, o controle não é capaz de discriminar o sinal necessário de atuação. Uma das formas mais utilizadas para contornar esse problema é modular um dos sinais de controle do laser e medir o sinal do fotodetector considerando a fase do sinal demodulado. Esse tipo de técnica, chamada de demodulação síncrona, produz uma inversão de sinal exatamente no pico ou no vale do sinal de referência, dada a inversão de fase do sinal de referência. Essa inversão fornece um sinal altamente desejável para o controle, como mostrado na figura 21(b).

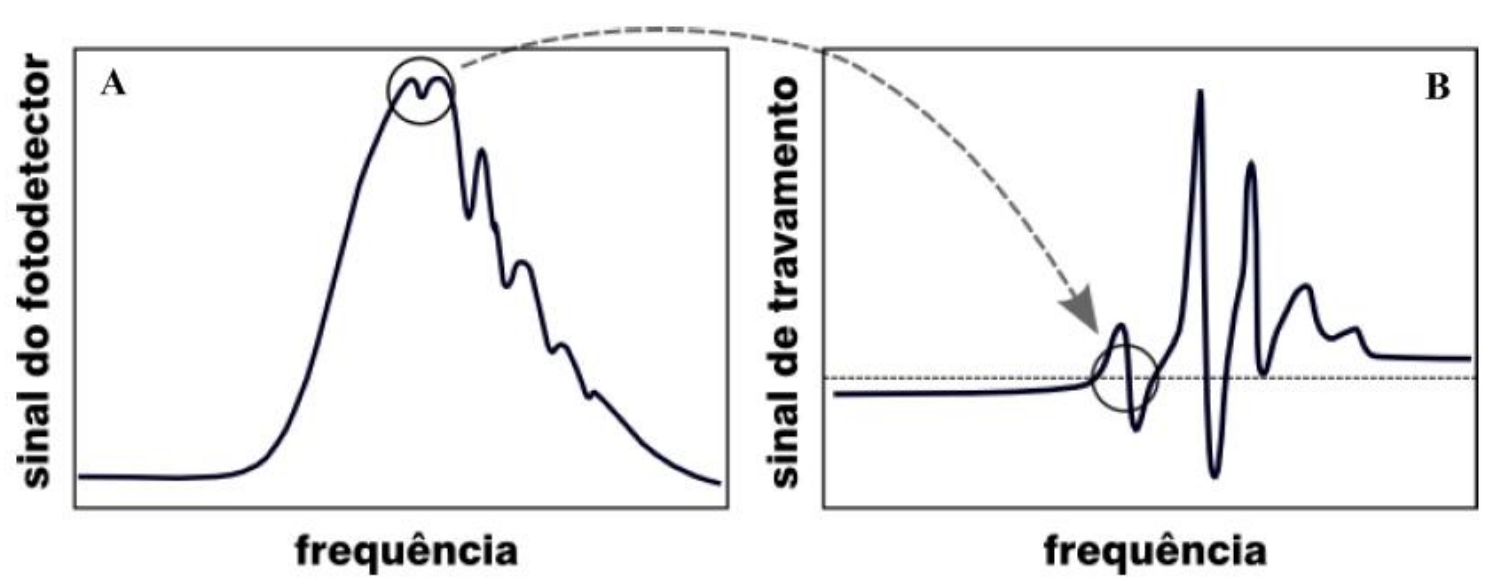

Figura 19: (a)Sinal de absorção saturada de uma célula de vapor de Cs133 com destaque para a transição a ser usada como referência para o travamento do laser; (b) Sinal de saída do demodulador síncrono usado para gerar o sinal de erro para o circuito de controle.

O conjunto numerado 1 da figura 20 é um amplificador lock-in e é constituído por um amplificador, um demodulador e um gerador de sinal. O gerador de sinal produz um sinal de referência para o circuito de demodulação e um sinal de modulação na corrente do laser. $\mathrm{O}$ sinal do fotodetector é amplificado e enviado para um circuito de demodulação, onde é gerado um sinal de erro para a correção do sistema. Na etapa de correção, um circuito de travamento 
é utilizado para fornecer um sinal de atuação para a corrente e para o circuito de alta tensão que gera a ddp para uma cerâmica piezoelétrica (PZT) que sustenta o espelho de saída da cavidade estendida. Este último serve de controle de comprimento para a cavidade e auxilia no travamento da frequência do laser, agindo no modo ressonante longitudinal. Um circuito oscilador de mais baixa frequência gera um sinal de varredura que permite visualizar as linhas de transições atômicas dos átomos na célula de referência.

Especificamente neste projeto o amplificador lock-in não foi desenvolvido, de modo que nos testes utilizamos um amplificador lock-in já construído anteriormente em nosso laboratório. A razão disso é que pretendemos utilizar outra técnica de modulação/demodulação, de modo que preferimos, nesse momento, não investir esforços nesse tipo de circuito. Isso será melhor discutido nas considerações finais.

\subsection{Laser de diodo (Chip)}

O laser utilizado no projeto é um laser de diodo modelo SDL 5422 H1 com encapsulamento TO-3 (Photonic Solutions, 2013). A vantagem desse laser está relacionada ao seu encapsulamento, pois, nele estão integrados o sensor de temperatura (termistor) e o peltier, com isso, a montagem mecânica é facilitada e o tempo de resposta para o controle de temperatura bastante reduzido. Alguns parâmetros importantes para serem observados são mostrados na tabela 1 e na figura 22 é mostrado o gráfico de potência óptica de saída versus corrente de injeção.

Tabela 1: Caracteristicas do laser de diodo

\begin{tabular}{|l|l|l|}
\hline Caracteristica do laser & Máx. & Unidade \\
\hline Potência de saída & 150 & $\mathrm{~mW}$ \\
\hline Corrente de Operação & 210 & $\mathrm{~mA}$ \\
\hline Corrente de limiar & 45 & $\mathrm{~mA}$ \\
\hline Comprimento de onda & $852 \pm 4$ & $\mathrm{~nm}$ \\
\hline
\end{tabular}




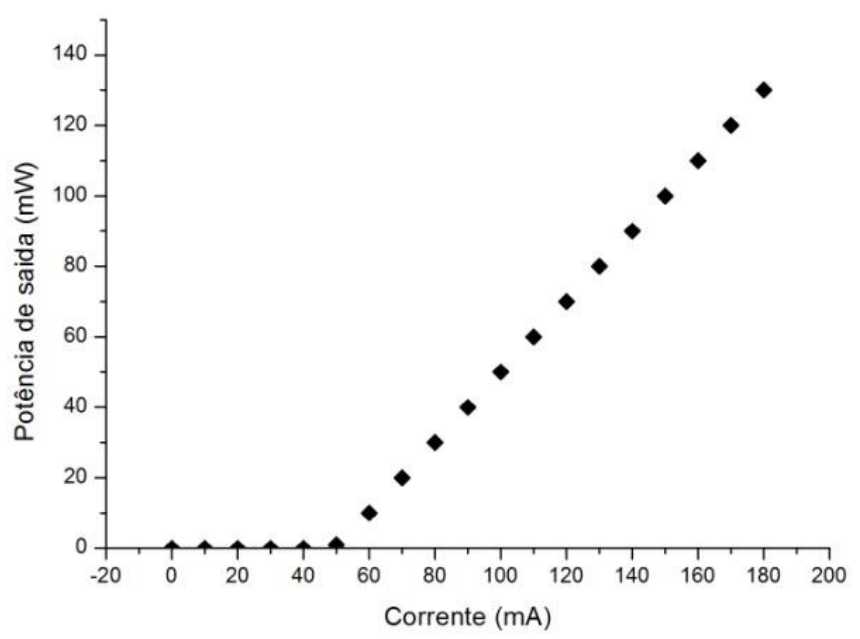

Figura 20: Curva característica de potência de saída versus corrente de injeção

A figura 23 mostra uma foto do componente utilizado no projeto e no anexo A encontra-se a folha de especificações mais detalhadas do laser, de acordo com o fabricante.

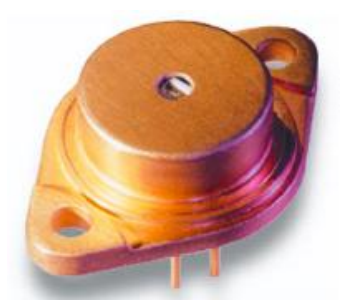

Figura 21: Laser de diodo, SDL 5422 H1 em encapsulamento TO-3.

\subsection{Controle de temperatura da caixa do laser}

O controle de temperatura da caixa do laser tem por finalidade minimizar a variação do tamanho da cavidade externa do laser devido à mudança da temperatura ambiente. Todos componentes ópticos do laser (suporte do filtro, espelho, lente colimadora e laser) são montados numa base de alumínio, de modo que a temperatura ambiente tem influência direta no tamanho da cavidade. Por exemplo, considerando a expansão térmica linear do alumínio igual à $24 \times 10^{-6} \mathrm{~m} /{ }^{0} \mathrm{C}$ e um comprimento de cavidade de $6 \mathrm{~cm}$, para uma variação de $1^{0} \mathrm{C}$ da temperatura na base de alumínio do laser teríamos uma alteração de 1,44 $\mu \mathrm{m}$ na cavidade. Isso seria um desastre no sistema, pois trabalhamos com comprimento de onda de $852 \mathrm{~nm}$ e tal variação corresponderia a quase dois comprimentos de onda da luz emitida. 
O controle de temperatura da caixa não atua diretamente na estabilização do laser, pois sua realimentação é fornecida através de um sensor de temperatura, no entanto, o bom funcionamento desse controlador é fundamental para o desenvolvimento do sistema de travamento de frequência do laser de diodo. A figura 24 ilustra o esquema da montagem do atuador (peltier) e do sensor (termistor) na base do laser.

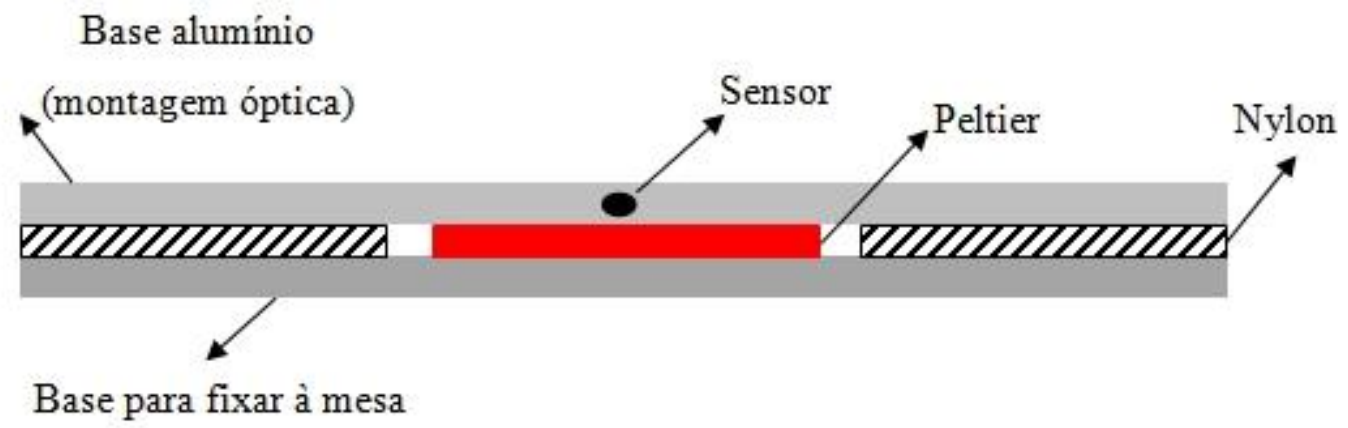

Figura 22: Esquema da vista lateral da montagem do elemento sensor (termistor) e de atuação (peltier) base do laser.

Utilizamos um termistor NTC modelo (NTCLE100E3 - Vishay) com resistência de $10 \mathrm{k} \Omega$, sendo fixado no centro da base do laser e um peltier modelo TEC1-12706 (HB Electronic Components). Observando-se na figura 21 a base de alumínio para a montagem óptica é separada por duas peças de nylon da base que fixa a caixa do laser na mesa, para prover sustentação mecânica e manter a isolação térmica necessária ao controle de temperatura. Para garantir o desempenho do controle de temperatura foi utilizado um controlador Proporcional Integral e Derivativo (PID). O diagrama de blocos do controle desenvolvido é mostrado na figura 25.

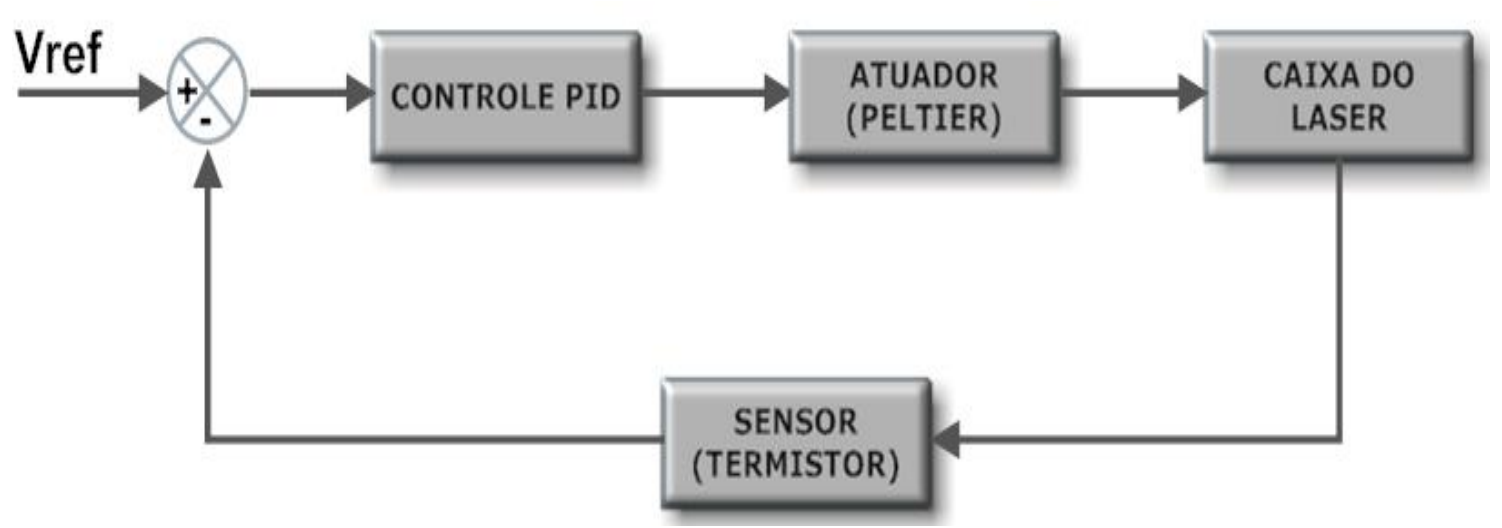

Figura 23: Diagrama de blocos do controlador PID 
Para condicionar o sinal do sensor, o mesmo foi montado em uma ponte de Wheatstone, para fornecer o sinal de erro e permitir o ajuste de ponto de operação. Para amplificar o sinal da ponte utilizamos um amplificador operacional de instrumentação (modelo AMP01 - Analog Devices) com ganho de 400. Com isso o sinal de erro será tratado pelo controlador PID que agirá no controle de temperatura da caixa. O ajuste de temperatura é feito através de dois potenciômetros, ajuste fino e grosso, que irão desequilibrar a ponte, permitindo assim o aquecimento ou resfriamento da caixa.

A sintonia dos parâmetros do controlador PID é feita utilizando-se o método de Ziegler-Nichols. Essa abordagem será tratada com mais detalhes no controle de temperatura do laser. O apêndice A representa o circuito eletrônico do controlador.

\subsection{Controle de temperatura do laser}

O controle de temperatura do laser é utilizado como um ajuste fino para buscar as linhas de transição dos átomos do sistema de referência. É de grande importância para o sistema laser, pois a variação de temperatura interfere diretamente na estabilidade da frequência do laser, podendo causar, inclusive, saltos de modo modo. Sendo assim, uma estabilidade de temperatura da ordem de $m K$ é fundamental.

Para alcançar esse patamar foi desenvolvido um controlador PID similar ao controle de temperatura da caixa, porém com ganhos e constantes de tempo diferentes. A vantagem desse controlador está relacionado a capacidade de minimizar o tempo de resposta do sistema para uma mudança no ponto de operação, mostrado na figura 26, isso é bastante útil quando varremos a temperatura do laser. Além disso, a condição de ganhos ideais minimiza o ruído na condição de operação estacionária. 


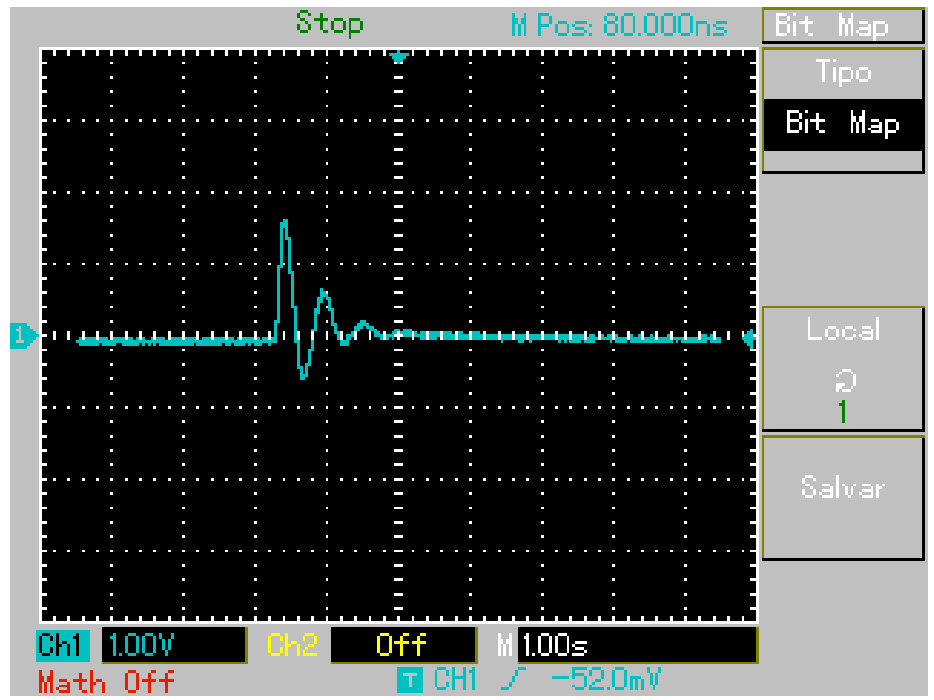

Figura 24: Resposta do controle PID de temperatura.

No controle de temperatura do laser de diodo o elemento sensor e atuador estão integrados em um encapsulamento TO-3 na versão SDL 5422 H1. O elemento sensor é um termistor de $10 \mathrm{k} \Omega\left(@ 25^{\circ} \mathrm{C}\right)$ e o atuador é um Peltier. A figura 27 ilustra a malha de controle desse sistema.

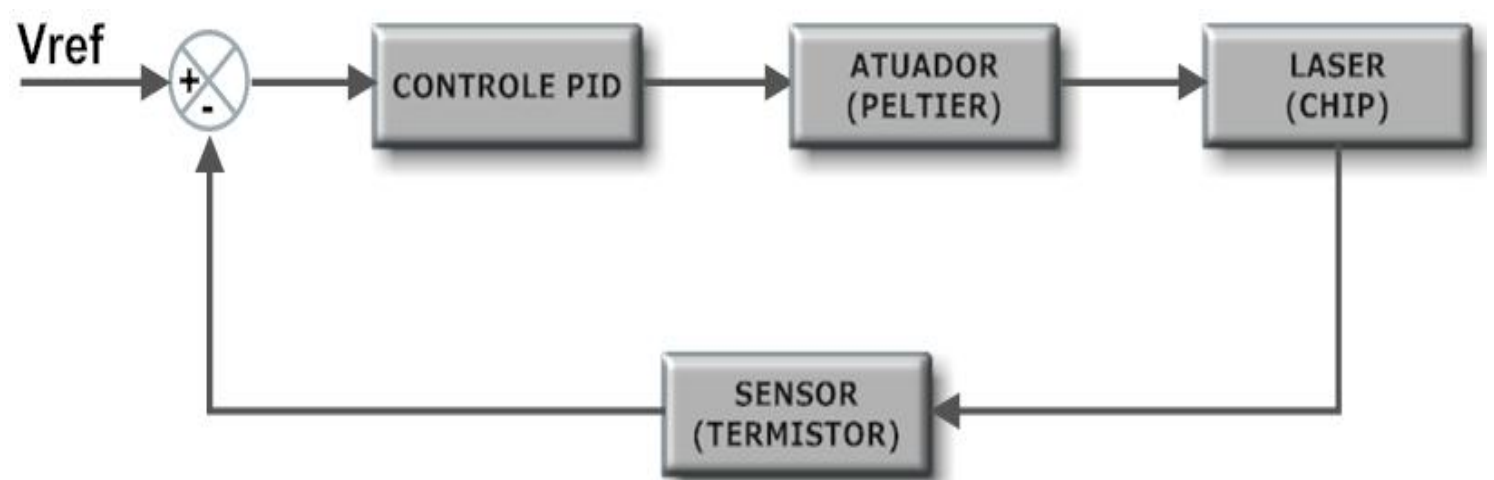

Figura 25: Diagrama de bloco do controle de temperatura do laser

O funcionamento desse controlador é identico ao controle de temperatura da caixa, a única diferença é em relação aos ganhos P,I e D do controlador. A sintonia é feita utilizando o método de Ziegler-Nichols modificado (OGATA,1998) e a resposta do controlador é dada por:

$$
H(s)=K_{p}+\frac{1}{T_{i} s}+T_{d} s
$$


onde $K_{p}$ é o ganho proporcional, $T_{i}$ é a constante de tempo para o integrador e $T_{d}$ é a constante de tempo para o derivativo. Os parâmetros de sintonia são determinados a partir do ganho proporcional, ou seja, inicialmente ligamos apenas o controlador proporcional, através de uma chave seletora de três posições, como mostrado na figura 28.

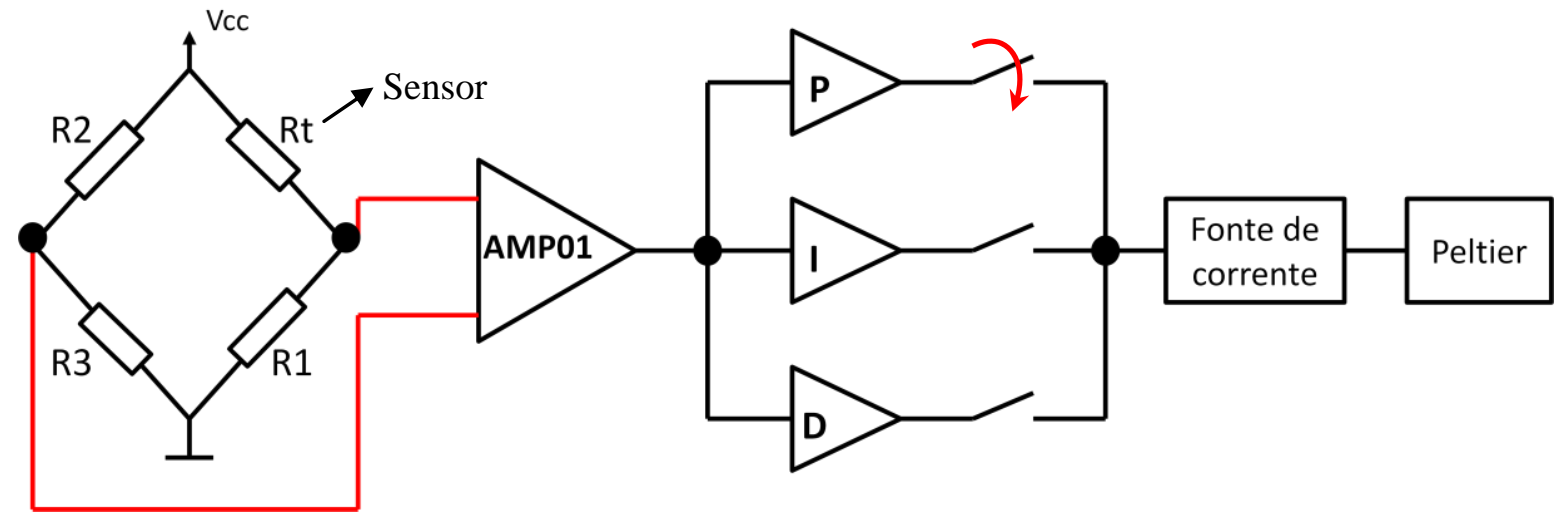

Figura 26: Sintonização do controlador PID.

Em seguida elevamos o ganho até atingir o limite de estabilidade do sistema, ou seja, quando o sistema começa oscilar em torno de um ponto de operação como mostrado na figura 29.

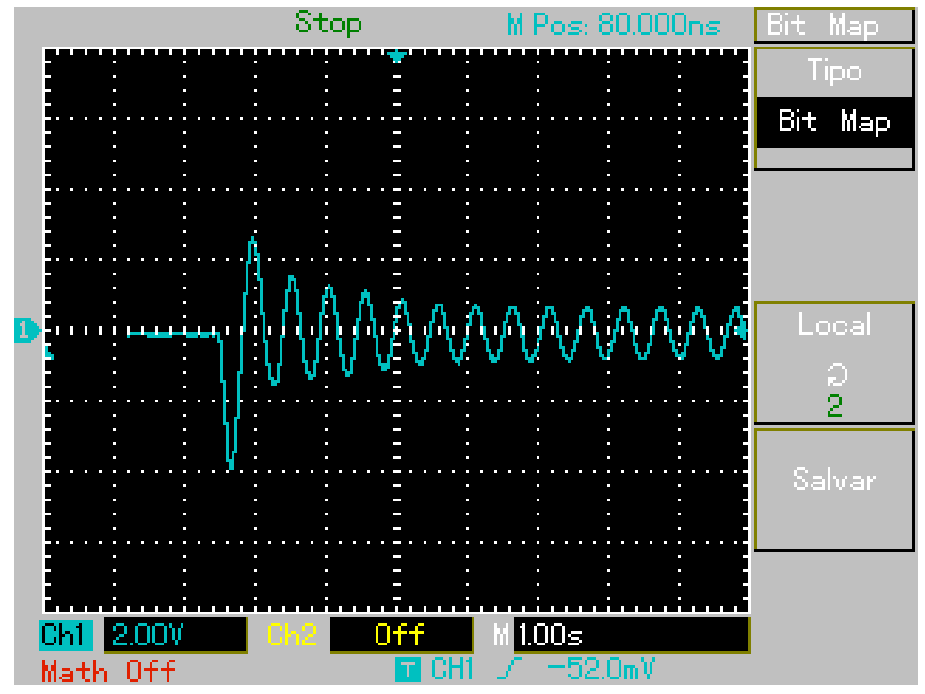

Figura 27: Medida do sinal de erro para a operação no limite de estabilidade do sistema (ganho crítico).

O método Z-N estabelece que:

$$
H(s)=K_{p}\left(1+\frac{1}{T_{i}^{\prime} s}+T_{d}^{\prime} s\right)
$$


onde

$$
T_{i}^{\prime}=K_{p} T_{i}
$$

$\mathrm{e}$,

$$
T_{d}^{\prime}=\frac{T_{d}}{K_{p}}
$$

Quando o sistema começa a oscilar o ganho proporcional é chamado de ganho crítico $\left(K_{c r}\right)$ e a oscilação é chamada de período crítico $\left(P_{c r}\right)$, o método estabelece que:

$$
\begin{gathered}
K_{p}=0,6 K_{c r} \\
T_{i}=0,5 P_{c r} \\
T_{d}=0,125 P_{c r}
\end{gathered}
$$

A partir esses parâmetros é que determinamos os valores de capacitores e resistores de cada controlador.

\subsection{Controle de corrente}

Como já discutido anteriormente, para que ocorra a ação laser é necessária a inversão de população na região ativa do laser. Essa inversão pode ser conseguida com a injeção de corrente através da região ativa. A fonte de corrente do laser deverá fornecer uma corrente elétrica suficiente para a operação em uma determinada região, não obrigatoriamente o valor máximo suportado pelo diodo, mas definido por condições estáveis de operação (ruído e estabilidade térmica, por exemplo). O valor máximo da corrente para o modelo SDL $5422 \mathrm{H} 1$ é de $210 \mathrm{~mA}$, porém trabalhamos com valores de corrente em torno de $100 \mathrm{~mA}$.

O circuito de controle de corrente desenvolvido no projeto possui dois ajustes manuais (grosso e fino), um ajuste para limitar a corrente, chave liga-desliga, chave para selecionar o ganho da modulação externa, entrada para modulação, usada para fazer a correção da frequência do laser e um monitor de corrente. 
Um dos grandes desafios em uma fonte de corrente é sua estabilidade, sendo assim, os componentes eletrônicos utilizados no circuito têm características especiais. Por exemplo, utilizamos um CI modelo LM 4140 (Texas Instruments - TI) com alta estabilidade térmica $\left(3 \mathrm{ppm} /{ }^{0} \mathrm{C}\right)$ como referência na fonte de corrente e componentes SMDs (Surface Mounted Devices) para a montagem do circuito eletrônico. O circuito eletrônico da fonte de corrente é mostrado no apêndice B.

\subsection{Amplificador de Alta tensão}

O amplificador de alta tensão foi desenvolvido com a finalidade de controlar o tubo piezoelétrico (MD-44 - Jodon 4,4 nm/V) onde o espelho de realimentação óptica é afixado, o diagrama da figura 30 ilustra o funcionamento.

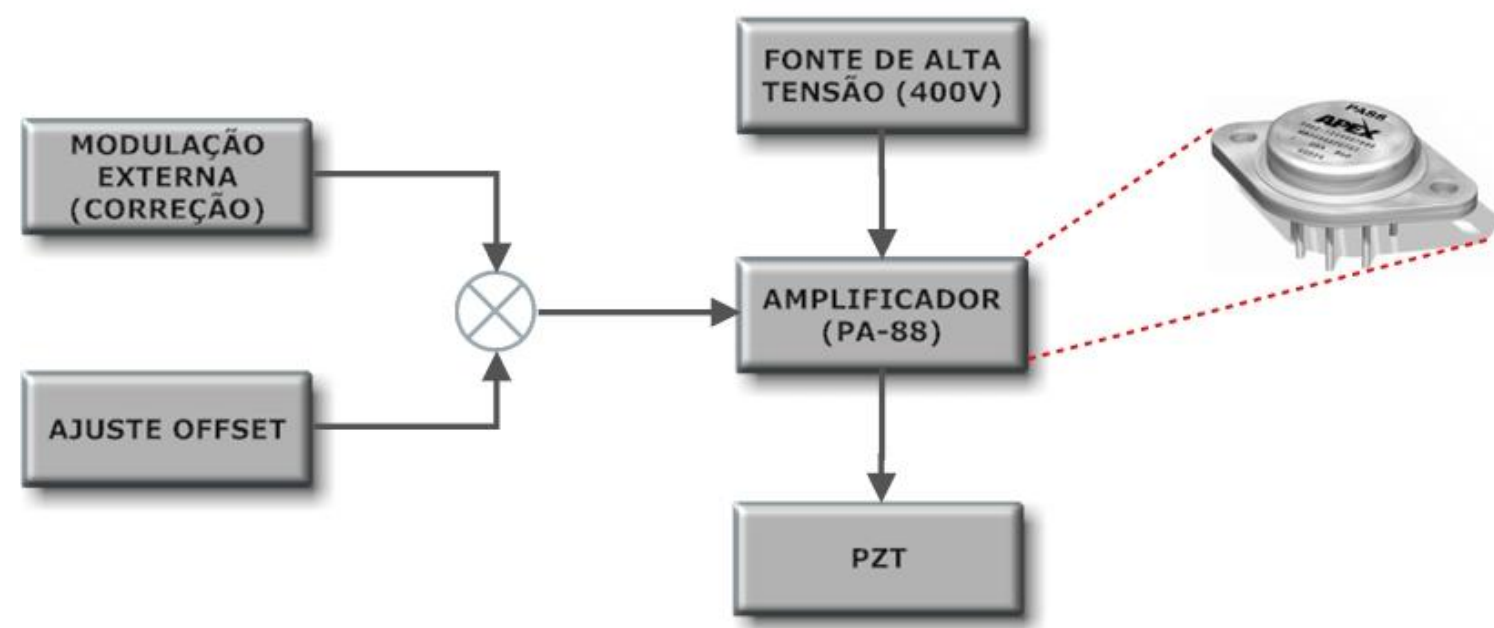

Figura 28: Diagrama de blocos do amplificador de alta tensão.

O circuito funciona com uma fonte de alta tensão ajustada em 400V (modelo P5310/1250V-25W High Voltage Power Supply da Stanford Research Systems), que alimenta um amplificador operacional de alta tensão (modelo PA88 - Apex (Apex Microtechnology, 2013) com ganho de 200. No circuito há duas entradas para um somador inversor. Uma entrada de modulação é utilizada para fazer a varredura e correção da cavidade e outra utilizada como um ajuste manual. Por fim, a saída do amplificador (com excursão de 10 à $400 \mathrm{~V}$ ) alimenta a cerâmica piezoelétrica, o apêndice C representa o circuito eletrônico desenvolvido do amplificador de alta tensão. 


\subsection{Circuito de travamento}

O travamento dos sistemas de laser de diodo nos padrões de frequência têm por finalidade a frequência do laser estável, tomando como referência uma linha de transição atômica. $\mathrm{O}$ circuito utilizado para travar a frequência do laser atua na corrente (resposta mais rápida) e no comprimento da cavidade estendida (resposta mais lenta). A figura 31 mostra o diagrama de blocos do circuito.

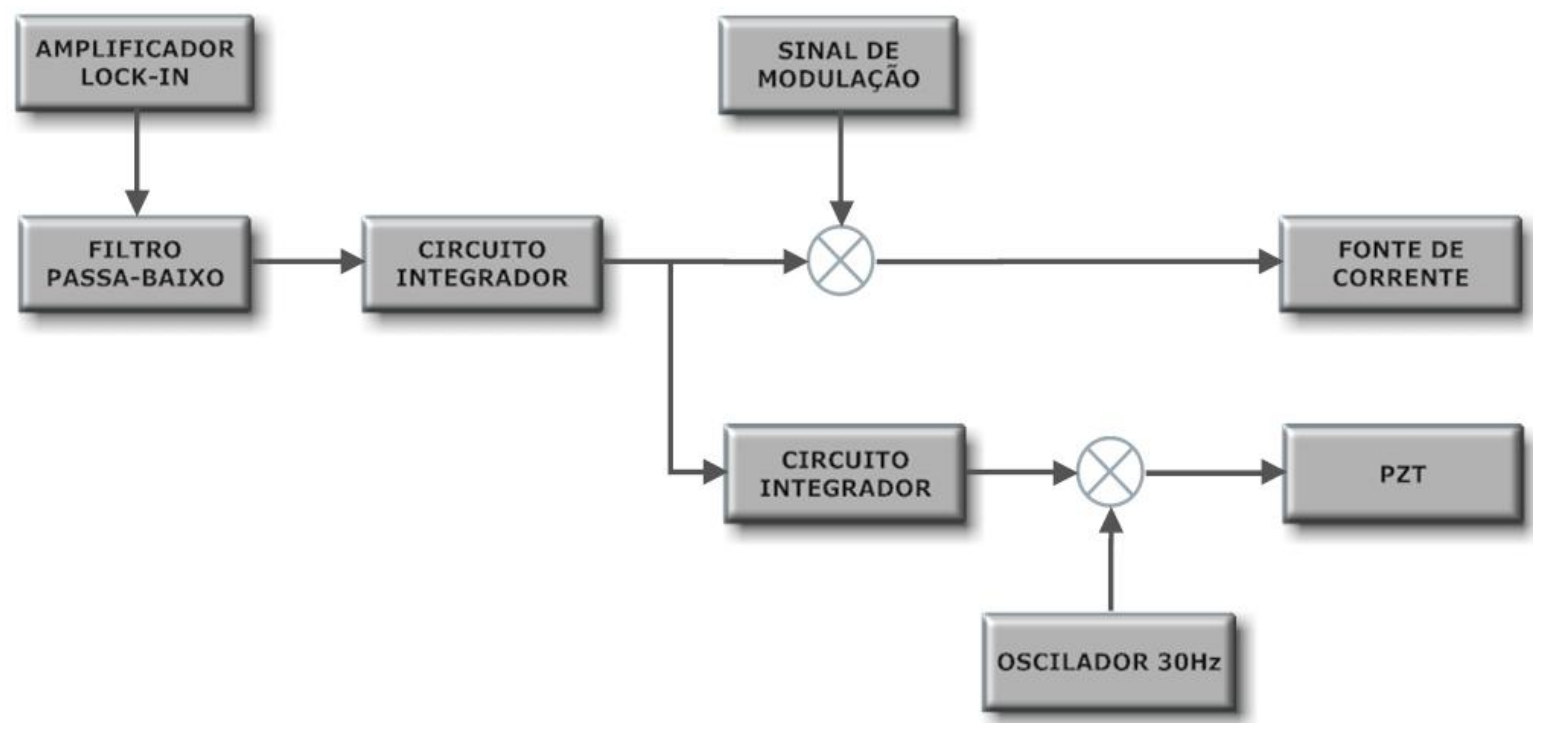

Figura 29: Diagrama de blocos do circuito de travamento (lock).

No estágio de entrada do circuito, temos um sinal de erro proveniente do amplificador lock-in, passando por um filtro passa-baixa passivo para minimizar a influência da frequência da modulação do sinal (acima de $80 \mathrm{kHz}$ ). Após esse estágio o sinal é enviado para um integrador com um interruptor, que nos permite ligar e desligar o circuito de travamento. O sinal de saída do integrador fornece a correção na corrente do laser de diodo. Na saída, um circuito somador nos permite adicionar o sinal de modulação na corrente.

O sinal de correção de corrente é integrado novamente para gerar o sinal de correção no PZT, sua saída é somada a um sinal de varredura de baixa frequência. $\mathrm{O}$ apêndice D representa o circuito eletrônico do circuito de travamento.

\subsection{Amplificador Lock-in}

O amplificador lock-in é um instrumento utilizado para fazer medidas de alta resolução de sinais na presença ruído, desenpenhando funções como medidor de fase e 
demodulação síncrona. Uma das vantagens em utilizar esse instrumento para estabilização de comprimento de onda de laser de diodo esta na capacidade de filtrar o ruído do sinal adquirido pelo fotodetector. A figura 32 mostra um diagrama de blocos esquematizando suas partes principais.

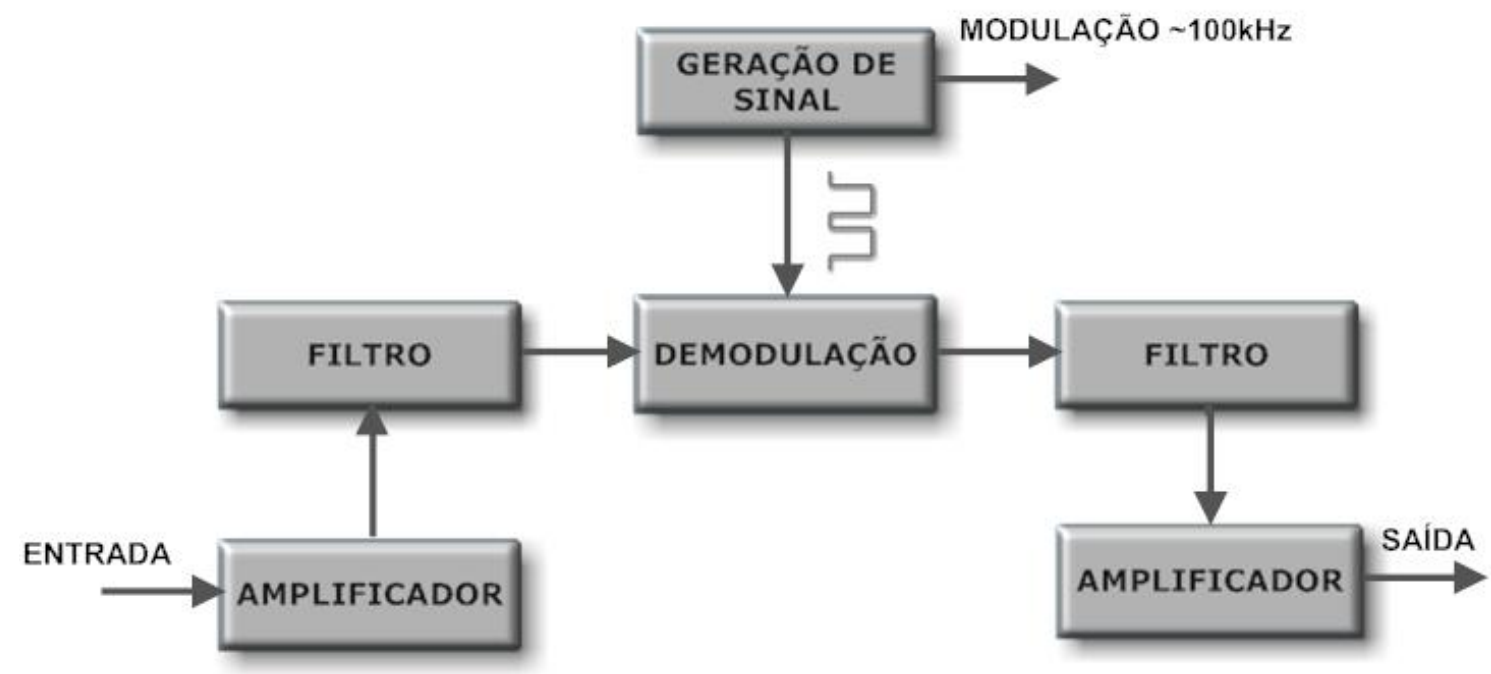

Figura 30: Diagrama de blocos do amplificador lock-in.

O gerador de sinal é utilizado como um sinal de referência para o circuito de demodulação e gera o sinal de modulação na frequência do laser de modo. A amplitude do sinal de modulação é ajustada de modo a gerar o mínimo de perturbação no sistema, tais como: saltos de modo e alargamento da linha do laser. Na entrada do amplificador lock-in o sinal do fotodetector é amplificado e filtrado de modo a minimizar sinais espúrios que prejudiquem o circuito de controle, esse sinal de entrada possui uma modulação que será multiplicada pelo sinal de referência no demodulador. O demodulador gera um sinal sensível à diferença de fase entre o sinal de entrada e o sinal de referência. Por fim esse sinal é filtrado, de modo a eliminar a componente $2 \mathrm{f}$ do sinal que resulta da multiplicação, e amplificado para ser utilizado como um sinal de erro para o travamento do laser. Um típico sinal do amplificador lock-in é representado na figura 33. 


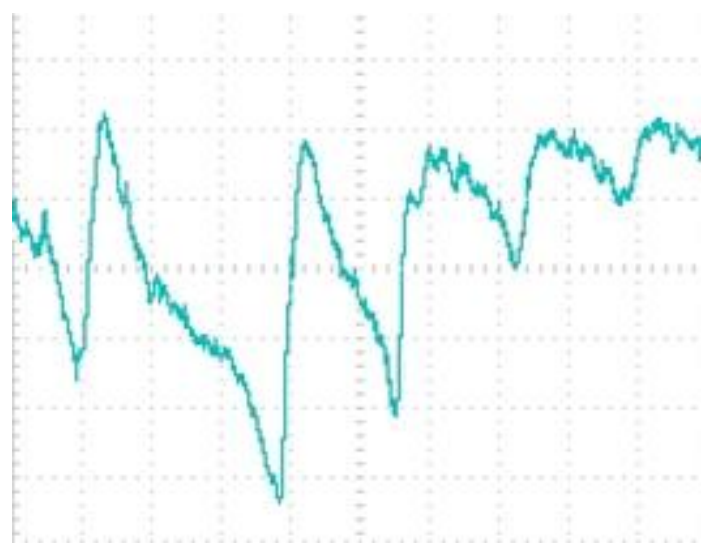

Figura 31: Sinal de saída do amplificador lock-in.

Uma observação importante desse circuito em relação ao travamento do laser, é que os vales que representam cada transição provocam uma inversão de fase no sinal de modulação. Esse sinal de inversão gera então um sinal de erro adequado para travar a frequência do laser no máximo da transição atômica.

\subsection{Sistema de referência para travar o laser}

Para fazer o travamento dos lasers de diodo na frequência de interesse é utilizada uma técnica denominada absorção saturada em célula de vapor. A montagem óptica que utilizamos é esquematizada na figura 34. Os componentes ópticos desse sistema são constituídos por um espelho (5), célula de vapor de Cs (4), lâmina $\lambda / 4$ (3), cubo polarizador (2), lâmina de $\lambda / 2$ (1) e um fotodetector (6).

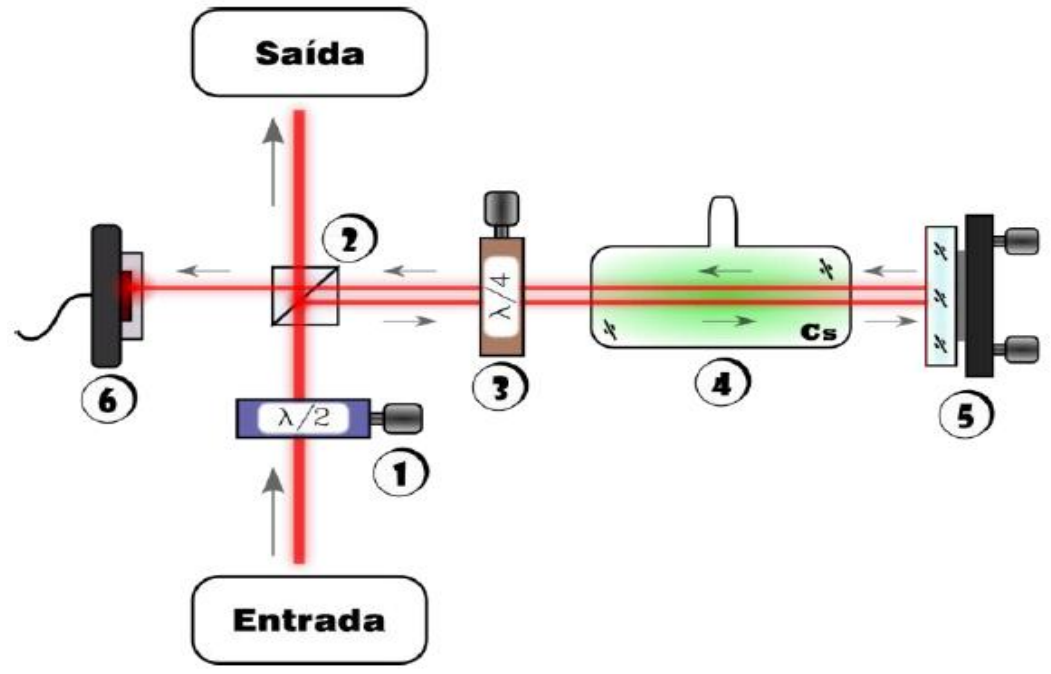

Figura 32: Sistema de referência de absorção saturada (Alves, 2012). 
Quando o sinal de varredura é injetado no circuito de alta tensão que controla a posição do espelho de saída do laser (OC), temos uma variação de comprimento da cavidade externa do laser que nos permite visualizar o perfil característico das transições atômicas, como visto na figura 35.

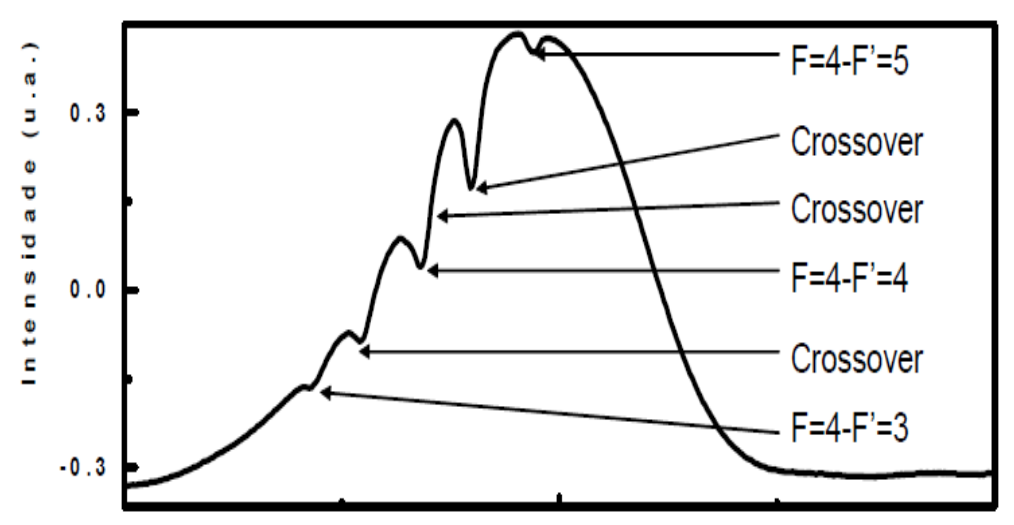

Figura 33: Perfil Doppler do átomo de Césio (Magalhães, 2004).

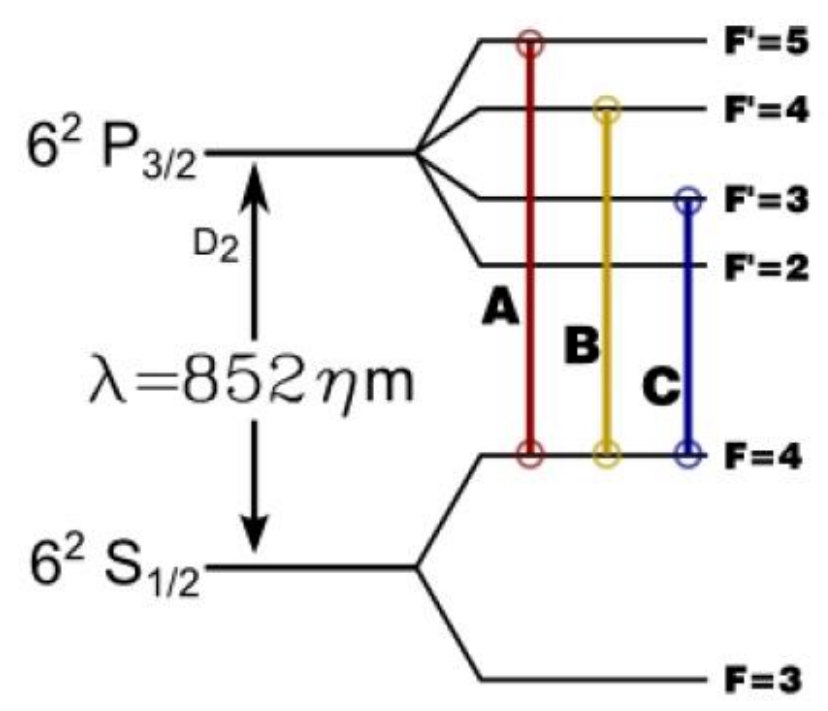
A) $F=4 \rightarrow F^{\prime}=5$
B) $F=4 \rightarrow F^{\prime}=4$
C) $F=4 \rightarrow F^{\prime}=3$

Figura 34: Níveis atômicos do átomo de Césio.

Com essa técnica podemos visualizar as transições atômicas de interesse do átomo de césio e travar em uma certa transição de energia, por exemplo entre os níveis $\mathrm{F}=4$ e F' = 5 , mostrado na figura 36, utilizada para o aprisionamento e resfriamento, os anexos B e C apresentam em uma forma mais detalhada as caracteristicas do átomo de Césio e os níveis de energia. 


\subsection{Caixa do laser de diodo}

Temos atualmente a necessidade em obter um sistema de laser de diodo compacto e robusto, tanto para ser usado no chafariz atômico ou no novo padrão de frequência compacto, visando aplicações móveis. Sendo assim, uma das etapas desse trabalho está relacionada com a redução de tamanho do sistema optomecânico do laser de cavidade estendida.

A caixa do laser de diodo é feita de alumínio, pois sua caracteristica de condutividade térmica aliada ao seu peso é bastante favorável para nossos objetivos. Suas dimensões atuais são de 140x22x50mm e sua usinagem foi feita na própria oficina mecânica do Instituto de Física de São Carlos.

Como já discutido anteriomente, utilizamos uma configuração de cavidade estendida com filtro de interferência, visando a compactação e estabilidade do sistema. A figura 37 ilustra em o projeto em CAD da caixa do laser com todos os componentes ópticos, na figura 38 temos uma visão superior da caixa e na figura 39 temos uma comparação do tamanho da caixa do laser em relação a uma caneta.

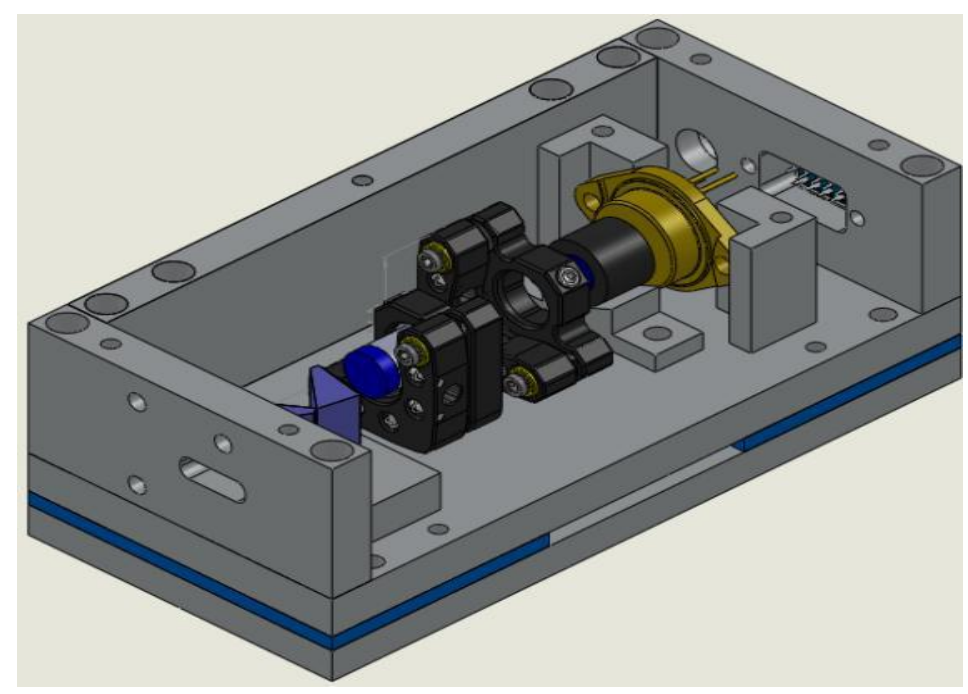

Figura 35: Desenho 3D da caixa do laser. 


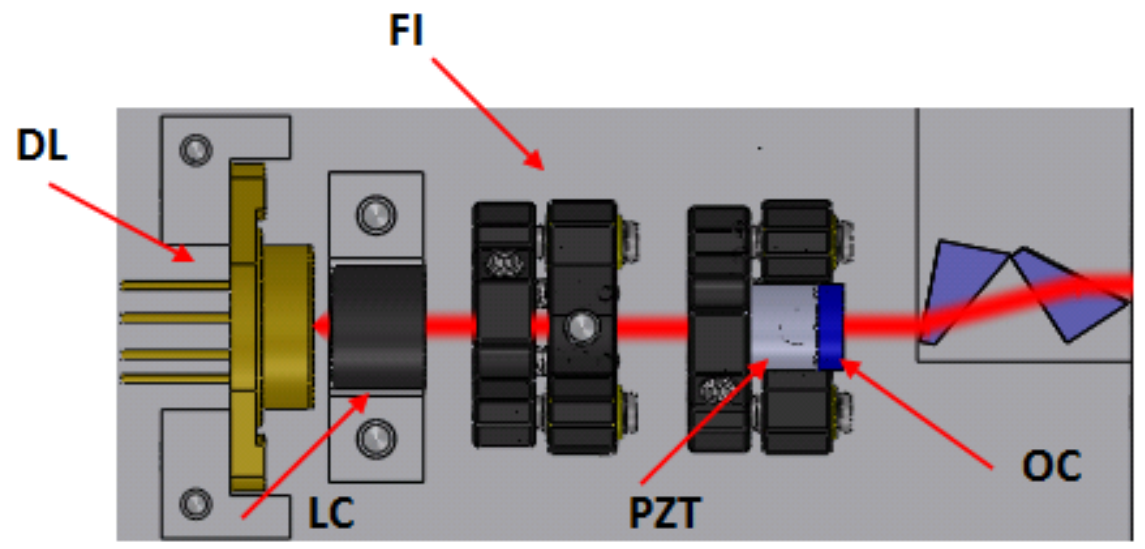

Figura 36: Vista superior da caixa do laser.

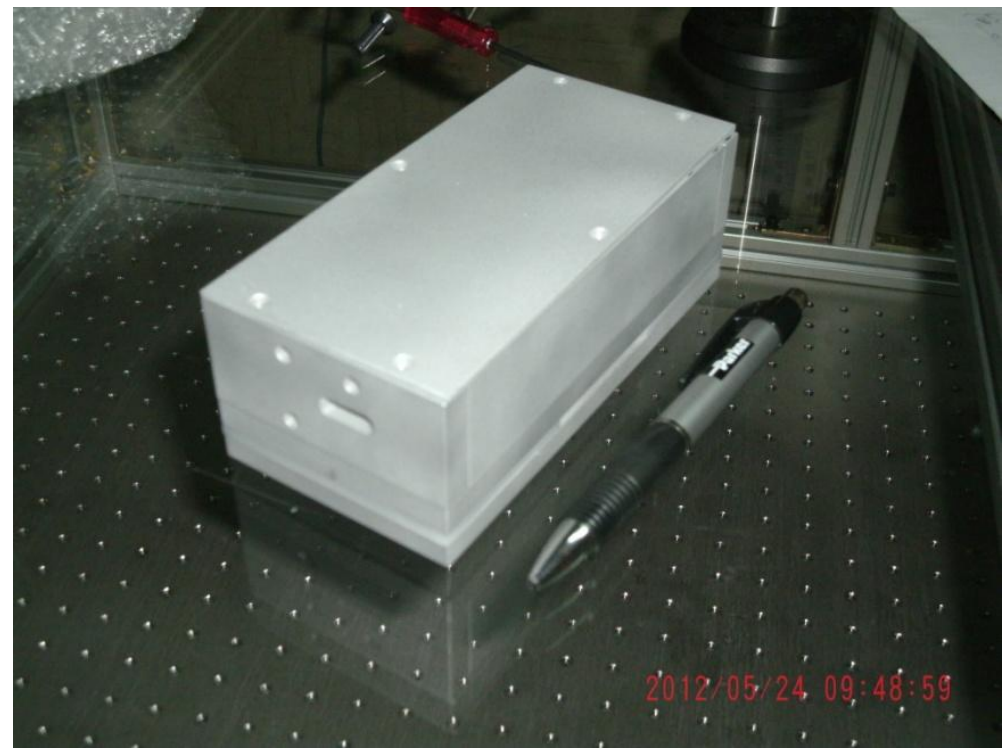

Figura 37: Laser compacto.

A nova caixa com relação às caixas antigas tem as seguintes características:

- Fácil montagem e manuseio com relação os componentes ópticos;

- Seleção do modo longitudinal feita com um filtro de interferência;

- Estabilidade mecânica;

- Compacto.

A figura 40 ilustra as gerações de lasers de diodo utilizados em nosso laboratório. O laser maior é do fabricante TOPTICA, o laser do meio foi feito em nosso laboratório e, por último, o novo projeto.

A cavidade estendida desenvolvida neste projeto possui os seguintes componentes ópticos:

- Lente colimadora (LC) modelo Melles Griot 06GLC002/D; 
- $\quad$ Filtro de interferência (FI) de $5 \times 5 \mathrm{~mm}$ e transmissão de $90 \%$ para um ângulo incidente de $6^{\circ}$, com comprimento de onda de $852 \mathrm{~nm}$ fornecido pela empresa Radiant Dyes ;

- Espelho de saída (OC) com 70\% de transmitância.

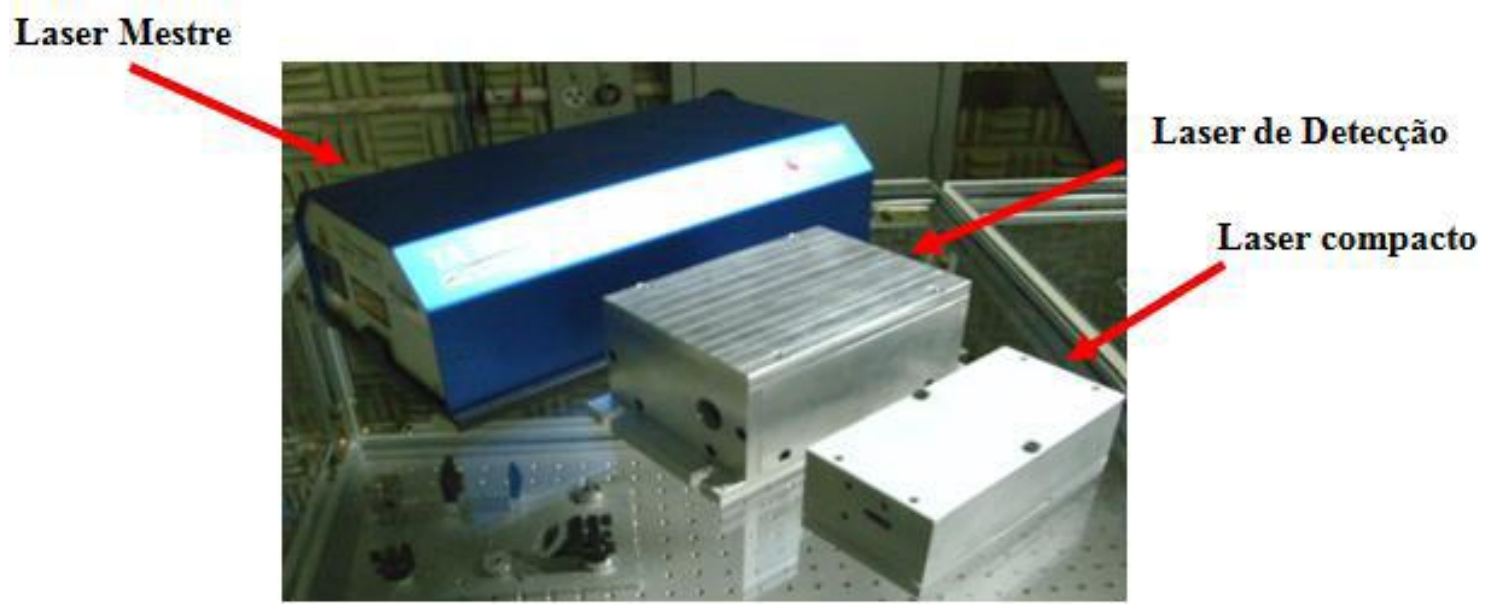

Figura 38: Gerações de lasers de diodo no nosso laboratório 


\section{Capítulo 4}

\section{Caracterização de subsistemas}

\subsection{Estabilidade dos controles de temperatura}

Um controle de temperatura estável é fundamental num laser de diodo que é utilizado em sistemas como o de um padrão de frequência, já que o comprimento de onda do laser depende diretamente da temperatura.

As medidas de estabilidade dos controles de temperatura são feitas à partir de um ponto de operação (temperatura desejada), observando-se o comportamento ao longo do tempo. Para fazer a aquisição dos dados, foi utilizado um programa em LABVIEW, mostrado no apêndice E, e uma placa de aquisição de dados (modelo NI PCI - 6259).

Começando com o controle de temperatura da caixa, mostrado na figura 41, cujo objetivo é minimizar a deformação térmica na base da caixa do laser, medimos o sinal de erro durante um período de seis dias. As medidas mostram uma variação máxima de $17 \mathrm{mV}$, implicando numa variação na temperatura de $8,5 \times 10^{-3}{ }^{0} \mathrm{C}$, isso conduz uma variação máxima no comprimento da cavidade externa de $12 \mathrm{~nm}$.

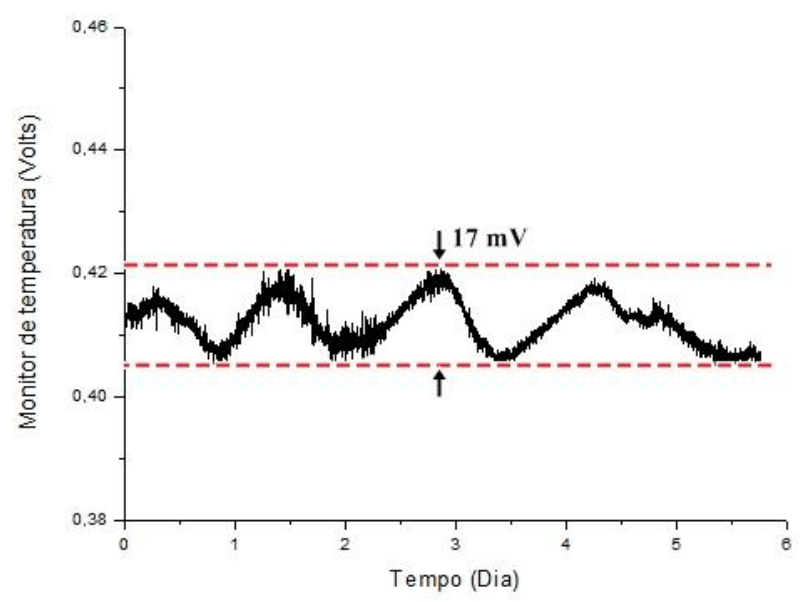

Figura 39: Estabilidade do controle PID de temperatura da caixa do laser. 
A medida da estabilidade do controle de temperatura do laser seguiu os mesmo procedimentos do controle de temperatura da caixa. Na figura 42 é mostrado o sinal de erro medido durante um período de seis dias. Foi observada uma variação máxima de $1,5 \mathrm{mV}$, significando uma variação na temperatura do laser de $7,5 \times 10^{-4}{ }^{\circ} \mathrm{C}$. Essa máxima variação observada está condizente com as necessidades para o nosso laser que é de variações da ordem de milésimos de ${ }^{\circ} \mathrm{C}$.

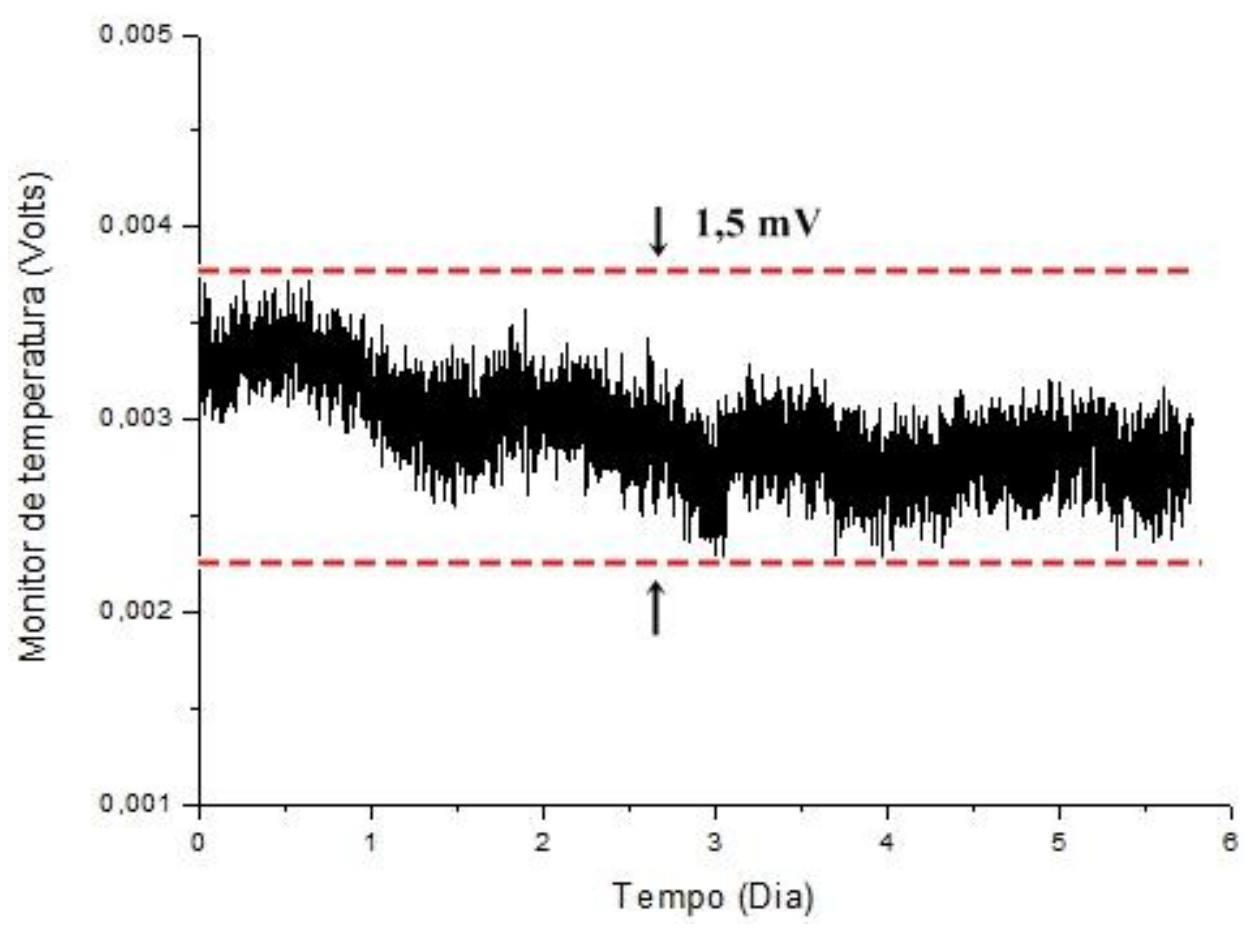

Figura 40: Estabilidade do controle PID de temperatura do laser

\subsection{Análise dos controles de corrente}

Para avaliar a estabilidade da fonte de corrente do sistema laser de diodo foi utilizado o monitor de corrente do circuito do laser e uma placa de aquisição de dados (NI PCI - 6259) com um software em LABVIEW, visto no apêndice E. A corrente foi ajustada em torno de $93 \mathrm{~mA}$ e a duração da medida foi de seis dias. A figura 43 ilustra a medida na fonte de corrente. 


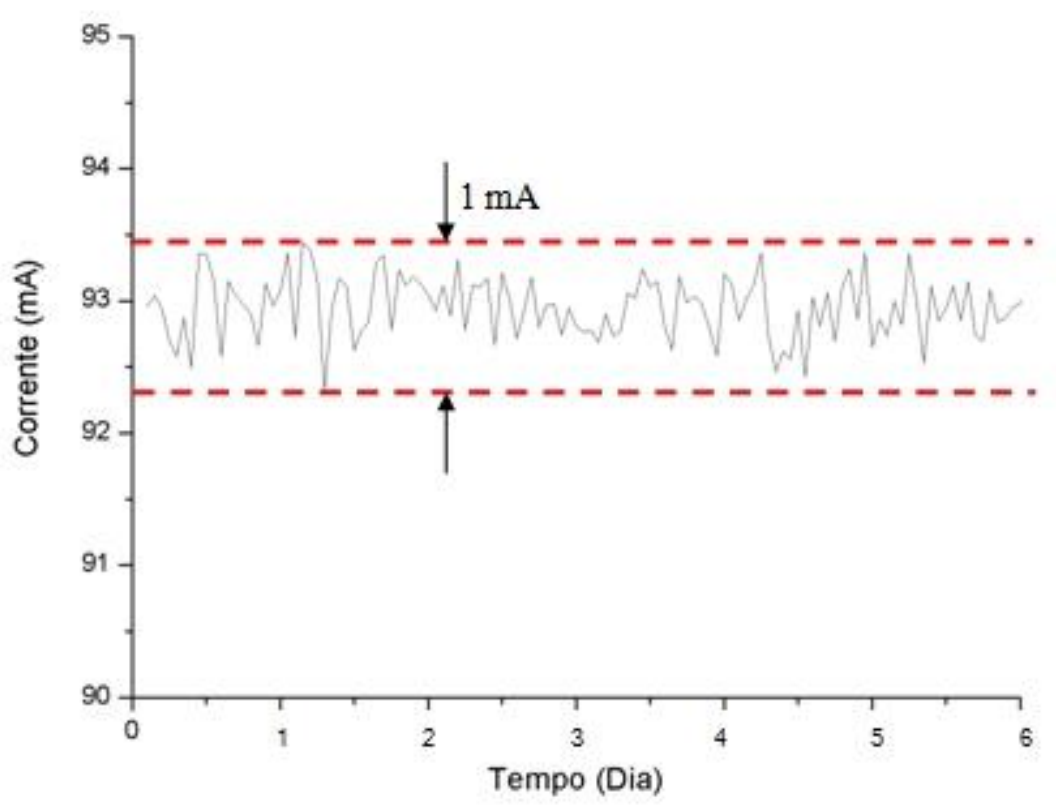

Figura 41: Estabilidade da fonte de corrente

Na figura 43 pode-se observa que a corrente no laser de diodo tem uma oscilação menor que $1 \mathrm{~mA}$, considerando o ponto de operação em $93 \mathrm{~mA}$. Apesar de parecer grande a variação, para a nossa aplicação em particular, a corrente recebe o sinal de retorno de realimentação para corrigir a frequência baseada na transição atômica. A resposta lenta será, de qualquer modo, influenciada por essa correção. Mesmo assim, verificamos que a principal fonte de variação é o resistor utilizado como referência para a fonte de corrente, que será futuramente substituído por um componente de maior estabilidade térmica.

A característica de resposta em frequência da fonte também foi levantada. Para isso injetamos um sinal senoidal na entrada de modulação externa no driver do laser, utilizada para fazer a correção em corrente no laser, e através de um osciloscópio observamos quando o sinal diminui para $-3 \mathrm{~dB}$ (frequência de corte). Medimos assim uma largura de banda de 400 $\mathrm{kHz}$.

O ruído na fonte de corrente também foi avaliado com um analisador de sinais (modelo HP3561A), que nos permite visualizar o espectro do sinal numa faixa de poucos $\mathrm{Hz}$ a $100 \mathrm{kHz}$. Foram analisados a fonte de corrente do laser já desenvolvido em nosso laboratório e o laser desse projeto, como mostrado na figura 44. 


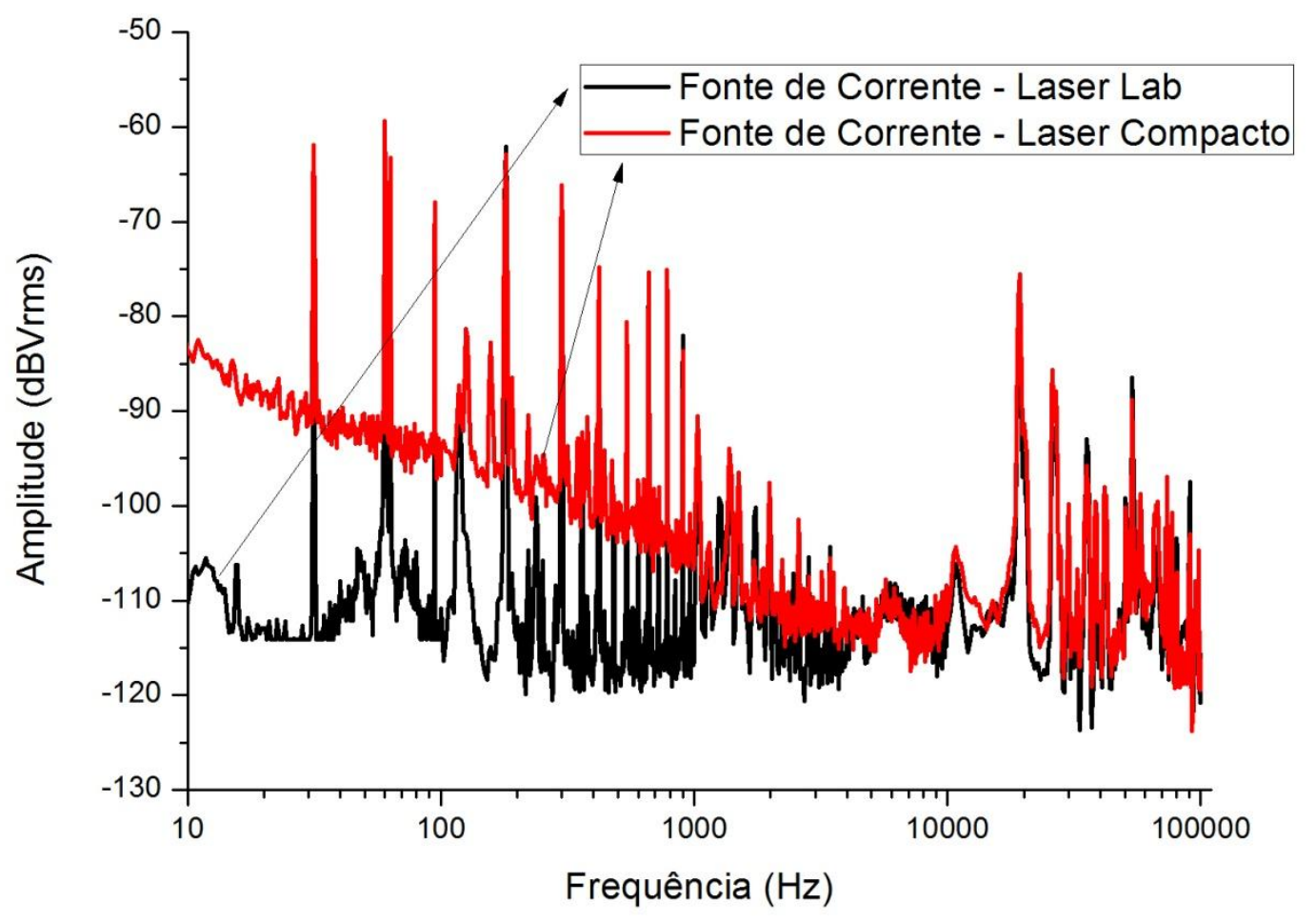

Figura 42: Espectro do sinal na fonte de corrente

O gráfico da figura 44, nos permite avaliar o patamar do ruído entre as duas fonte de corrente, sendo assim, observa-se que a fonte de corrente do novo projeto possui amplitudes de ruídos maiores em comparação a outra fonte, isso nos levou a investigar em mais detalhes os componentes do circuito.

A verificação das fontes de ruído desse circuito é um processo árduo, pois vários parâmetros devem ser levantados, tais como: cabeamento, componentes eletrônicos, fonte de alimentação, laços de terra, iluminação da sala, etc. Todos esses parâmetros foram verificados, porém uma atenção maior foi em relação aos componentes eletrônicos, principalmente com os resistores SMDs utilizados no desenvolvimento dos circuitos eletrônicos.

Os componentes SMDs foram utilizados com o intuito de compactar as placas eletrônicas, porém sua forma de construção, material e coeficiente térmico são parâmetros importantes para serem avaliados, nesse caso.

Uma análise de ruído foi feita com o interesse de verificar se o tipo de resistor, em seus detalhes construtivos, seria capaz de influenciar o desempenho do circuito. A configuração para fazer essa medida é bastante simples, como mostrada na figura 45 . 


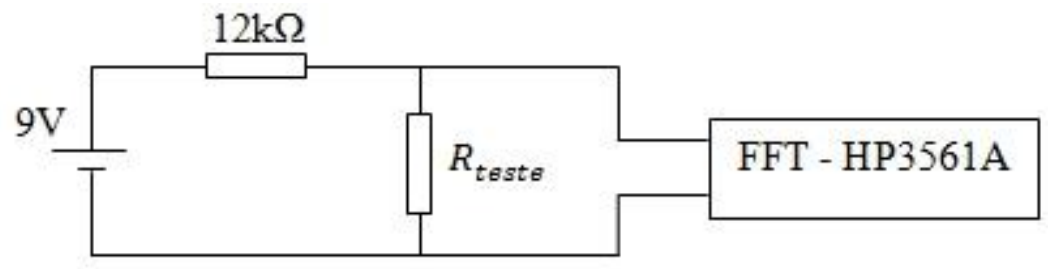

Figura 43: Configuração do sistema para avaliação de ruído nos resistores.

Para essa avaliação foi montado um divisor de tensão alimentado por uma bateria de $9 \mathrm{~V}$ e uma referência resistiva de seis faixas de $12 \mathrm{k} \Omega$. O valor de tensão na resistência de teste $R_{\text {teste }}$ foi medido utilizando um analisador de espectro (FFT-HP3561A). Foram analisados quatro tipos de resistores com valores de resistência de $10 \mathrm{k} \Omega$. A figura 46 representa os espectros dos sinais medidos.

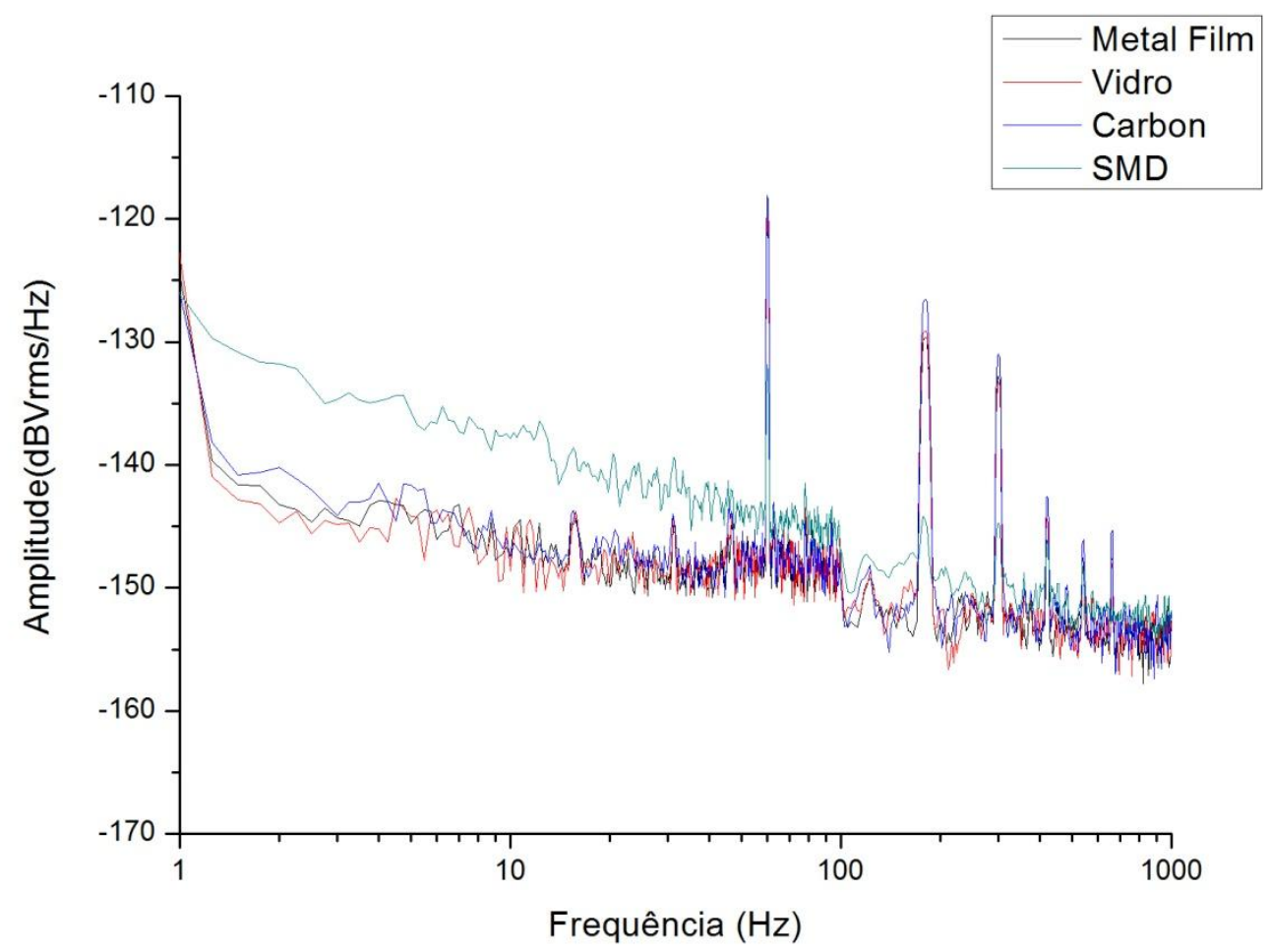

Figura 44: Sinais espectrais do ruído nos resistores.

Na figura 46 observa-se que o resistor SMD utilizado tem ruído de excesso para uma faixa considerável de frequências, em alguns casos chegando a $10 \mathrm{~dB}$ de diferença, isso implica em um ganho de tensão de 3,2. Esse tipo de ruído aumenta com o valor de tensão aplicada e diminui com a resistência, pois é relacionado à corrente circulando no resistor. 
Com essa medida de ruído, observou-se que o melhor tipo de resistor para utilizar nos circuitos eletrônicos é de Vidro ou Metal Film, ou ainda, segundo Heefner, 2007, resistores de filme fino (Thin Film) apresentam as menores amplitude de ruído. Pudemos assim verificar porque os valores de ruído principalmente na fonte de corrente apresentaram valores significativos. Passamos então a utilizar uma fonte com componentes discretos de Metal Film, enquanto resistores SMD mais apropriados eram adquiridos.

\subsection{Amplificador de alta tensão}

Para obter a resposta em frequência do amplificador, utilizamos a entrada de modulação externa com um gerador de sinal senoidal e um osciloscópio, como mostrado na figura 47.

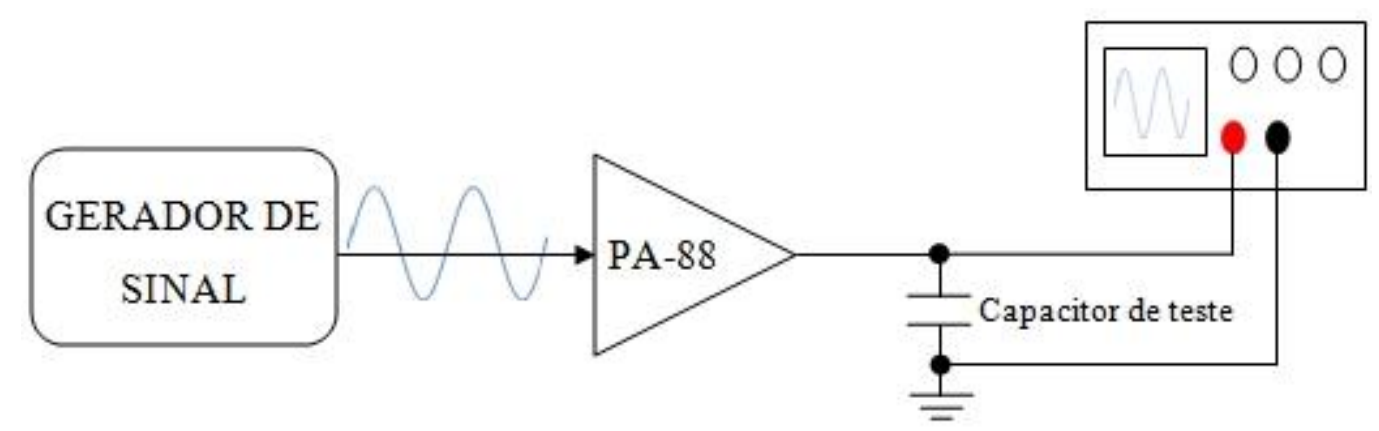

Figura 45: Frequência de corte - SETUP

Variando a frequência na entrada do circuito, foi observado o decaimento em $3 \mathrm{~dB}$ do sinal de saída do amplificador. Foram testados três capacitores simulando a carga da cerâmica piezoelétrica $(2,2 \mathrm{nF}, 3,3 \mathrm{nF}$ e $4,7 \mathrm{nF})$, com os resultados sumarizados na tabela 2 .

Tabela 2: Frequência de corte do amplificador de alta tensão

\begin{tabular}{|l|l|}
\hline Capacitância & Resposta em frequência \\
\hline $2,2 \mathrm{nF}$ & $16 \mathrm{kHz}$ \\
\hline $3,3 \mathrm{nF}$ & $7 \mathrm{kHz}$ \\
\hline $4,7 \mathrm{nF}$ & $7 \mathrm{kHz}$ \\
\hline
\end{tabular}

A resposta em frequência obtida nas medidas mostra que o circuito amplificador de alta tensão está em condições mais que suficientes para atuar no espelho de saída. A modulação normalmente utilizada para a visualização das transições atômicas é de $30 \mathrm{~Hz}$ e o 
tempo limite de resposta deverá ser limitado pela própria estrutura mecânica da cerâmica e do espelho de saída do laser. Limitamos propositadamente a resposta em frequência em torno de $500 \mathrm{~Hz}$.

\subsection{Circuito de travamento}

O circuito de travamento é utilizado para travar o laser em uma determinada transição entre níveis de energia do $\mathrm{Cs}^{133}$, como por exemplo a transição entre os níveis $\mathrm{F}=4$ e $F^{\prime}=5$, utilizada para o aprisionamento de átomos. Esse circuito trabalha em conjunto com o amplficador lock-in, que é utilizado para gerar o sinal de erro do sistema para que o circuito de travamento atue.

Montamos uma topologia composta por dois filtros PI (Proporcional Integral), dois amplificadores somadores e um filtro passa-baixa passivo. Na etapa de entrada, o filtro passa-baixa atenua a componente $2 f_{\text {mod }}$ do sinal de erro, remanescente no amplicador lockin. Em seguida, um filtro PI com ganho variável e com uma chave em paralelo com o capacitor, permite ligar e desligar o circuito de travamento, como mostrado na figura 48.

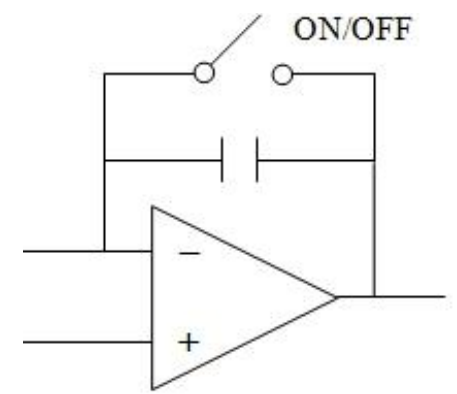

Figura 46: Filtro Integrador.

Quando a chave é fechada, a sintonia pode ser feita manualmente, ou seja, através da varredura na cavidade. Utilizando o ajuste manual do amplificador de alta tensão, sintonizamos a frequência de interesse. Logo após essa sintonia, abrimos a chave e o filtro começa a agir sobre o sistema.

$\mathrm{Na}$ etapa de sintonia, os vales que representam cada transição provocam uma inversão de fase no sinal de modulação, idealmente esse sinal cruza zero exatamente no pico de frequência onde trava-se o laser de diodo, como mostrado na figura 49. 


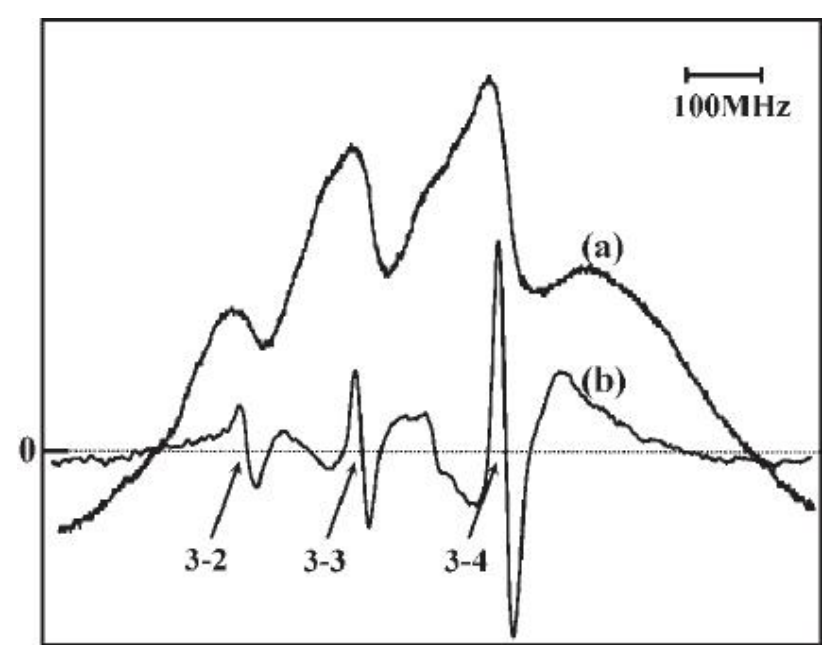

Figura 47: Sinal utilizado para fazer o travamento do laser (Zhao, et. al. 2004).

Os ganhos do circuito de travamento são ajustados de modo a minimizar eletronicamente os ruídos de frequência do laser, mantendo o sistema abaixo do limite de oscilação. A sintonia é feita com os ajustes para vários valores de ganho e analisando-se o comportamento do sistema através de um analisador de sinal (FFT- HP 3561A), como mostrado na figura 50 .

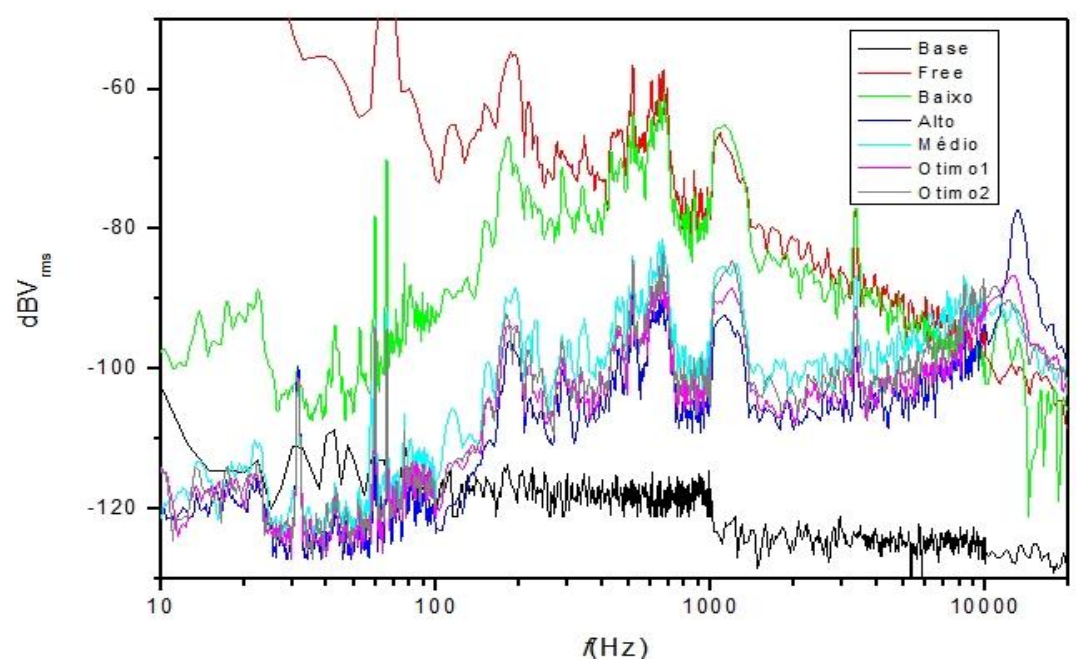

Figura 48: Ajuste dos ganhos do circuito de travamento.

Avaliando-se os espectros podemos definir o ganho que mais reduz o ruído e observar quando a oscilação limitada pela resposta do sistema inteiro começa a se fazer importante, como observado em torno de $10 \mathrm{kHz}$. 


\subsection{Fontes de alimentação}

A fonte de alimentação utilizada também é considerada componente crítico. $\mathrm{O}$ modelo utilizado é MPL-3303 (Minipa), com dois canais com excursão de 0 a 30V, corrente máxima de $3 \mathrm{~A}$ e um canal de $5 \mathrm{~V}$ com corrente máxima de $3 \mathrm{~A}$. Foram utilizadas duas fontes de alimentação.

A análise de ruído na fonte de alimentação, mostrada na figura 51, é uma medida importante a ser tomada no desenvolvimento do sistema de laser de diodo, pois dependendo da amplitude do ruído produzido nestas fontes, a estabilidade de todos os circuitos eletrônicos desenvolvidos fica prejudicada.

Para fazer a medida de ruído na fonte de alimentação, foram utilizados um analisador de sinal (FFT - HP3561A) e um resistor de $1 \Omega \times 5 \mathrm{~W}$. O resistor foi ligado em série com o positivo da fonte e o negativo e o terra foram ligados direto no circuito de controle, como mostrado no esquemático da figura 46.

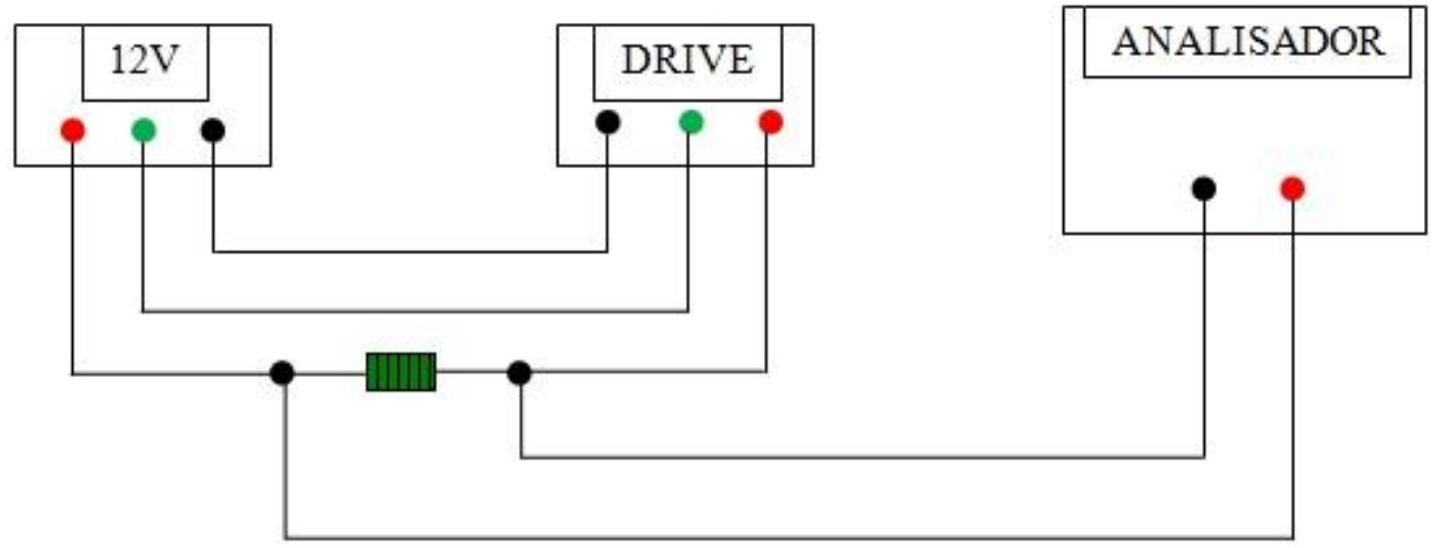

Figura 49: Esquemático da análise de ruído na fonte de alimentação

Na figura 52, observa-se que o ruído de $60 \mathrm{~Hz}$ apresenta a maior amplitude de ruído, $-90 \mathrm{dBV}$ para $12 \mathrm{~V}$ e $-115 \mathrm{dBV}$ para $5 \mathrm{~V}$, no entanto, a amplitude de ruído é muito baixa em relação à tensão utilizada, ou seja, a amplitude de ruído máxima em volts é de $3 \mu \mathrm{V}$, considerando uma tensão de $12 \mathrm{~V}$ e de $0,2 \mu \mathrm{V}$ para uma tensão de $5 \mathrm{~V}$.

Além disso, observa-se os harmônicos de mais alta ordem com amplitude em torno de $-100 \mathrm{dBV}$ para $12 \mathrm{~V}$ e $-120 \mathrm{dBV}$ para $5 \mathrm{v}$, considerando os dois primeiros harmônicos, e alguns picos em alta frequência em torno de $-100 \mathrm{dbV}$ para $12 \mathrm{~V}$ e $-130 \mathrm{dBV}$ para $5 \mathrm{~V}$, causados por chaveamentos da fonte. Mesmo assim consideramos a fonte adequada para a nossa aplicação. 


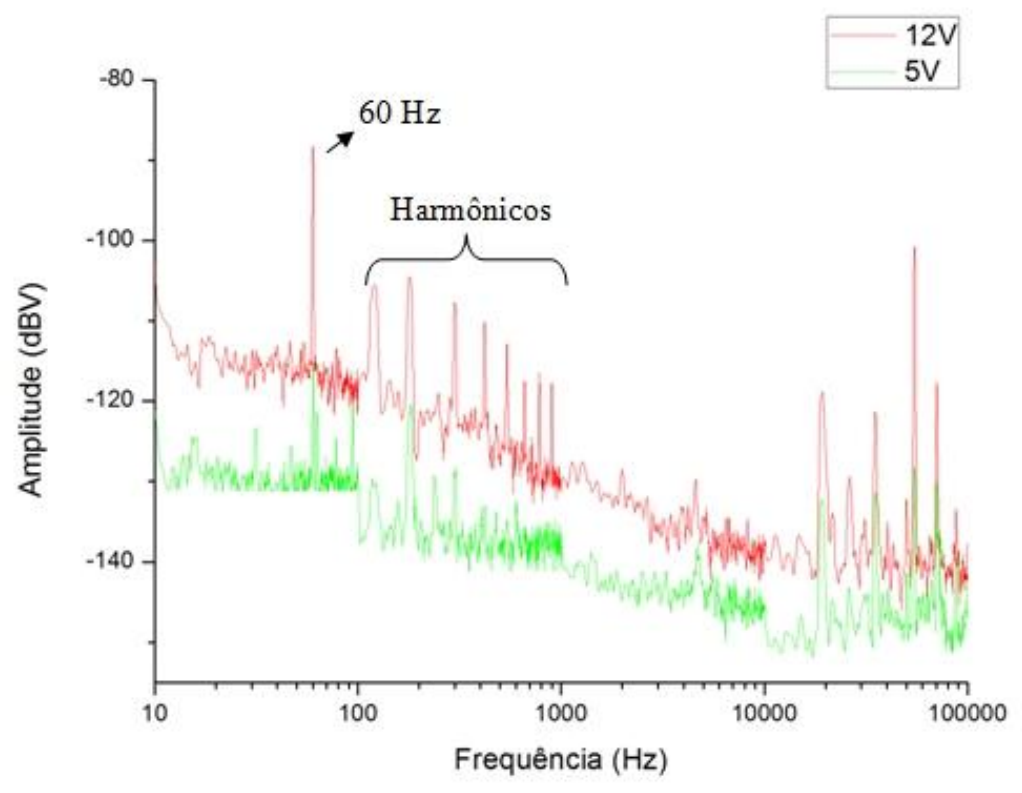

Figura 50: Análise de ruído na fonte de alimentação 


\section{Capítulo 5}

\section{Caracterização em operação do laser de diodo}

\subsection{Sintonia da Cavidade Estendida}

A sintonia da cavidade estendida com filtro de interferência é feita pela seleção de um dos modos longitudinais de oscilação da cavidade estendida. Utilizamos um filtro de interferência de 0,3 $\mathrm{nm}$ de largura espectral e a sintonia fina é feita pelo ajuste de ângulo do componente. Para ajustar o sistema, injetamos uma corrente em torno de $60 \mathrm{~mA}$ e medimos a potência de saída no filtro, assim a potência de saída foi maximizada pelos ajustes no suporte do filtro. Posteriormente fixamos o semi-espelho que fecha a cavidade resonante e ajustamos a realimentação óptica. Utizando um espectrometro modelo HR2000CG - UV - NIR, Ocean Optics e um PC, podemos observar, ainda que com baixa resolução, possíveis modos na transmissão na cavidade, como mostrado na figura 53.

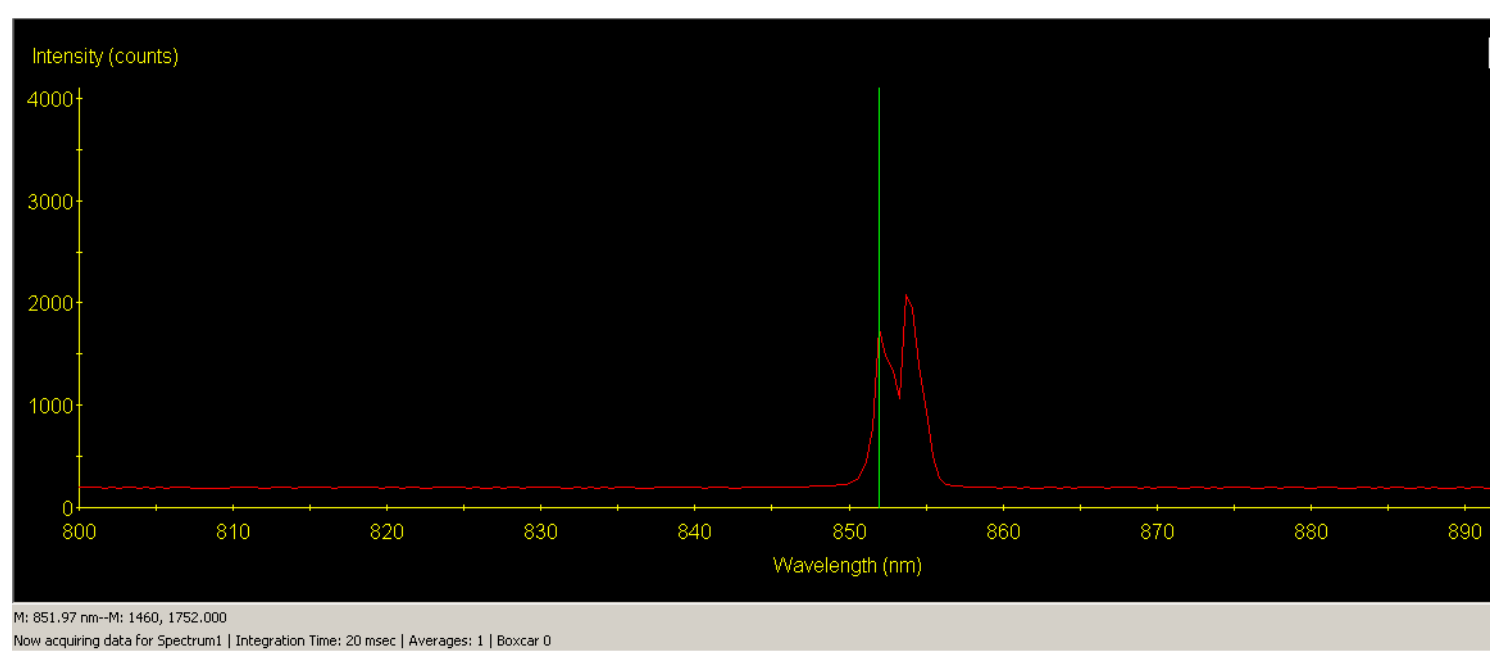

Figura 51: Modos na transmissão da cavidade externa do laser.

De modo a prevalecer apenas um modo em $852 \mathrm{~nm}$, sintonizamos a temperatura do laser e a posição do semi-espelho, assim conseguimos um modo em aproximadamente $852 \mathrm{~nm}$, como mostrado na figura 54. 


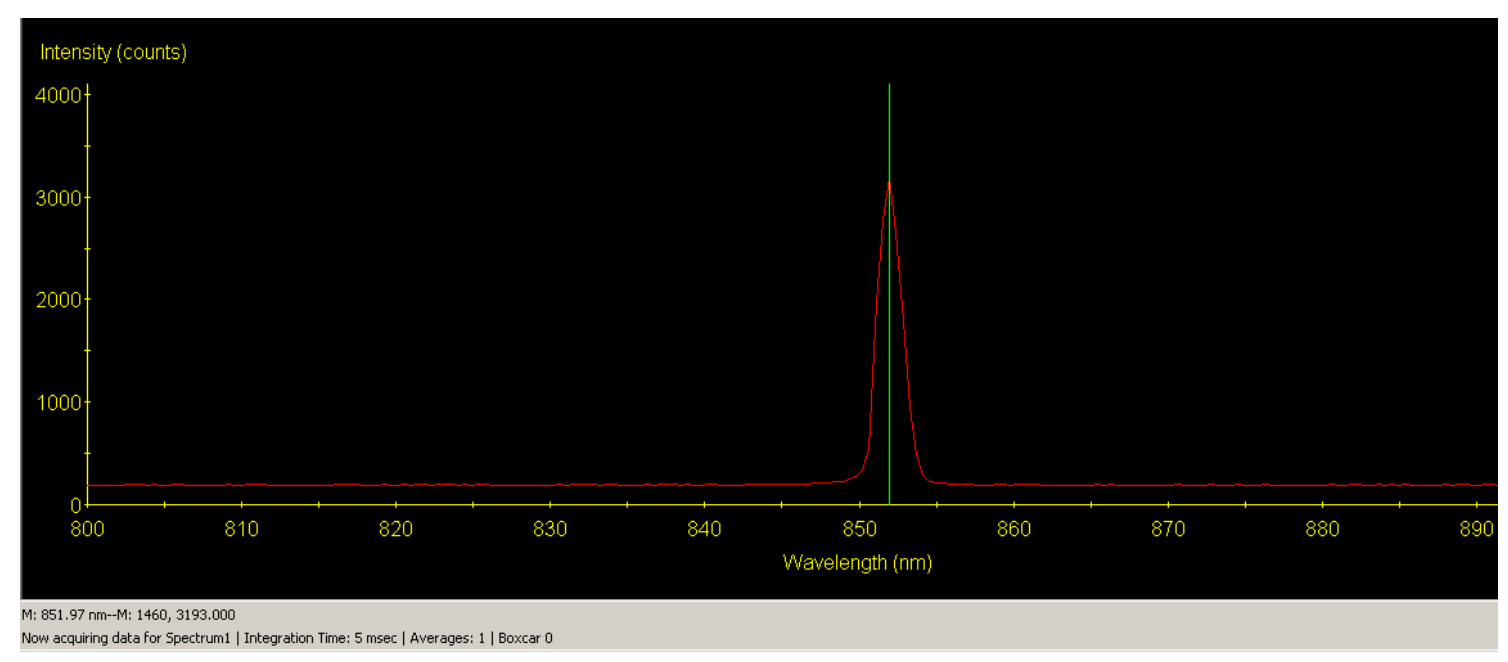

Figura 52: Seleção do modo em aproximadamente 852nm.

Para o ajuste fino da frequência do laser utilizamos uma célula com vapor de Césio. Variando finamente a temperatura e a corrente do laser, observamos através de um visor de infra-vermelho a fluorescência da célula, indicando a excitação de transições atômicas.

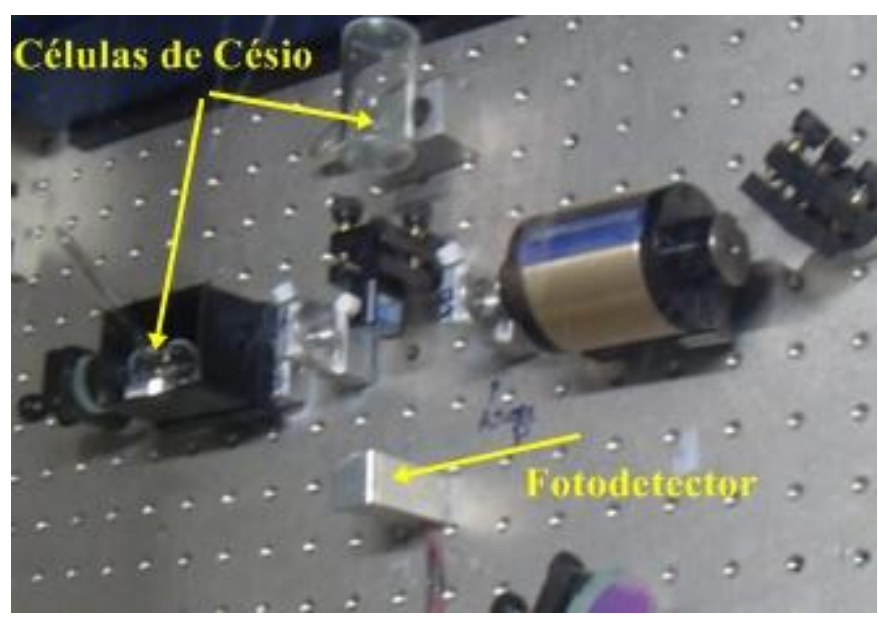

Figura 53: Sistema de absorção saturada montado para servir de referência para o laser de cavidade estendida.

Após o acendimento da célula de vapor de Cs, procedemos o alinhamento do sistema de referência de absorção saturada, como indicado na figura 55. Esse tipo de sistema é necessário para indicar com mais exatidão as linhas de transição, já que a fluorescênca da célula sofre a influência forte de efeitos doppler da distribuição de velocidades do vapor. A técnica de absorção saturada, com feixes laser em sentidos opostos, gera vales no perfil doppler, referentes aos átomos com velocidade nula na direção de propagação dos feixes. Outros vales no sinal se situam exatamente entre as frequências das transições atômicas e são 
chamados de crossovers, pois os átomos numa velocidade bem definida iteragem com os feixes laser, por causa das duas transições. O perfil doppler e os vales referentes às transições atômicas podem ser visualizados na figura 57.

\subsection{Estimando a largura de linha}

A largura de linha de um laser está relacionada aos ruídos que perturbam a característica perfeitamente senoidal do campo eletromagnético. Essa perturbação é causada, por exemplo, pela emissão espontânea na região ativa do laser, ruídos provenientes dos circuitos de controle e vibrações mecânicas na cavidade.

A largura de linha do laser é um parâmetro fundamental na utilização em padrões de frequência, pois define diretamente a capacidade de resolução do sistema desenvolvido. Para fazer a estimativa, usamos o próprio sistema de refência de absorção saturada, mostrado na foto da figura 56, como discriminador de frequência.

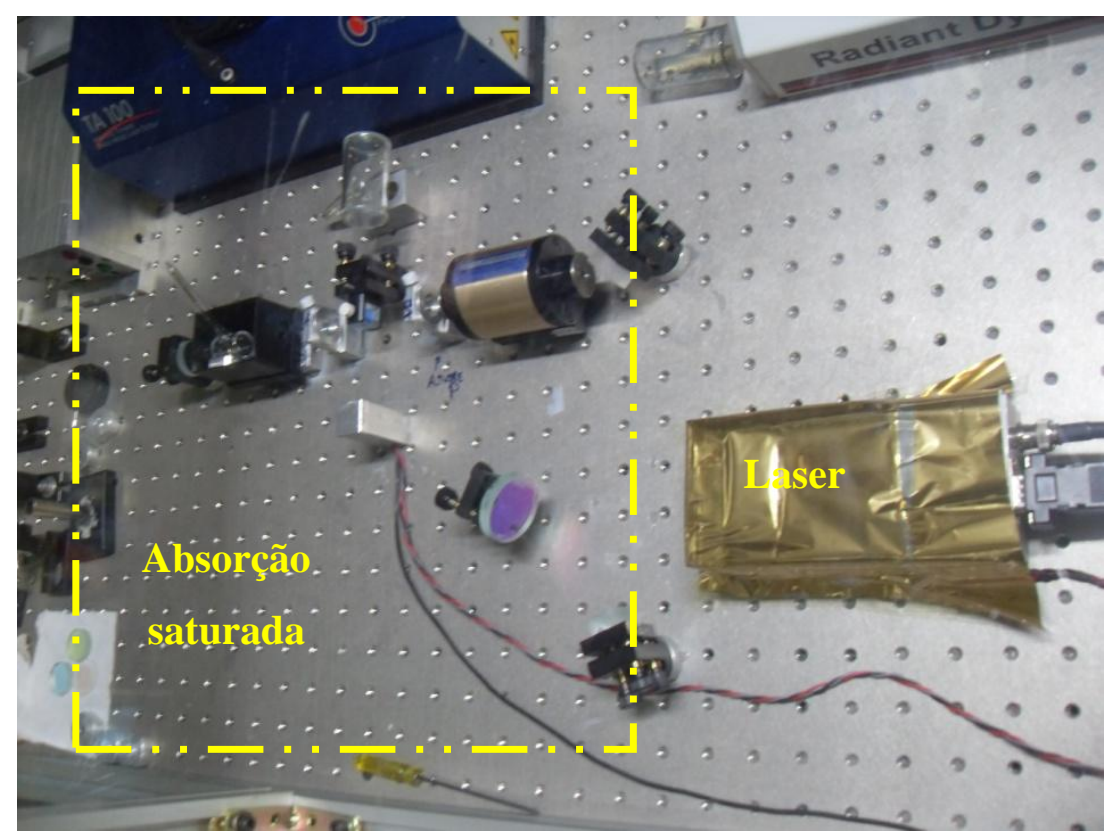

Figura 54: Montagem óptica do novo sistema.

Com uma corrente de injeção em torno de $60 \mathrm{~mA}$, visualizamos o perfil Doppler do átomo de Césio (laranja) e o sinal do amplificador lock-in (azul), como mostrado na figura 57. 


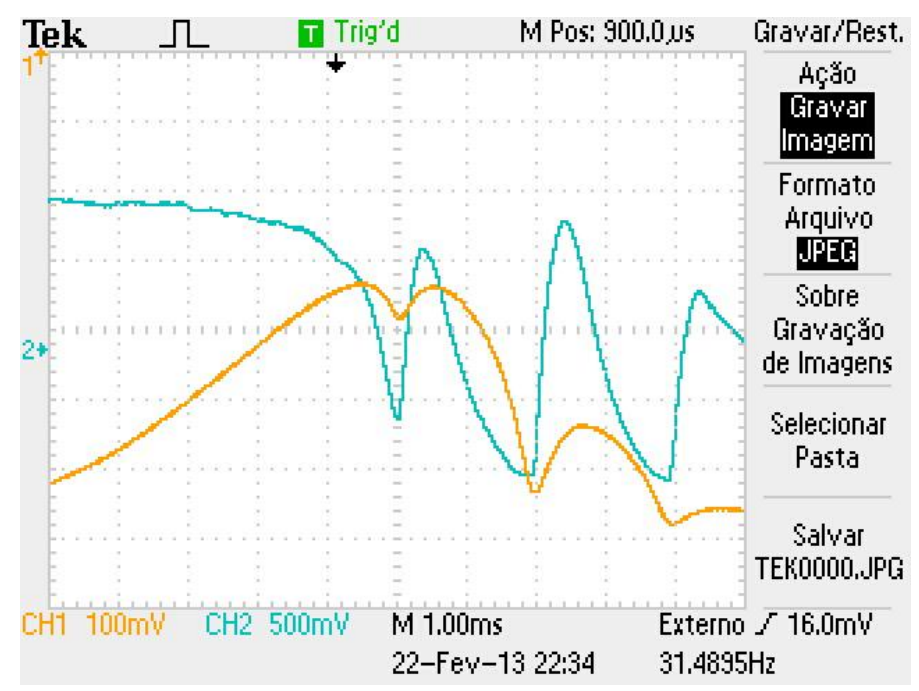

Figura 55: Perfil Doppler (laranja) e o sinal utilizado para fazer o travamento (azul).

O primeiro parâmetro para se obter na medida é a sensibilidade do sistema, que nesse caso é $\frac{M H z}{V}$. Sabemos que a diferença entre o primeiro vale da absorção e o segundo é de $125 \mathrm{MHz}$, assim, temos um valor de $125 \mathrm{MHz}$ para $7 \mathrm{~ms}$, como mostrado na figura 58.

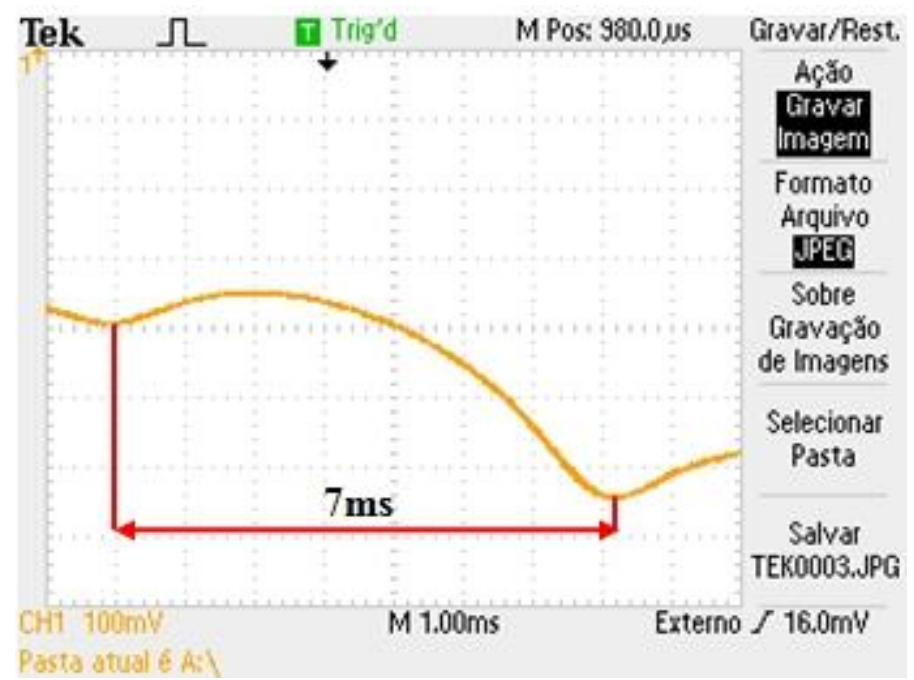

Figura 56: Diferença entre o primeiro vale da absorção e o segundo.

O discriminador de frequência será o primeiro vale da absorção saturada, correspondente à transição entre os níveis $\mathrm{F}=4$ e $\mathrm{F}^{\prime}=5$. $\mathrm{O}$ sinal de saída do amplificador lock-in, representado na figura 59, para essa transição mostra uma diferença pico-vale correspondente a 


$$
\frac{125 \mathrm{MHz}}{7 \mathrm{~ms}}=\frac{x \mathrm{MHz}}{1 \mathrm{~ms}} \cong 18 \mathrm{MHz}
$$

Esse valor representa aproximadamente a largura de linha da transição observada na célula de vapor de Cs, apesar de corresponder aos pontos de inflexão do vale do sinal de fluorescência. Esse valor é bem superior à largura de linha natural da transição (5,3 MHz), já que sofre de fatores que alargam o sinal observado, como pressão de vapor da célula, distribuição de velocidade dos átomos do vapor e intensidade do laser e alinhamento dos feixes contra-propagantes. Esse dois últimos foram otimizados com alinhamento e observação do sinal, mas os dois primeiros dependem de parâmetros mais complicados de variar, já que a pressão da célula é fixa e se diminuirmos a temperatura teremos condições muito baixas de sinal, sem muito ganho no estreitamento espectral.

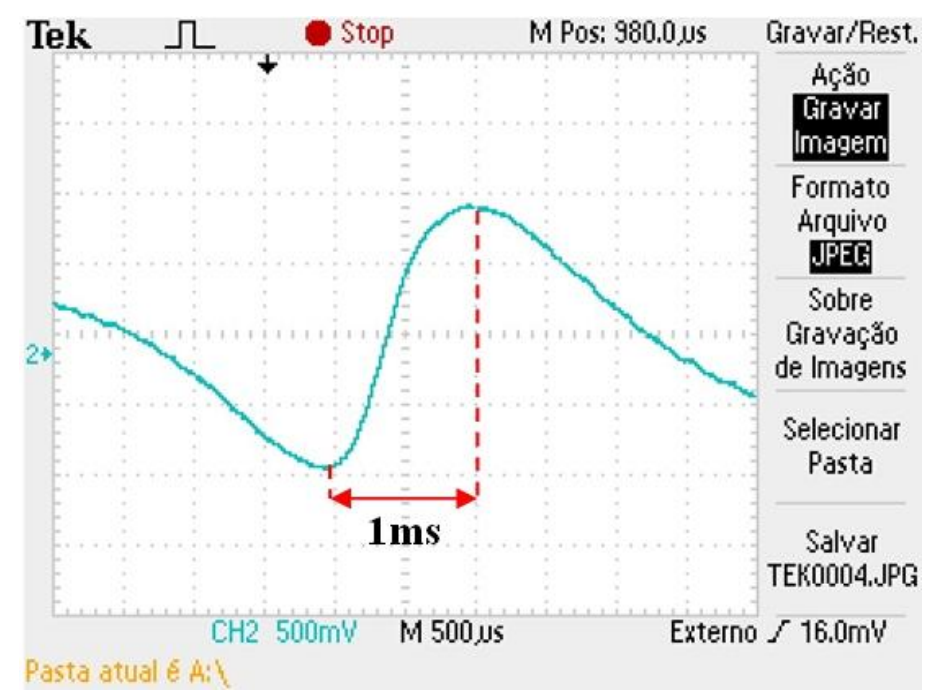

Figura 57: Sinal de saída lock-in, utilizado para fazer o travamento do laser.

Utilizando a parte linear do sinal, representado na figura 60 , em torno do ponto de travamento do sinal obtemos:

$$
\frac{18 \mathrm{MHz}}{1 \mathrm{~ms}}=\frac{x \mathrm{MHz}}{0.25 \mathrm{~ms}} \cong 4,5 \mathrm{MHz}
$$




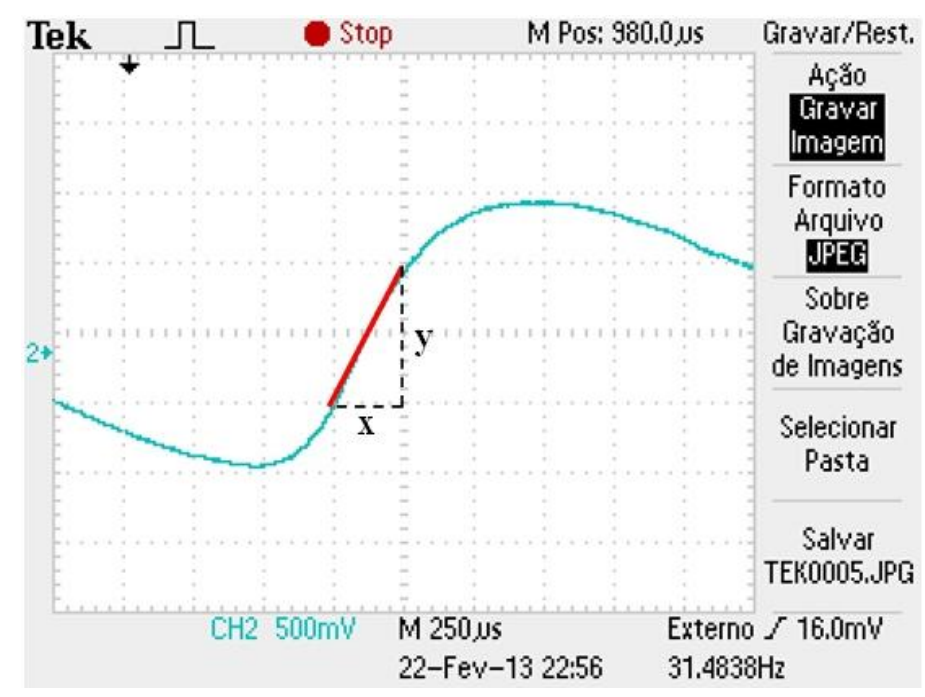

Figura 58: Definindo a sensibilidade.

A sensibilidade do nosso discriminador é, então, de $4,5 \mathrm{MHz} / \mathrm{V}$. Com esse valor podemos estimar a largura de linha travando o laser e medindo a amplitude do sinal travado, como representado na figura 61.

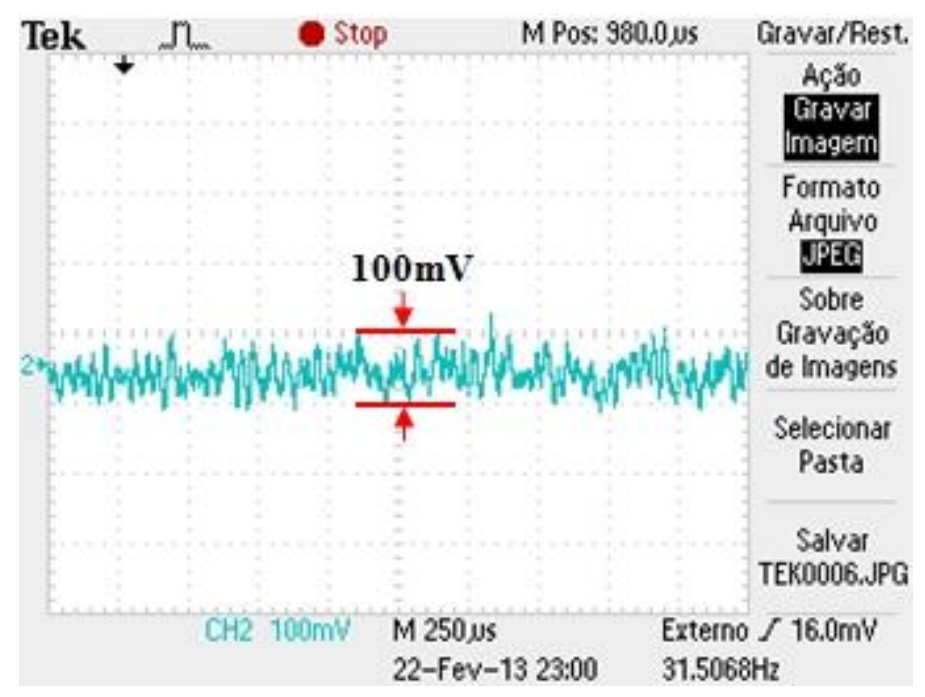

Figura 59: Sinal travado.

$\mathrm{O}$ valor medido foi de $100 \mathrm{mV}$ que resulta em uma largura de linha de $450 \mathrm{kHz}$. Esse é um valor superestimado, pois se considerarmos que o espectro de ruído tem uma distribuição gaussiana (ruído branco) deveríamos considerar a meia altura da distribuição.

Para avaliar a resposta espectral do sinal de erro do laser, quando travado na linha de transição, e poder comparar com outros sistemas do laboratório, utilizamos o analisador de sinais (HP3561A), como mostrado no diagrama da figura 62. 


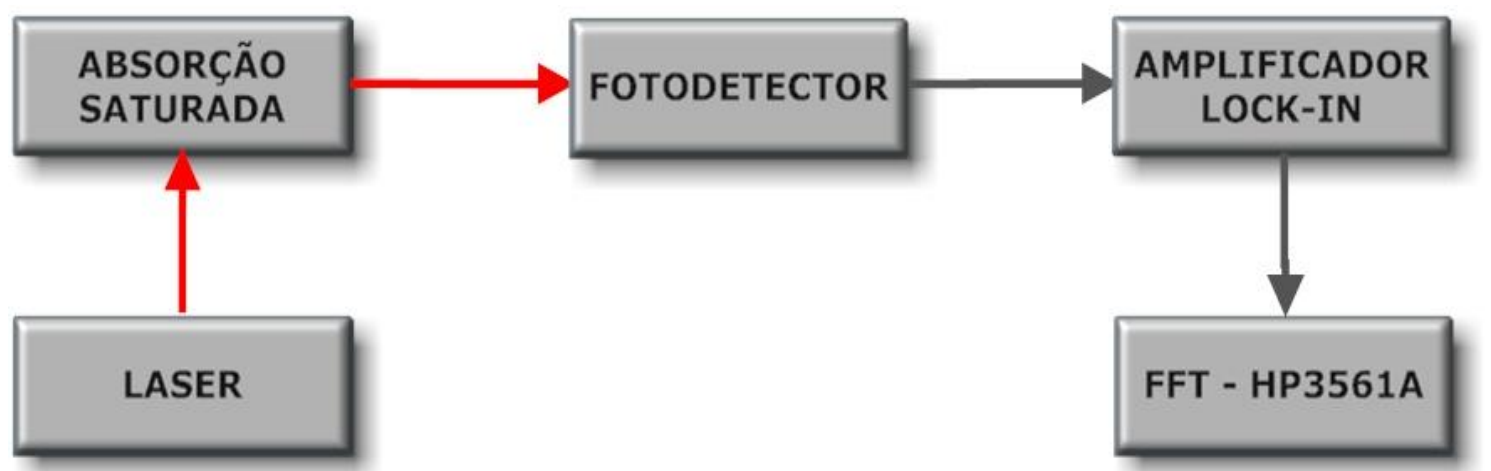

Figura 60: Configuração para a avaliação do sinal de ruído do laser.

Utilizamos a saída de monitoriamento do amplificador lock-in para análise de ruído. Sendo assim, primeiro travamos o laser na transição $F=4 \rightarrow F^{\prime}=5$ e lemos os dados do analisador de sinais através de uma interface GPIB. O espectro obtido é mostrado na figura 63.

Foram analisados três lasers de diodo: um comercial, modelo TA-100 da TOPTICA, um laser já desenvolvido no laboratório, com rede de difração para a cavidade estendida, e o laser mais compacto, com filtro de interferência. Na figura 63 observa-se que o laser compacto já tem o mesmo patamar de ruído com relação ao laser comercial. Pretendemos atingir ou superar, com alterações de ganho e uma avaliação mais precisa da resposta em frequência dos sub-sistemas, o patamar menor de ruído do laser de referência do laboratório. 


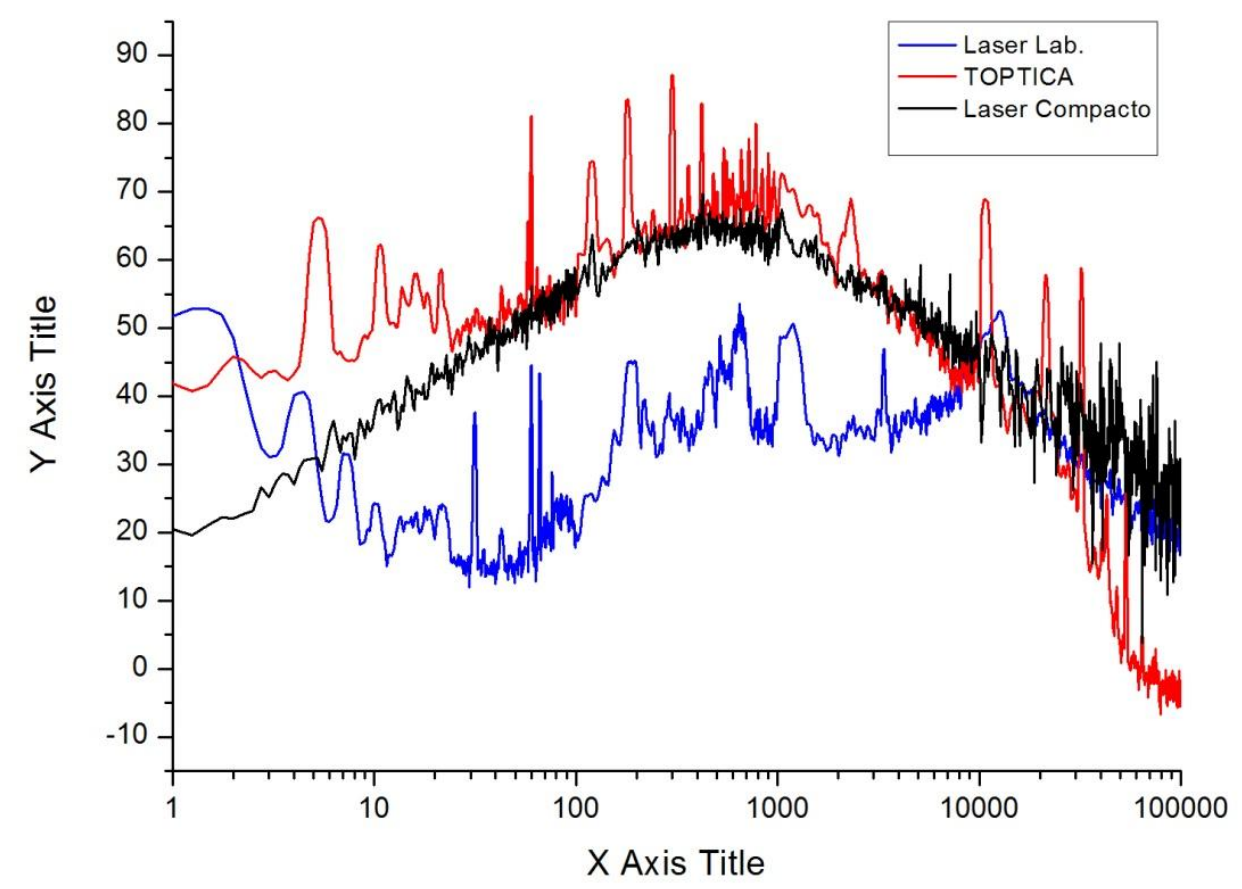

Figura 61: Espectros dos sinais de ruído dos lasers de diodo, utilizado para fazer a comparação entre os sistemas. 


\section{Capítulo 6}

\section{Conclusões}

Desenvolvemos nesse trabalho um sistema completo de laser de diodo de cavidade estendida, desde a circuitaria de controle até o sistema optomecânico. Com uma estabilidade em torno de $8,5 \times 10^{-3}{ }^{0} \mathrm{C}$ no controle de temperatura da caixa do laser de diodo mostrou-se bem melhor que os atualmente utilizados no nosso laboratório, que tem um estabilidade na ordem de $0,1^{0} \mathrm{C}$. Vale salientar que o intuito desse circuito é de minimizar as ações do controle de frequência. Além disso, pode-se aumentar ainda mais essa estabilidade utilizando um revestimento térmico (manta térmica) na caixa do laser.

A estabilidade do controle de temperatura do laser de diodo, de $7,5 \times 10^{-4}{ }^{0} \mathrm{C}$, mostrou-se um importante resultado neste projeto, pois o controle de temperatura de um laser de diodo é sempre crítico. Além disso, melhoramos uma ordem de grandeza na estabilidade em comparação à estabilidade dos controles de temperatura dos lasers atuais em torno de $5 \times 10^{-30} \mathrm{C}$.

Com relação a fonte de corrente do laser, observou-se que o ruído do circuito eletrônico prejudicou o tramento do laser. Utilizamos então um outro controle já desenvolvido em nosso laboratório, mas com componentes discretos de baixíssimo ruído, para caracterizar o restante do sistema optomecânico. A redução de ruído planejada para o controle novo deve ser conseguida com a troca dos componentes SMDs por resistores de filme fino, como discutido no capítulo 4.

Outro fator importante no controle de corrente é a largura de banda alcançada. Neste projeto o controle de corrente possui uma largura de banda de $400 \mathrm{kHz}$, quatro vezes maior que os controles antigos, isso significa que podemos modular o laser com frequência superior à $100 \mathrm{kHz}$, aumentando a banda de correção do laser.

O amplificador de alta tensão desenvolvido possui uma largura de banda mais que suficiente para utilizá-lo em nossos experimentos. No entanto, esse amplificador utiliza uma fonte de alta tensão externa, um dos problemas para utilização em um padrão móvel, necessitando de um conversor DC-DC de $12 \mathrm{~V}$ para $400 \mathrm{~V}$. Testamos um componente que 
tínhamos à disposição no laboratório, mas sua capacidade de fornecimento de corrente não foi suficiente para alimentar o amplificador de alta tensão. Estamos atualmente buscando componentes com capacidades de corrente maiores.

O circuito de travamento desenvolvido apresentou baixo ruído eletrônico, fator importante para ser analisado. Todos os circuitos eletrônicos desenvolvidos apresentaram entre si uma característica importante, uma redução de três vezes do tamanho das placas eletrônicas antigas, sendo assim, conseguiu-se construir um controle mais compacto, como mostrado na figura 64.

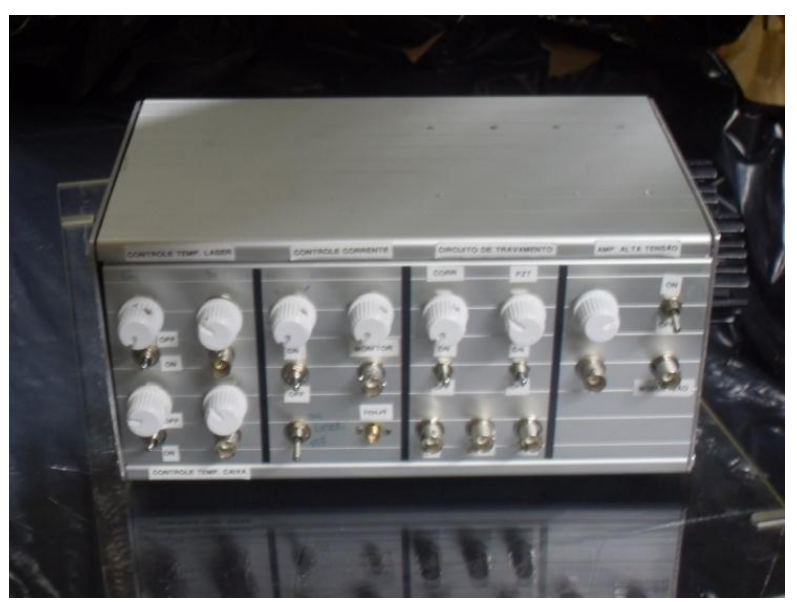

Figura 62: Caixa dos controles eletrônicos do sistema de laser de diodo desenvolvido nesse trabalho.

Podemos destacar as seguintes vantagens para o novo sistema optomecânico desenvolvido: Fácil manuseio e alinhamento, tamanho reduzido e menor sensibilidade a ruídos mecânicos.

Por fim, a largura de linha do laser de diodo de cavidade estendida com filtro intracavidade obteve o mesmo patamar do laser comercial (TOPTICA). Em comparação ao laser de referência desenvolvido no laboratório, observamos que ainda há pontos a serem melhorados.

\section{Trabalhos Futuros}

Um dos grandes problemas em relação à compactação do driver do laser está relacionado aos controles manuais, potênciometros, chaves e monitores. Eles limitam o tamanho do driver, sendo assim uma ação que deve ser tomada é a utilização de um sistema com microcontroladores em cada placa eletrôncia, ligados em uma rede de comunicação 
(CanBus, provavelmente) com uma configuração mestre-escravo, de modo que cada placa eletrônica possua um microcontrolador responsável pelos ajustes locais, por exemplo, ajuste grosso e fino no controle de temperatura, como mostrado na figura 65. A comunicação com um microcontrolador central (mestre), responsável pela interface microcontrolador local e computador. O computador ficará responsável pela interface homem e máquina (IHM). Essa configuração vista à aplicação remota do sistema laser de diodo.

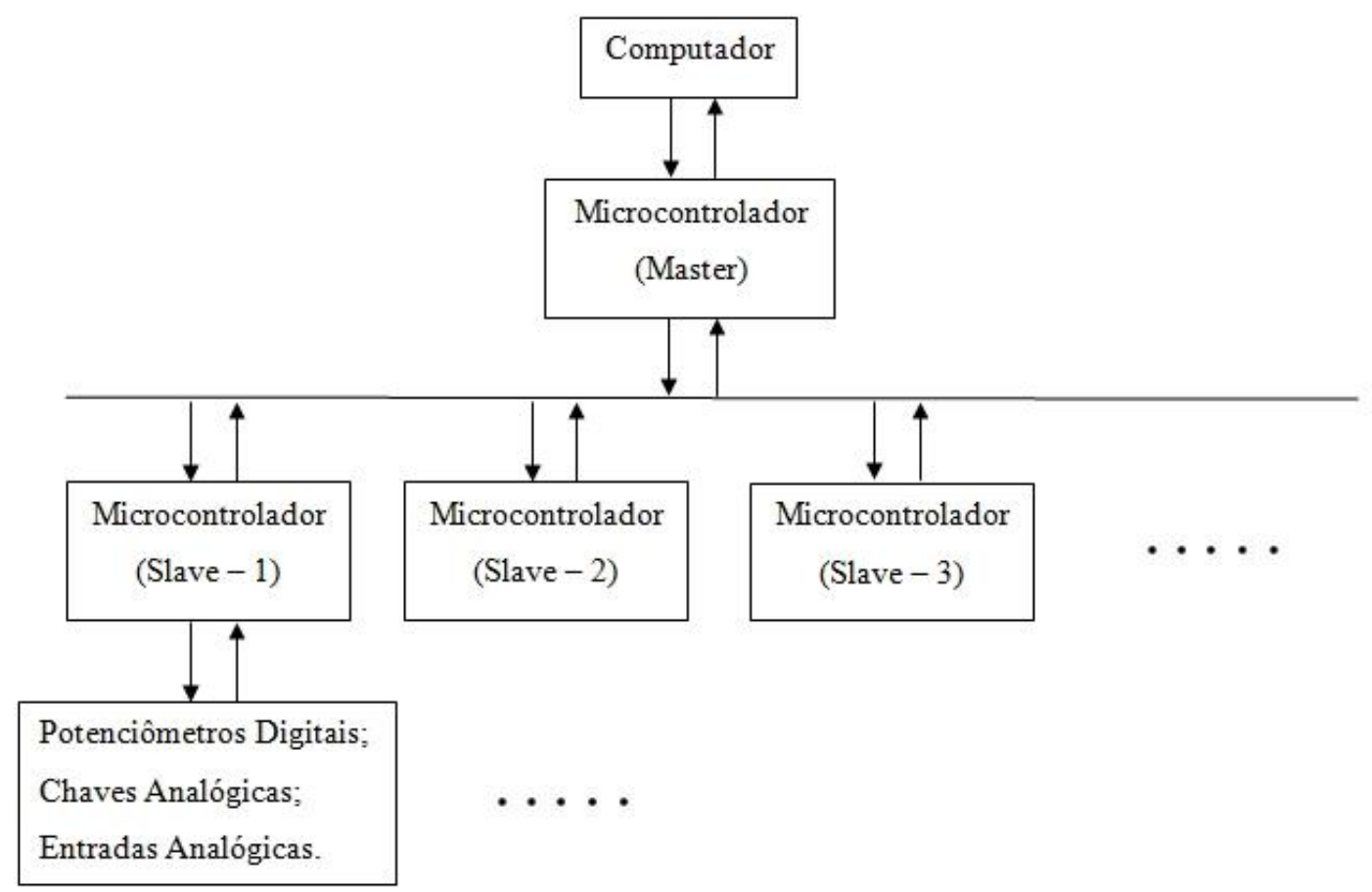

Figura 63: Topologias de conexão entre diversos controles de lasers interligados a um controle central.

Outra melhoria a ser perseguida é em relação ao amplificador lock-in. Ao invés de utilizarmos um sinal de modulação na entrada do circuito de corrente do laser que é em torno de $100 \mathrm{kHz}$, devemos passar a utilizar a técnica de Pound-Drever-Hall (Black, 2000) para um travamento mais robusto e com mais capacidade de redução de ruído, pois a injeção de modulação de RF será feita diretamente no chip do laser de diodo ou em um modulador eletro-óptico, liberando toda a banda de resposta em frequência do circuito de fonte de corrente para ser usada como banda de correção. 


\section{Referências bibliográficas}

AHMED, M; MAGAlHÃES, V. D; BEBEACHIBUli, A; MÜlleR, S; ALVES, F. R; ORTEGA, A. T; WEINER, J; BAGNATO, S. V. (2007) "The Brazilian Time and Frequency Atomic Standards Program”. Instituto de Física de São Carlos, São Carlos, p. 1.

ALFEROV, Z. I; KAZARINOV, R. F; CASEY, C. H; PANISH, M. B. (1963). “Heterostructure Lasers Part A: Fundamental Principles”. pp-272. Rússia.

ALVES, F.R. (2012). Chafariz Atômico de Cs133, Dissertação de Mestrado, Universidade de São Paulo, São Carlos.

APEX MICROTECHNOLOGY (2012).Estados Unidos: "Very High Voltage 450V, Low 2mA Standby Current Power Amplifier”. Disponível em: http://www.apexanalog.com/apexproducts/pa88/. Acesso em: 12 jan. 2012.

BAILLARD, X; GAUGUET, A; BIZE, S; LEMONDE, P; LAURENT, M. P; CLAIRON, A; ROSENBUSCH, P. (2006). "Interference-filter-stabilized external-cavity diode lasers", Observatorie de Paris, Paris, França, PP.1-12.

BEBEACHIBUli, A. (2003) Relógio Atômico a Feixe Efusivo de Césio: Estudo Da Estabilidade e da Acuracia como função do deslocamento da frequência atômica devido ao efeito Zeeman de Segunda ordem, ao Cavity Pulling e ao Rabi Pulling. Dissertação de Mestrado, Universidade de São Paulo, São Carlos.

BEBEACHIBULI, A. (2007) Espectroscopia Ramsey em um chafariz atômico. 2007. Tese de Doutorado, Universidade de São Paulo, São Carlos.

BIZE, S.(2001). "Tests Fondamentaux à L'aide D'horloges à atomes froids de rubidium et de césium". 224f. Tese (Doutorado) - Universidade de Paris, Paris, 2001. 
BLACK, E. D. (2000) “An introduction to Pound-Drever-Hall laser frequency stabilization”. California Institute of Technology, pp. 1-9. Estados Unidos da America.

CATALANI, F. (1997). Caracterização de Laser de Diodo para Espectroscopia de Alta Resolução. Dissertação de Mestrado, Universidade Estadual de Campinas, Campinas.

CEPOF - IFSC (2013). “The Laser and Applications". Disponível em: http://cepof.ifsc.usp.br/int.php?vid=14\&mid=119. Acesso em: 06/01/2013.

13 $3^{\mathrm{a}}$ Conférence Générale des Poids et Mesures (1967-1968), "Résolution 1; CR, 103", Metrologia, Vol. 4, p.43. França.

CUNYUN, Yb. (2004). “Tunable External Cavity Diode Lasers”. World Scientific, pp. 1-27. Londres.

HAWTHORN, J. C; WEBER, K. P; SCHOLTEN, R. E. (2001) “Littrow configuration tunable external cavity diode laser with fixed direction output beam", Rev. Sci.

Instrum. Vol.72, pp. 1-3, The University of Melbourne, Australia.

HEEFNER, J. (2007) "Resistor Noise Measurement Summary", Laser Interferometer Gravitational wave Observatory (LIGO), pp.1-5, California Institute of Technology, Massachusetts Institute of Technology, Estados Unidos da América.

HP 3561A, FFT- Dynamic Signal Analyser - Manual de Operação - HP (Atualmente Agilent).

KROEMER, H; CASEY, C. H; PANISH, M. B. (1963). “Heterostructure Lasers Part A: Fundamental Principles”. pp-272. New York, E.U.A.

LAURENT, M. P. (2001) 'L'Architecture optique d'une horologe atomique a atoms froids, lasers en cavite etendue”, Laboratoire Primaire Du Temps ET des Fréquences. chercheur CNRS , p.23, França.

MAGALHÃES, D. V. (2004) Desenvolvimento de uma fountain atômica para utilização como padrão primário de tempo. Tese de Doutorado, Universidade de São Paulo, São Carlos. 
MOORADIAN, A. (1985). “Laser linewidth”. Phys. Today. A. Mooradian. "Laser linewidth". Phys. Today, pp. 42-49. E.U.A.

MÜLLER, T. S; OTOBONI, A. F; MARTIN JR, J; PECHONERI, D. R; BAGNATO, S. V; MAGALHÃES, V. D.(2012) "Development of a Mobile Atomic Frequency Standard based on Cold Atoms". In Latin America Optics and Photonics Conference (LAOP). São Sebastião, Brazil, pp.1-3.

NBS Technical News Bulletin (1964) - p.209, E.U.A.

OGATA (1998) "Engenharia de Controle Moderno", Prentice - Hall, Brasil.

PHOTONIC SOLUTIONS (2013). Reino Unido: “Laser SDL 5400 series”. Disponível em: "http://www.photonic.solutions.zen.co.uk/downloads/acrobat/jdsu/sdl/JD5400laserdiode.pdf. Acesso em: 20 jan.2013.

RP PHOTONICS (Alemanha). Dr. Rüdiger Paschotta. “External Cavity Diodo Lasers”, Fev. 2011, http://www.rp-photonics.com/external_cavity_diode_lasers.html. Acesso em: 27 Dec. 2012.

SCHAWLOW, A. L; TOWNES, C. H.(1958) "Infrared and optical masers". Physical Review, vol. 112, pp. 1940-1949. E.U.A.

SILFVAST, W. T. (2004) “Lasers Fundamentals”, Cambridge University press, pp.-625. E.U.A.

TUBOY. A. M. (1990) Estabilização de lasers de diodo para utilização em espectroscopia atômica. Dissertação de Mestrado, Universidade de São Paulo, São Carlos.

TUBOY. A. M. (1996) Preparação de laser de diodo e sua utilização no aprisionamento e estudo de átomos frios. Tese de Doutorado, Universidade de São Paulo, São Carlos. 
WIEMAN, C. E; HOLLBERG, L. (1990) “Using diode lasers for atomic physics”, Rev. Sci. Instrum. Vol.62, pp. 1-20. Boulder, E.U.A.

WIKIPÉDIA. “Laser de diodo", Jul. 2012, http://pt.wikipedia.org/wiki/Laser_d\%C3\%ADodo. Acesso em 27 Dec. 2012.

ZHAO, Y.T; ZHAO, J.M; HUANG, T; XIAO, L.T; JIA, S. T. (2004) “Frequency Stabilization of na external cavity diodo laser with a thin Cs vapour cell”. Journal of Physics, pp. 1316-1317. China.

ZILIO, C. S.(2009) “Óptica Moderna: Fundamentos e Aplicações”. Instituto de Física de São Carlos, pp. 136-139. São Carlos. 


\section{ANEXO (A)}

(Data Sheet - Laser de diodo Modelo: SDL 5400 H1 Series) 


\section{Product Bulletin}

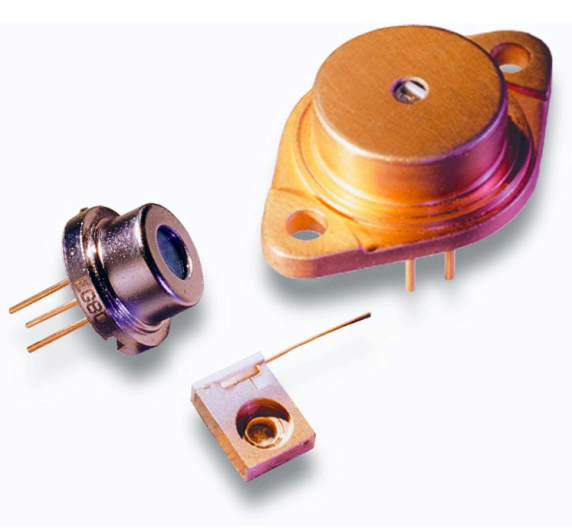

High-resolution applications including optical data storage, image recording, spectral analysis, printing, point-to-point free-space communications and frequency doubling all require diffraction-limited sources. Faster writing, wider dynamic range and better signal-to-noise ratio may be achieved with JDS Uniphase's high-reliability SDL-5400 series single-mode laser diodes.

Available in power levels up to $200 \mathrm{~mW}$ kinkfree, this advanced laser diode combines a quantum well structure and a real-refractive index-guided single-mode waveguide to provide high power, low astigmatism, narrow spectral width and a single spatial mode Gaussian far field. SD L-5400 series laser diodes are among the most reliable high-power laser diodes available in the industry today.

The SD L-5400 series laser diodes operate in single longitudinal mode under some conditions. Like in all Fabry-Perot index-guided laser diodes, spectral broadening, mode hopping, and longitudinal mode instability may occur due to small changes in drive current, diode junction temperature, or optical feedback.

\section{SDL-5400 Series 50 to $200 \mathrm{~mW}$, $810 / 830 / 852 \mathrm{~nm}$ Single-mode Laser Diodes}

The unique diode structure features high reliability with long operating life and very low early failure rate. Very high brightness ( $20 \mathrm{M} \mathrm{W} / \mathrm{cm}^{2}$ steradian) is provided by the SDL-5430.

Useful packaging options include open heatsink, SOT or TO-3 packages, internal photodiode, thermoelectric cooler and wavelength selection.

\section{Key Features}

- Up to $200 \mathrm{~mW}$ continuous wave (CW) output power

- Wavelengths available:

- $810 \pm 4 \mathrm{~nm}$ or $\pm 10 \mathrm{~nm}$

- $830 \pm 10 \mathrm{~nm}$ or $\pm 20 \mathrm{~nm}$

- $852 \pm 4 \mathrm{~nm}$ or $\pm 10 \mathrm{~nm}$

- Diffraction-limited beam

- $\mathrm{TEM}_{00}$ single transverse mode

\section{Applications}

- Image recording

- Printing

- Spectral analysis

- Optical data storage

- Point-to-point communications 


\section{SDL-5400 Series}

\section{Laser Diodes | 2}

\section{Available Configurations}

$\begin{array}{ll}\text { SDL-5400 Series } & \text { SDL-5410 Series } \\ \text { SDL-5400-C } & \text { SDL-5410-C } \\ \text { SDL-5401-G1 } & \text { SDL-5411-G1 } \\ \text { SDL-5402-H 1 } & \text { SDL-5412-H 1 }\end{array}$

\section{Electro-optical Performance}

\begin{tabular}{|c|c|c|c|c|c|c|c|c|}
\hline \multirow[b]{2}{*}{ Laser Characteristics } & \multirow[b]{2}{*}{ Symbol } & \multicolumn{3}{|c|}{ SDL-5400 Series } & \multicolumn{3}{|c|}{ SDL-5410 Series } & \multirow[b]{2}{*}{ Unit } \\
\hline & & Min. & Typ. & Max. & Min. & Typ. & Max. & \\
\hline CW output power, kink-free & $P_{0}$ & - & - & 50 & - & - & 100 & $\mathrm{~mW}$ \\
\hline Center wavelength & $\lambda_{c}$ & - & $\left(\right.$ note $\left.^{7}\right)$ & - & - & $\left(\right.$ note $\left.^{7}\right)$ & - & \\
\hline Spectral width $^{1}$ & $\Delta \lambda$ & - & 3 & 5 & - & 3 & 5 & $\mathrm{~nm}$ \\
\hline Slope efficiency & $\eta_{D}=P_{0} /\left(I_{o p}-I_{t h}\right)$ & 0.75 & 0.85 & - & 0.75 & 0.85 & - & $\mathrm{mW} / \mathrm{mA}$ \\
\hline Conversion efficiency & $\eta=P_{o} /\left(I_{o p} V_{o p}\right)$ & - & 30 & - & - & 30 & - & $\%$ \\
\hline Emitting dimensions & $\mathrm{W} \times \mathrm{H}$ & - & $3 \times 1$ & - & - & $3 \times 1$ & - & $\mu \mathrm{m}$ \\
\hline \multicolumn{9}{|l|}{ FWHM beam divergence } \\
\hline Parallel to junction & $\theta_{/ /}$ & - & 9 & - & - & 9 & - & degrees \\
\hline Perpendicular to junction & $\theta_{\perp}^{\prime \prime}$ & - & 30 & - & - & 30 & - & degrees \\
\hline Threshold current & $I_{\text {th }}$ & - & 35 & 45 & - & 35 & 45 & $\mathrm{~mA}$ \\
\hline Operating current & $\mathrm{I}_{\mathrm{op}}$ & - & 95 & 105 & - & 160 & 170 & $\mathrm{~mA}$ \\
\hline Operating voltage & $V_{o p}$ & - & $\left(\right.$ note $\left.^{6}\right)$ & - & - & $\left(\right.$ note $\left.^{6}\right)$ & - & \\
\hline Series resistance & $\mathrm{R}_{\mathrm{S}}$ & - & 4.0 & 6.0 & - & 4.0 & 6.0 & $\Omega$ \\
\hline Thermal resistance & Rth & - & 60 & - & - & 60 & - & ${ }^{\circ} \mathrm{C} / \mathrm{W}$ \\
\hline Recommended case temperature & $\mathrm{T}_{\mathrm{C}}$ & -20 & - & 30 & -20 & - & 30 & ${ }^{\circ} \mathrm{C}$ \\
\hline \multicolumn{9}{|l|}{ Absolute Maximum Ratings } \\
\hline Reverse voltage & $\mathrm{V}_{\mathrm{rl}}$ & - & - & 3 & - & - & 3 & $\mathrm{~V}$ \\
\hline Case operating temperature & $\mathrm{T}_{\mathrm{op}}$ & -20 & - & 50 & -20 & - & 50 & ${ }^{\circ} \mathrm{C}$ \\
\hline Storage temperature range & $T_{\text {stg }}$ & -40 & - & 80 & -40 & - & 80 & ${ }^{\circ} \mathrm{C}$ \\
\hline Lead soldering temperature & $\mathrm{T}_{\text {is }}$ & - & - & 250 & - & - & 250 & ${ }^{\circ} \mathrm{C}$ (5 sec.) \\
\hline \multicolumn{9}{|l|}{ Monitor Photodiode $^{2}$} \\
\hline Sensitivity & - & 0.1 & - & 20 & 0.1 & - & 20 & $\mu \mathrm{A} / \mathrm{mW}$ \\
\hline Capacitance & - & - & 6 & - & - & 6 & - & $\mathrm{pF}$ \\
\hline Breakdown voltage & $\mathrm{V}_{\mathrm{bd}}$ & - & 25 & - & - & 25 & - & $\mathrm{V}$ \\
\hline Operating voltage & $V_{o p}$ & - & 10 & - & - & 10 & - & V \\
\hline \multicolumn{9}{|l|}{ Thermoelectric Cooler $^{2,3}$} \\
\hline Drive current & $\mathrm{I}_{\mathrm{TE}}$ & - & 2.0 & - & - & 2.0 & - & A \\
\hline Drive voltage & $\mathrm{V}_{\mathrm{TE}}$ & - & 4.0 & - & - & 4.0 & - & $\mathrm{V}$ \\
\hline Thermal resistance & $R_{\text {th }}$ & - & 15 & - & - & 15 & - & ${ }^{\circ} \mathrm{C} / \mathrm{W}$ \\
\hline Thermistor resistance & $R_{\text {therm }}$ & - & 10 & - & - & 10 & - & $\mathrm{k} \Omega$ \\
\hline \multicolumn{2}{|c|}{$\begin{array}{l}\text { 1. Emission bandwidth for } 90 \% \text { integrated power. } \\
\text { 2. Not available on } \mathrm{C} \text { package. } \\
\text { 3. Not available on } \mathrm{G} 1 \text { package. } \\
\text { 4. Typical values at } 25{ }^{\circ} \mathrm{C} \text { and } 0.6 \mathrm{NA} \text { collection optics. } \\
\text { 5. Features common to all SDL- } 5400 \text { series laser } \\
\text { diodes include: } \\
\text { a. Duty factor of } 100 \% \text {. } \\
\text { b. Temperature coefficient of wavelength is approximately } 0.3 \mathrm{~nm} /{ }^{\circ} \mathrm{C} \text {. } \\
\text { c. Temperature coefficient of threshold current can be modeled as: } \\
\text { ITH2 }_{T}=I_{T H 1} \text { exp }\left[\left(\mathrm{T}_{2}-\mathrm{T}_{1}\right) / \mathrm{T}_{0}\right] \text { where } \mathrm{T}_{0} \text { is a device constant of about } \\
\text { d. Temperature coefficient of operating current is approximately } 0.5 \text { to } \\
0.7 \% \text { per }{ }^{\circ} \mathrm{C} \text {. } \\
\text { 6. Forward voltage is typically: } \mathrm{V}_{f}=1.5 \mathrm{~V}+\mathrm{I}_{\mathrm{op}} \times \mathrm{R}_{\mathrm{s}} \text {. }\end{array}$} & & $\begin{array}{l}\text { 7. Waveleng } \\
810 \pm 4 \mathrm{nt} \\
830 \pm 10 \mathrm{r} \\
852 \pm 4 \mathrm{n} \\
\text { 8. Astigmat } \\
\text { 9. SDL-54X }\end{array}$ & $\begin{array}{l}\text { ranges for } \\
\text { or } \pm 10 \mathrm{~nm} \\
\text { or } \pm 20 \mathrm{n} \\
\text { of } \pm 10 \mathrm{~nm} \\
\text { is less th } \\
-(\mathrm{C}, \mathrm{G} 1 \\
-0-\mathrm{No} \\
1-\mathrm{MC} \\
2-\mathrm{MC} \\
-0-50 \\
1-10\end{array}$ & $\begin{array}{l}-5400 \text { and } \\
\text { kage) } \\
\text { todiode } \\
\text { otodiode, }\end{array}$ & ooler & & \\
\hline
\end{tabular}




\section{SDL-5400 Series}

\section{Laser Diodes | 3}

\section{Available Configurations}
SDL-5420 Series
SDL-5430 Series
SD L-5420-C
SD L-5430-C
SD L-5421-G1
SDL-5431-G1
SD L-5422-H 1
SD L-5432-H 1

\section{Electro-optical Performance}

\begin{tabular}{|c|c|c|c|c|c|c|c|c|}
\hline \multirow[b]{2}{*}{ Laser Characteristics } & \multirow[b]{2}{*}{ Symbol } & \multicolumn{3}{|c|}{ SDL-5420 Series } & \multicolumn{3}{|c|}{ SDL-5430 Series } & \multirow[b]{2}{*}{ Unit } \\
\hline & & Min. & Typ. & Max. & Min. & Typ. & Max. & \\
\hline CW output power, kink-free & $P_{0}$ & - & - & 150 & - & - & 200 & $\mathrm{~mW}$ \\
\hline Center wavelength & $\lambda_{c}$ & - & $\left(\right.$ note $\left.^{7}\right)$ & - & - & $\left(\right.$ note $\left.^{7}\right)$ & - & \\
\hline Spectral width ${ }^{1}$ & $\Delta \lambda$ & - & 3 & 5 & - & 3 & 5 & $\mathrm{~nm}$ \\
\hline Slope efficiency & $\eta_{D}=P_{0} /\left(I_{o p}-I_{t h}\right)$ & 0.75 & 0.85 & - & 0.75 & 0.85 & - & $\mathrm{mW} / \mathrm{mA}$ \\
\hline Conversion efficiency & $\eta=P_{0} /\left(I_{o p} V_{o p}\right)$ & - & 30 & - & - & 30 & - & $\%$ \\
\hline Emitting dimensions & $\mathrm{W} \times \mathrm{H}$ & - & $3 \times 1$ & - & - & $3 \times 1$ & - & $\mu \mathrm{m}$ \\
\hline \multicolumn{9}{|l|}{ FWHM beam divergence } \\
\hline Parallel to junction & $\theta_{/ /}$ & - & 9 & - & - & 9 & - & degrees \\
\hline Perpendicular to junction & $\theta_{\perp}^{\prime \prime}$ & - & 30 & - & - & 30 & - & degrees \\
\hline Threshold current & Ith & - & 35 & 45 & - & 40 & 50 & $\mathrm{~mA}$ \\
\hline Operating current & $\mathrm{I}_{\mathrm{op}}$ & - & 210 & 230 & - & 270 & 300 & $\mathrm{~mA}$ \\
\hline Operating voltage & $V_{\text {op }}$ & - & $\left(\right.$ note $\left.^{6}\right)$ & - & - & $\left(\right.$ note $\left.^{6}\right)$ & - & \\
\hline Series resistance & $\mathrm{R}_{\mathrm{S}}$ & - & 4.0 & 6.0 & - & 4.0 & 6.0 & $\Omega$ \\
\hline Thermal resistance & $R_{\text {th }}$ & - & 60 & - & - & 60 & - & ${ }^{\circ} \mathrm{C} / \mathrm{W}$ \\
\hline Recommended case temperature & $\mathrm{T}_{\mathrm{C}}$ & -20 & - & 30 & -20 & - & 30 & ${ }^{\circ} \mathrm{C}$ \\
\hline \multicolumn{9}{|l|}{ Absolute Maximum Ratings } \\
\hline Reverse voltage & $\mathrm{V}_{\mathrm{rl}}$ & - & - & 3 & - & - & 3 & V \\
\hline Case operating temperature & $\mathrm{T}_{\text {op }}$ & -20 & - & 50 & -20 & - & 50 & ${ }^{\circ} \mathrm{C}$ \\
\hline Storage temperature range & $\mathrm{T}_{\text {stg }}$ & -40 & - & 80 & -40 & - & 80 & ${ }^{\circ} \mathrm{C}$ \\
\hline Lead soldering temperature & $\mathrm{T}_{\text {is }}$ & - & - & 250 & - & - & 250 & ${ }^{\circ} \mathrm{C}(5 \mathrm{sec})$. \\
\hline \multicolumn{9}{|l|}{ Monitor Photodiode $^{2}$} \\
\hline Sensitivity & - & 0.1 & - & 20 & 0.1 & - & 20 & $\mu \mathrm{A} / \mathrm{mW}$ \\
\hline Capacitance & - & - & 6 & - & - & 6 & - & $\mathrm{pF}$ \\
\hline Breakdown voltage & $V_{b d}$ & - & 25 & - & - & 25 & - & V \\
\hline Operating voltage & $V_{\text {op }}$ & - & 10 & - & - & 10 & - & V \\
\hline \multicolumn{9}{|l|}{ Thermoelectric Cooler $^{2,3}$} \\
\hline Drive current & $\mathrm{I}_{\mathrm{TE}}$ & - & 2.0 & - & - & 2.0 & - & A \\
\hline Drive voltage & $\mathrm{V}_{\mathrm{TE}}$ & - & 4.0 & - & - & 4.0 & - & V \\
\hline Thermal resistance & $\mathrm{R}_{\mathrm{th}}$ & - & 15 & - & - & 15 & - & ${ }^{\circ} \mathrm{C} / \mathrm{W}$ \\
\hline Thermistor resistance & $\mathrm{R}_{\text {therm }}$ & - & 10 & - & - & 10 & - & $\mathrm{k} \Omega$ \\
\hline \multicolumn{3}{|c|}{$\begin{array}{l}\text { 1. Emission bandwidth for } 90 \% \text { integrated power. } \\
\text { 2. Not available on } \mathrm{C} \text { package. } \\
\text { 3. Not available on } \mathrm{G} 1 \text { package. } \\
\text { 4. Typical values at } 25^{\circ} \mathrm{C} \text { and } 0.6 \mathrm{NA} \text { collection optics. } \\
\text { 5. Features common to all SD L- } 5400 \text { series laser } \\
\text { diodes include: } \\
\text { a. Duty factor of } 100 \% \text {. } \\
\text { b. Temperature coefficient of wavelength is approximately } 0.3 \mathrm{~nm} /{ }^{\circ} \mathrm{C} \text {. } \\
\text { c. Temperature coefficient of threshold current can be modeled as: } \\
I_{T H 2}=I_{T H 1} \text { exp }\left[\left(T_{2}-\mathrm{T}_{1}\right) / \mathrm{T}_{0}\right] \text { where } \mathrm{T}_{0} \text { is a device constant of about } 110{ }^{\circ} \mathrm{K} \text {. } \\
\text { d. Temperature coefficient of operating current is approximately } 0.5 \text { to } \\
0.7 \% \text { per }{ }^{\circ} \mathrm{C} \text {. } \\
\text { 6. Forward voltage is typically: } \mathrm{V}_{\mathrm{f}}=1.5 \mathrm{~V}+\mathrm{I}_{\mathrm{op}} \times \mathrm{R}_{\mathrm{S}} \text {. }\end{array}$} & $\begin{array}{r}\text { SDL-5430 } \\
\text { 8. Astigmatis } \\
\text { 9. SDL-54X }\end{array}$ & $\begin{array}{l}\text { ranges: } \\
810 \pm \\
830 \pm \\
852 \pm \\
830 \pm \\
\text { is less th } \\
-(\mathrm{C}, \mathrm{G} 1 \\
-0-\mathrm{NC} \\
1-\mathrm{M} \\
2-\mathrm{M} \\
-2-15 \\
3-20\end{array}$ & $\begin{array}{l}10 \mathrm{~nm} \\
10 \mathrm{~nm} \\
\text { kage) } \\
\text { otodiode } \\
\text { otodiode, }\end{array}$ & cooler & & \\
\hline
\end{tabular}




\section{SDL-5400 Series}

\section{Laser Diodes | 4}

\section{Typical Optical Characteristics}
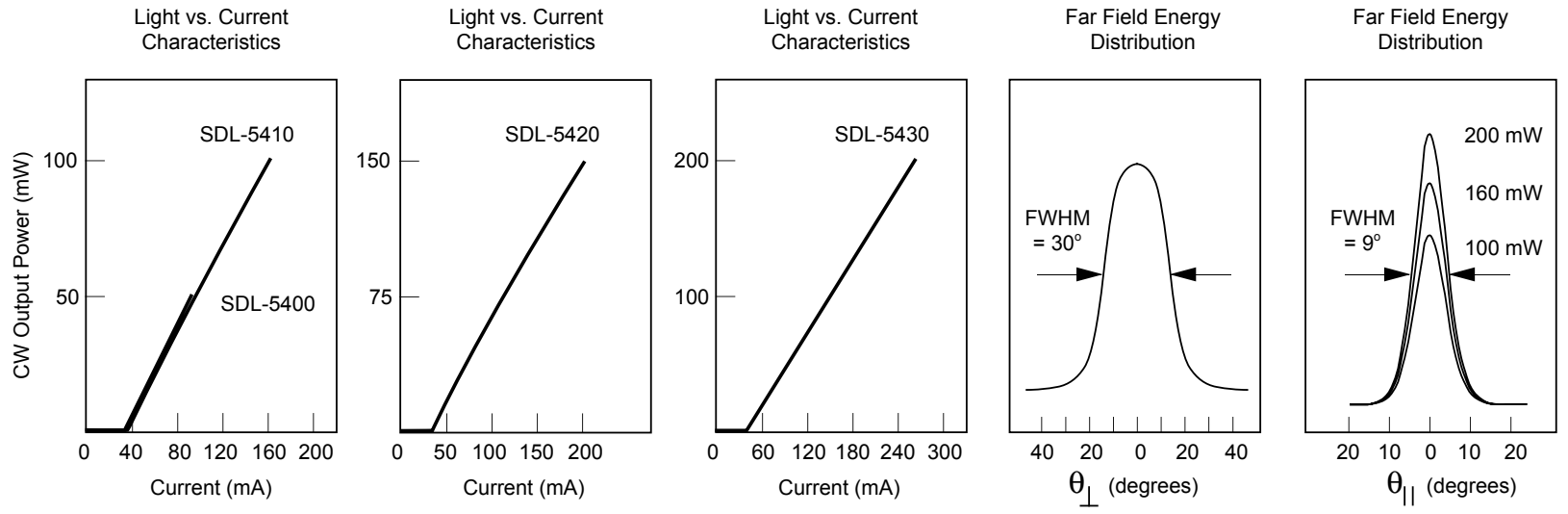


\section{SDL-5400 Series}

\section{Laser Diodes | 5}

\section{Package Dimensions (inches [mm])}

Standard Tolerances

inches: $\quad x . x x= \pm 0.02$

$x \cdot x x x= \pm 0.010$

$\mathrm{mm}: \quad \mathrm{x} . \mathrm{x}= \pm 0.5$

$x . x x= \pm 0.25$

C

Open Heatsink

Package

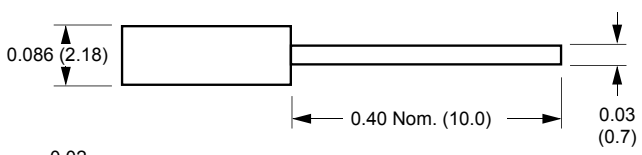

Case is

anode $(+)$
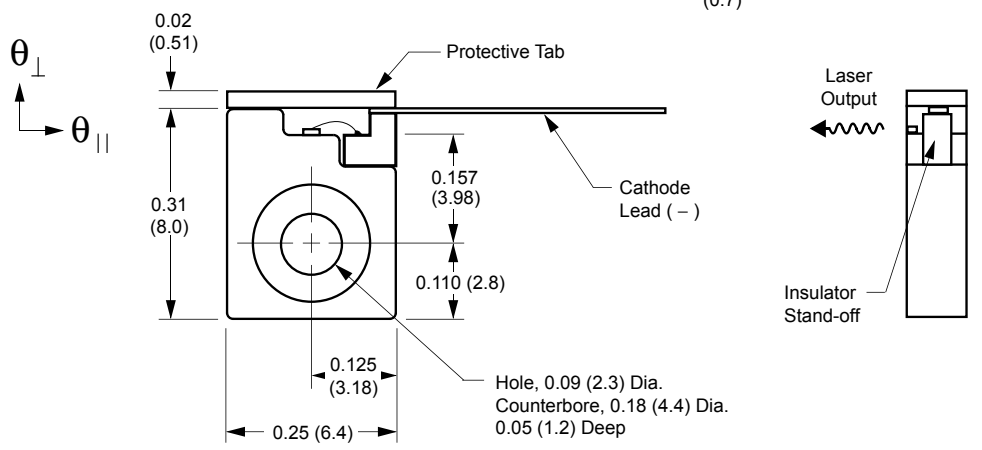

G1

SOT-148

Window Package
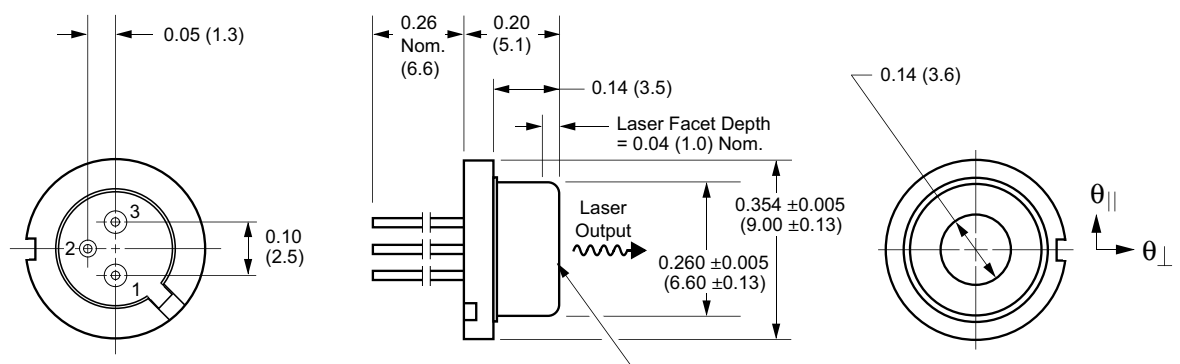

Pin-out

1. Laser cathode (-)

2. Laser anode, MPD cathode and case ground

3. Monitor photodiode anode $(+)$

H1

TO-3

Window Package

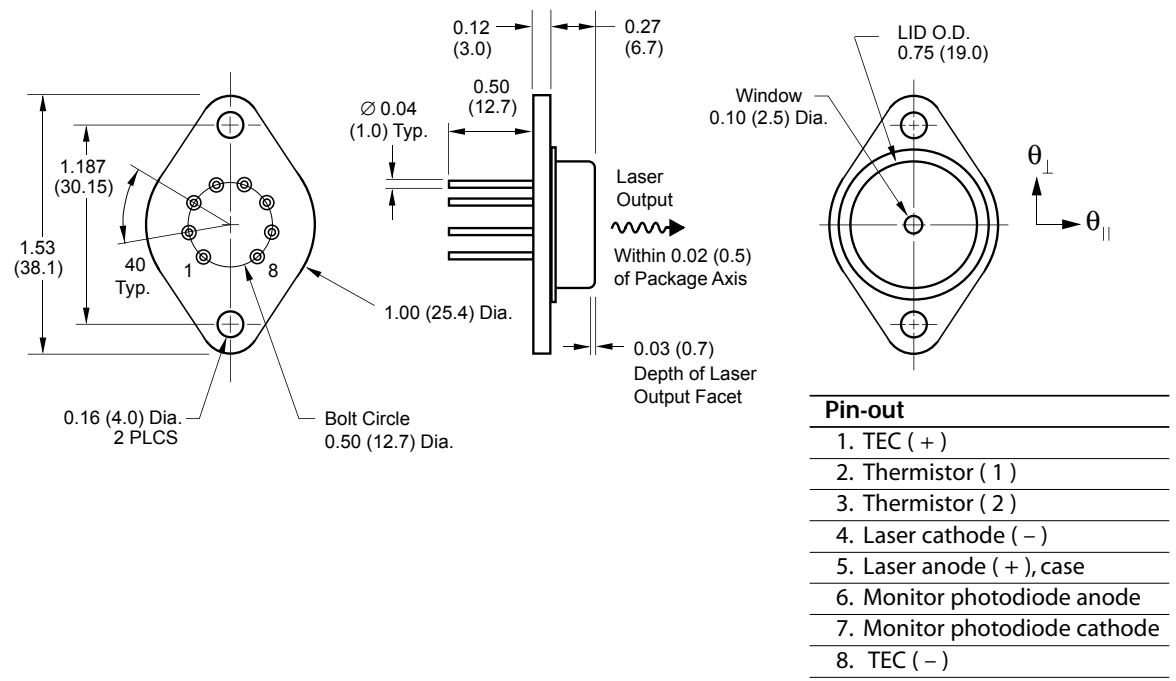




\section{SDL-5400 Series \\ Laser Diodes / 6}

\section{User Safety}

Safety and Operating Considerations

The laser light emitted from this laser diode is invisible and may be harmful to the human eye. Avoid looking directly into the laser diode or into the collimated beam along its optical axis when the device is in operation.

\section{CAUTION: THE USE OF OPTICAL INSTRUMENTS WITH THIS PRODUCT WILL INCREASE EYE HAZARD.}

Operating the laser diode outside of its maximum ratings may cause device failure or a safety hazard. Power supplies used with the component must be employed such that the maximum peak optical power cannot be exceeded. CW laser diodes may be damaged by excessive drive current or switching transients. When using power supplies, the laser diode should be connected with the main power on and the output voltage at zero. The current should be increased slowly while monitoring the laser diode output power and the drive current.

Device degradation accelerates with increased temperature, and therefore careful attention to minimize the case temperature is advised. For example, life expectancy will decrease by a factor of four if the case is operated at $50^{\circ} \mathrm{C}$ rather than $30^{\circ} \mathrm{C}$.

A proper heatsink for the laser diode on a thermal radiator will greatly enhance laser life. Firmly mount the laser on a radiator with a thermal impedance of less than $2{ }^{\circ} \mathrm{C} / \mathrm{W}$ for increased reliability.

ESD PROTECTION - Electrostatic discharge is the primary cause of unexpected laser diode failure. Take extreme precaution to prevent ESD. Use wrist straps, grounded work surfaces and rigorous antistatic techniques when handling laser diodes.

This product is export controlled under COCOM. The ECCN is A005; Harmonized Commodity is 8541.40.6050.

\section{CFR 1040.10 Compliance}

Because of the small size of these devices, each of the labels shown is attached to the individual shipping container. They are illustrated here to comply with 21 CFR 1040.10 as applicable under the Radiation Control for Health and Safety Act of 1968.

\section{Serial Number Identification Label}

\begin{tabular}{|c|c|c|}
\hline SAN JOSE, CALIFORNIA & 95134 & U.S.A. \\
\hline $\begin{array}{l}\text { MODEL: } \\
\text { MANUFACTURED: } \\
\text { WAVELENGTH: }\end{array}$ & $\begin{array}{l}\text { S/N: } \\
\text { I op: }\end{array}$ & \\
\hline
\end{tabular}

\section{Output Power Danger Label}
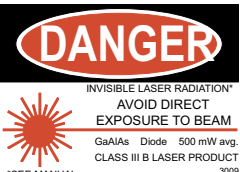

Package Aperture Labels

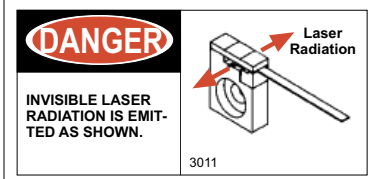

C Package Diodes

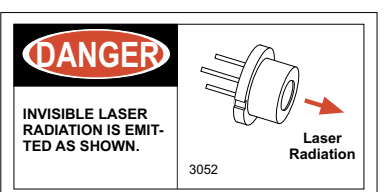

G1 Package Diodes

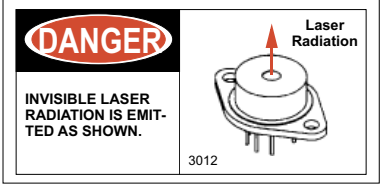

H1 Package Diodes

\section{Ordering Information}

For more information on this or other products and their availability, please contact your local JDS Uniphase account manager or JDS Uniphase directly at 800-871-8537 in North America and 1-800-8735-5378 worldwide or via e-mail at jdsu.sales@jdsu.com.

\section{JDS Uniphase}

North America toll-free: $800-871-8537$ Worldwide toll-free: 1-800-8735-5378 www.jdsu.com
All statements, technical information and recommendations related to the products herein are based upon information believed to be reliable or accurate. However, the accuracy or completeness thereof is not guaranteed, and no responsibility is assumed for any inaccuracies. The user assumes all risks and liability whatsoever in connection with the use of a product or its application. JDS Uniphase reserves the right to change at any time without notice the design, specifications, function fit or form of its products described herein, including withdrawal at any time of a product offered for sale herein. JDS Uniphase makes no representations that the products herein are free from any intellectual property claims of others. Please contact JDS Uniphase for more information. JDS Uniphase and the JDS Uniphase logo are trademarks of JDS Uniphase Corporation. Other trademarks are the property of their respective holders. Copyright JDS Uniphase Corporation. All rights reserved. 


\section{ANEXO (B)}

(Propriedades do átomo de Césio - (Alves, 2012)) 
Número Atômico

Massa Atômica

Elétron de Valência

Pressão de Vapor a $25^{\circ} \mathrm{C}$

Abundância do ${ }^{133} \mathrm{Cs}$

Tempo de vida nuclear

Spin nuclear

Fator de Landé nuclear

Fator de Landé Eletrônico $\left(6^{2} S_{1 / 2}\right)$

Frequência de transição hiperfina

Comprimento de onda da linha $D_{1}$ (no vácuo)

Comprimento de onda da linha $D_{2}$ (no vácuo)

Número de onda da linha $D_{2}\left(2 \pi / v_{D 2}\right)$

Frequência da linha $D_{2}$

Tempo de vida do estado excitado $6^{2} P_{3 / 2}$

Largura de linha natural, linh $a D_{2} 1 / \tau$

Intensidade de Saturação da linha $D_{2}\left(\pi h c / 3 \lambda^{3} \tau\right)$

Seção de choque de absorção $\left(D_{2}\right)$

Máxima aceleração da saturação da linha $D_{2}$

Velocidade de recuo do fóton $\left(D_{2}\right)$

Temperatura de recuo

Velocidade de captura $(1 / \tau k)$

Temperatura Doppler
55

$2,20694650(17) \times 10^{-25} \mathrm{Kg}$

$6 s^{1}$

$1,3 \times 10^{-6}$ Torr

$100 \%$

Estável

$I=7 / 2$

$g_{I}=-4,013 \times 10^{-4}$

$g_{J}=2,00254032(20)$

$9192631770 \mathrm{~Hz}$

$\lambda_{D 1}=894,36 \mathrm{~nm}$

$\lambda_{D 2}=852,34727582(27) \mathrm{nm}$

$k=7,0235 \times 10^{-6} \mathrm{~m}^{-1}$

$v_{D 2}=351,72571850(11) \mathrm{THz}$

$\tau=30,473(39)$ ns

$\Gamma=2 \pi \times 5,2152 \mathrm{MHz}$

$I_{5}=1,09 \mathrm{~mW} / \mathrm{cm}^{2}$

$\sigma_{g e}=346,9 \times 10^{-15}$

$a_{\max }=5,7 \times 104 \mathrm{~m} / \mathrm{s}^{2}$

$v_{r}=3,52 \mathrm{~mm} / \mathrm{s}$

$T_{r}=0,198 \mu \mathrm{K}$

$v_{C}=4,42 \mathrm{~mm} / \mathrm{s}$

$T_{D}=124 \mu \mathrm{K}$ 


\section{ANEXO (C)}

(Níveis de energia do Césio ${ }^{133}$ (Alves, 2012)) 


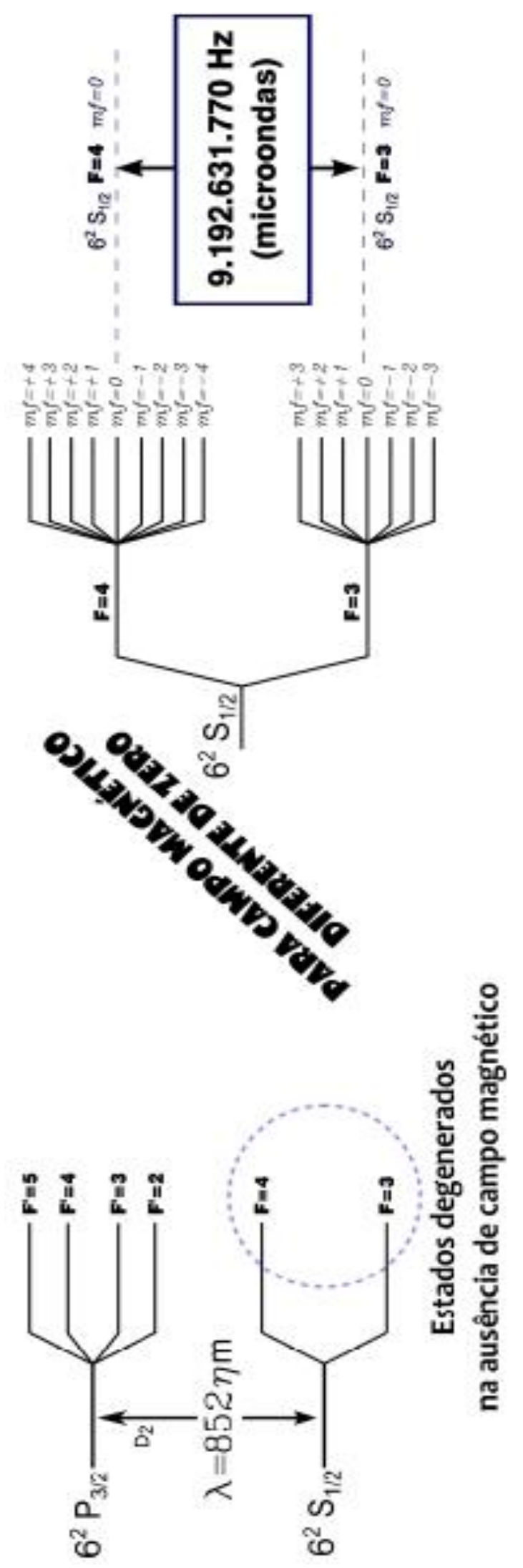




\section{APÊNDICE (A)}

(Circuito - Controle de Temperatura do laser e da caixa) 


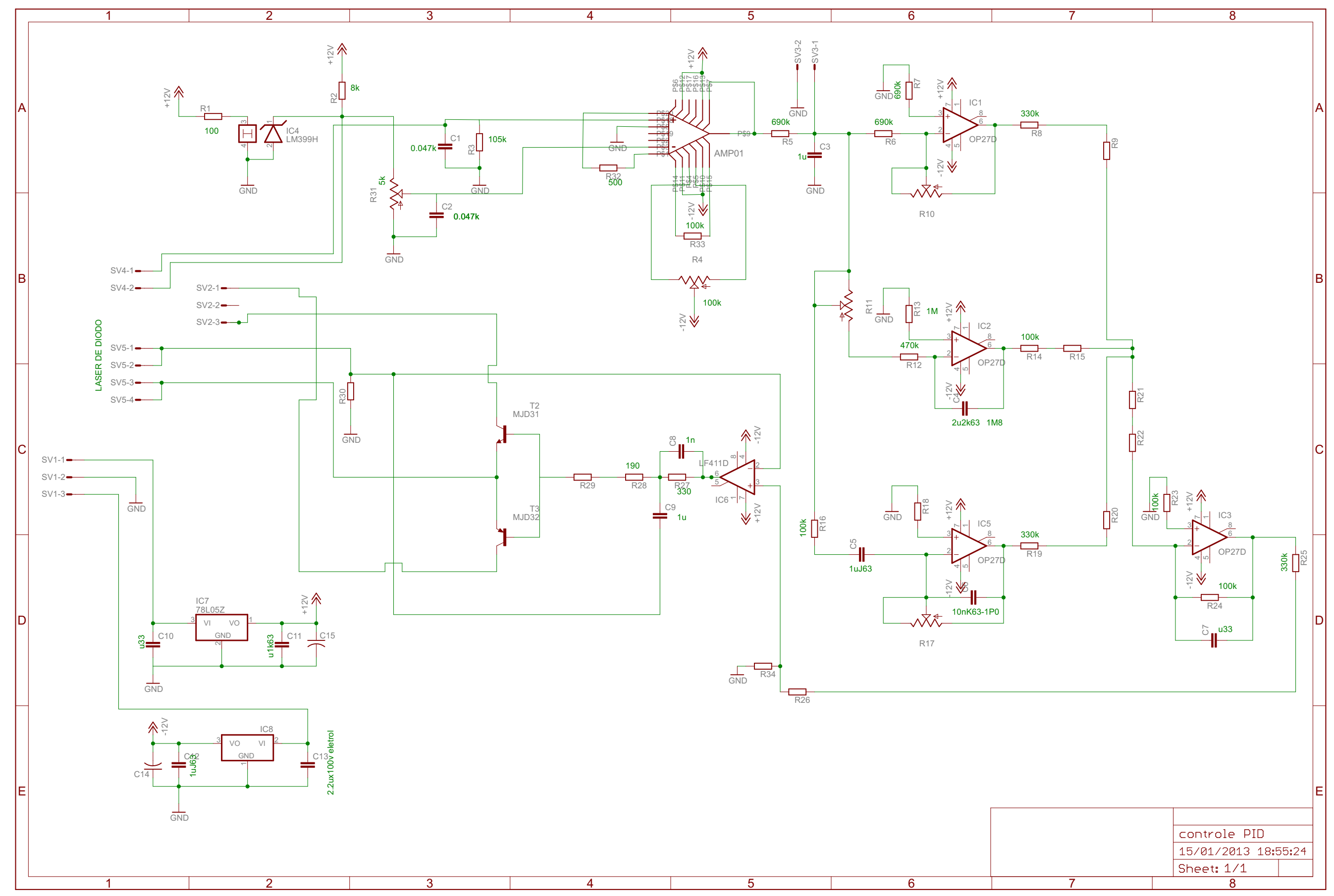




\section{APÊNDICE (B)}

(Circuito - Fonte de Corrente) 


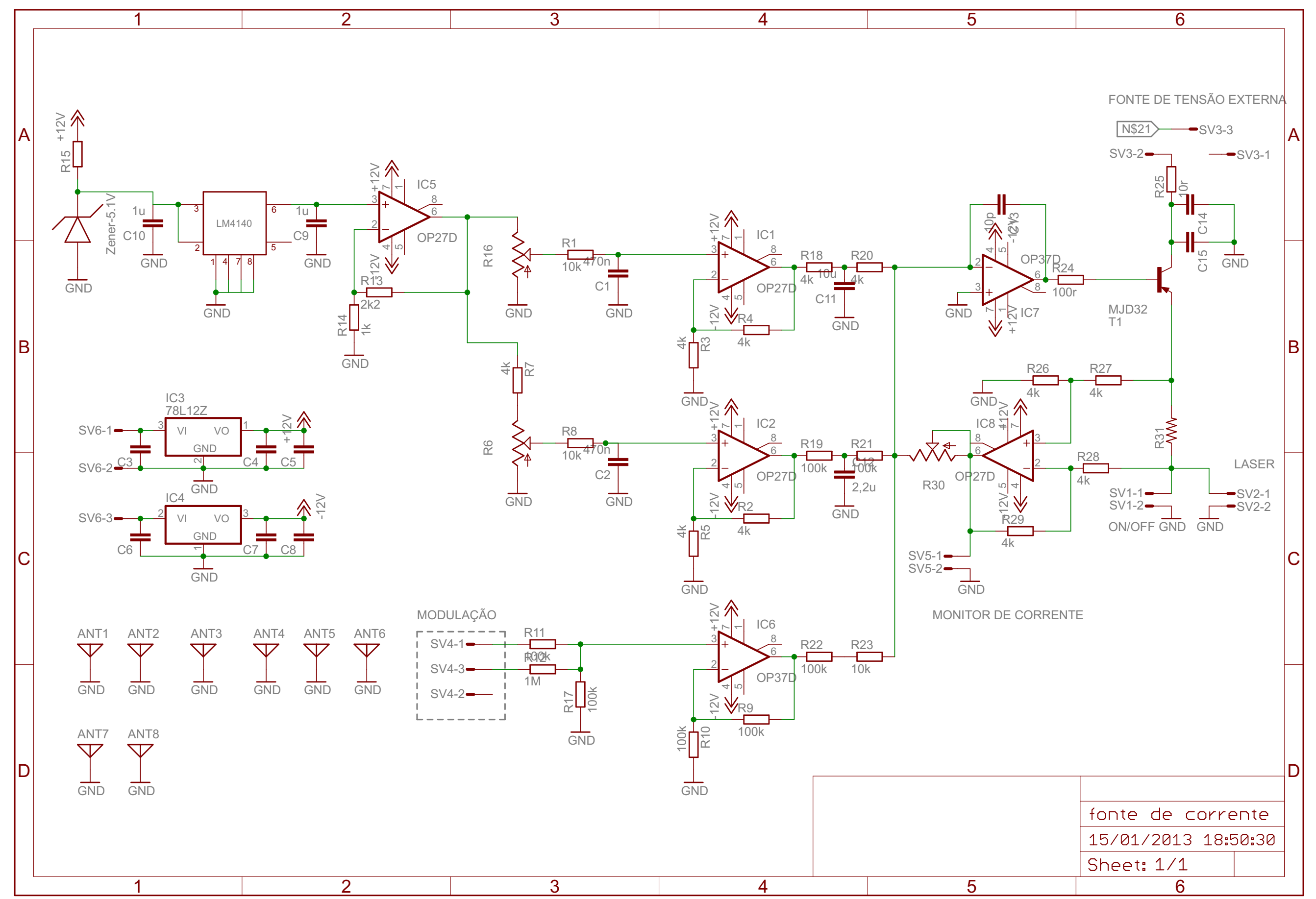




\section{APÊNDICE (C)}

(Circuito - Amplificador de alta tensão) 


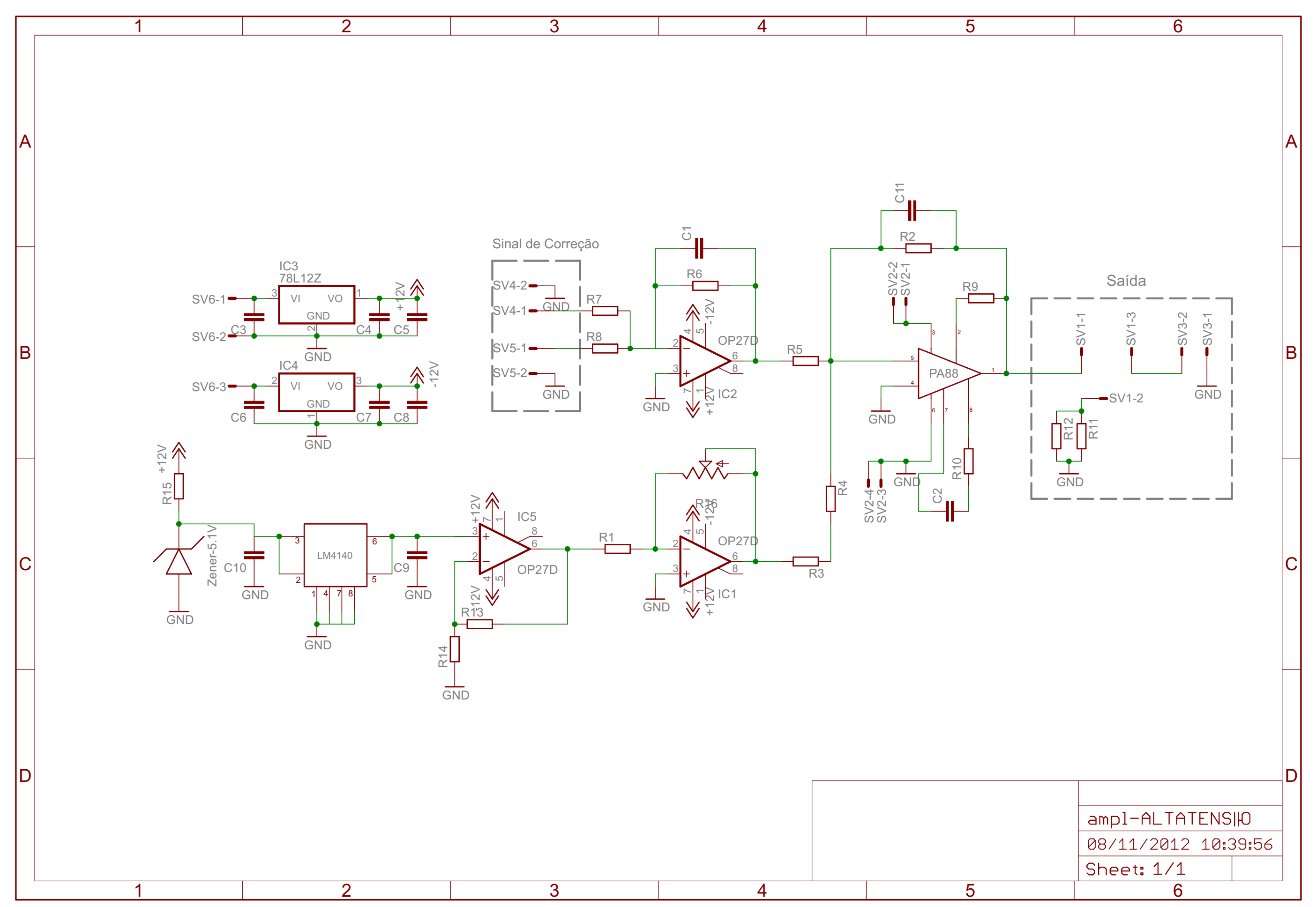




\section{APÊNDICE (D)}

(Circuito de travamento) 


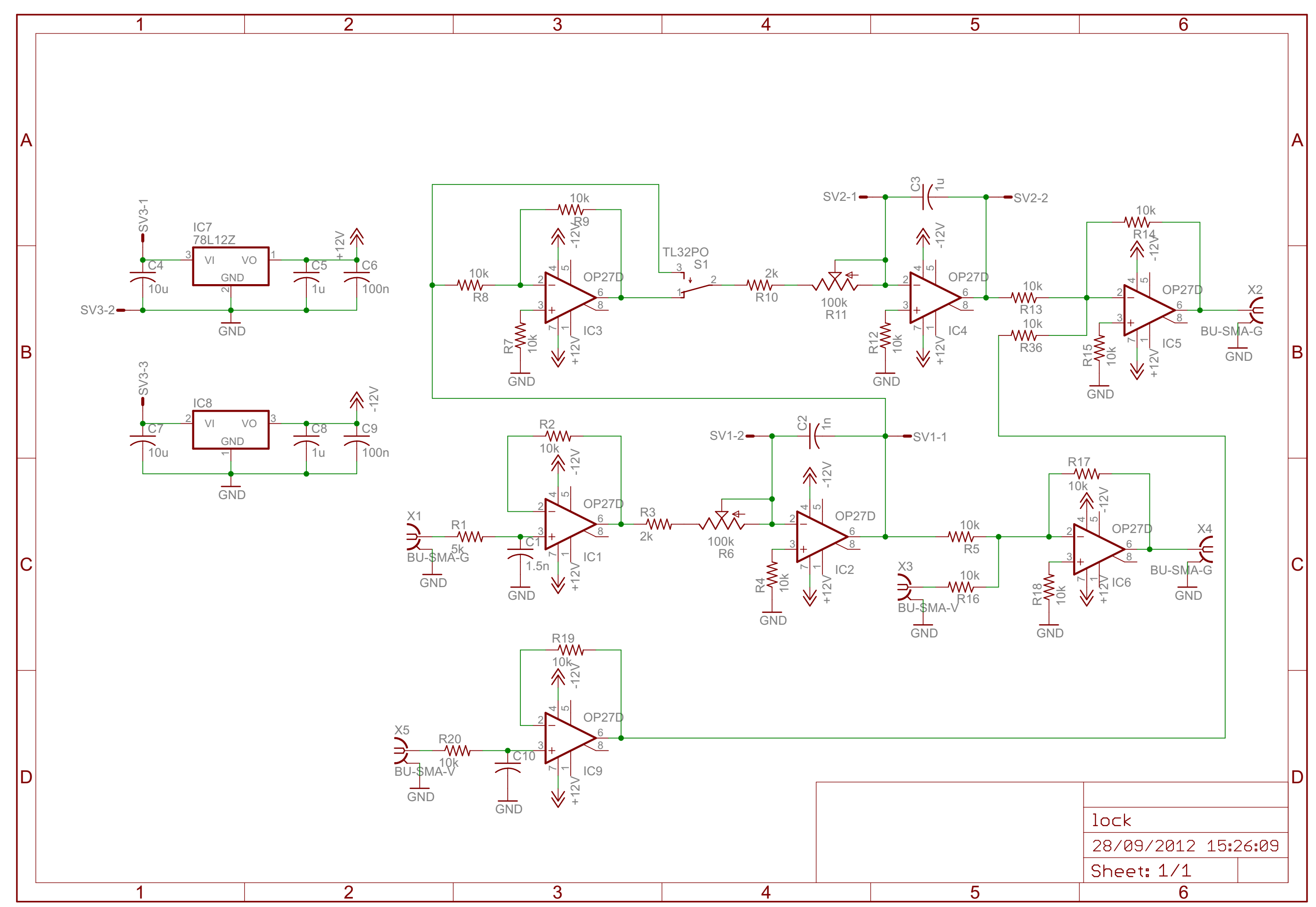




\section{APÊNDICE (E)}

(Programa LabVIEW) 


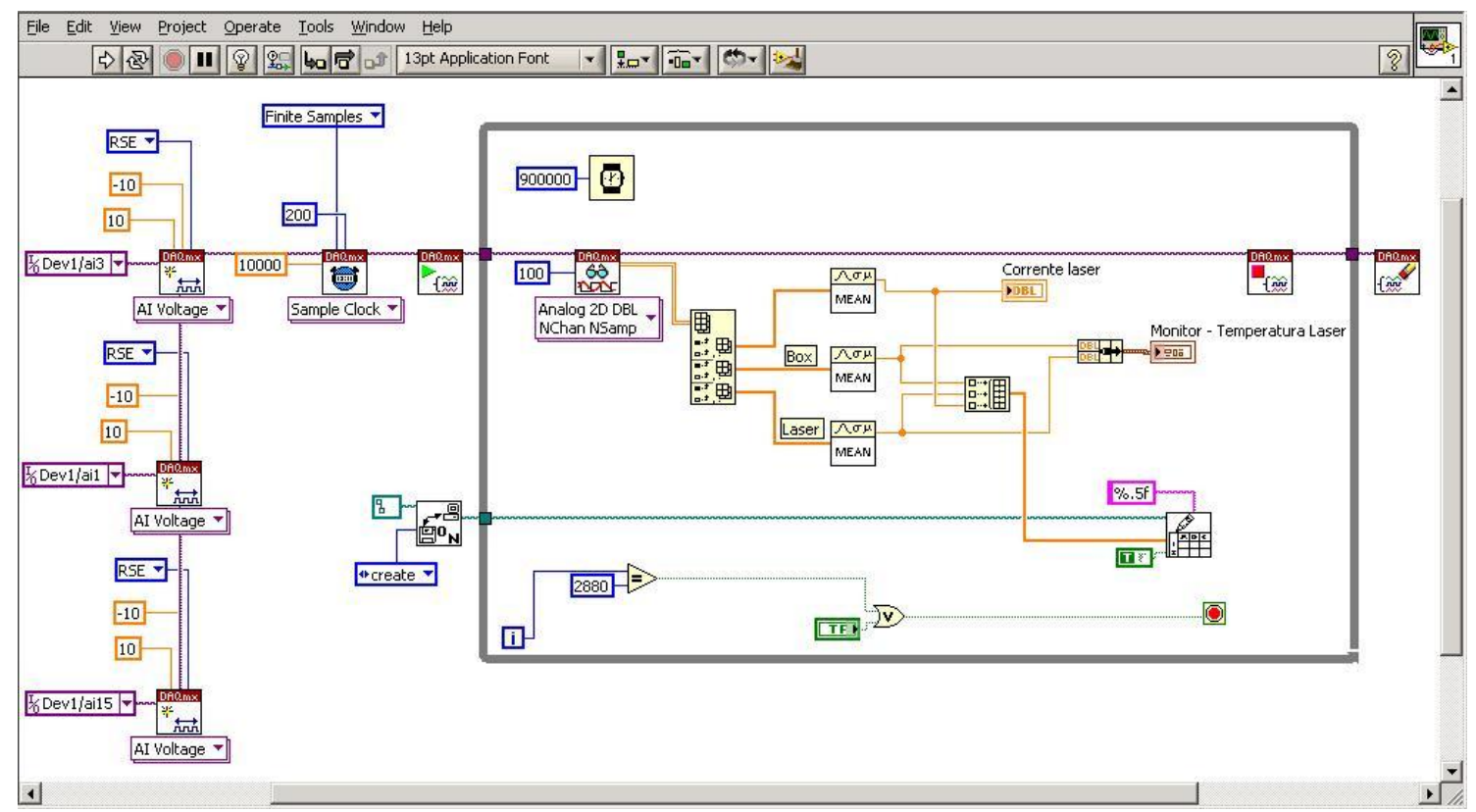

Diagrama de Blocos do programa

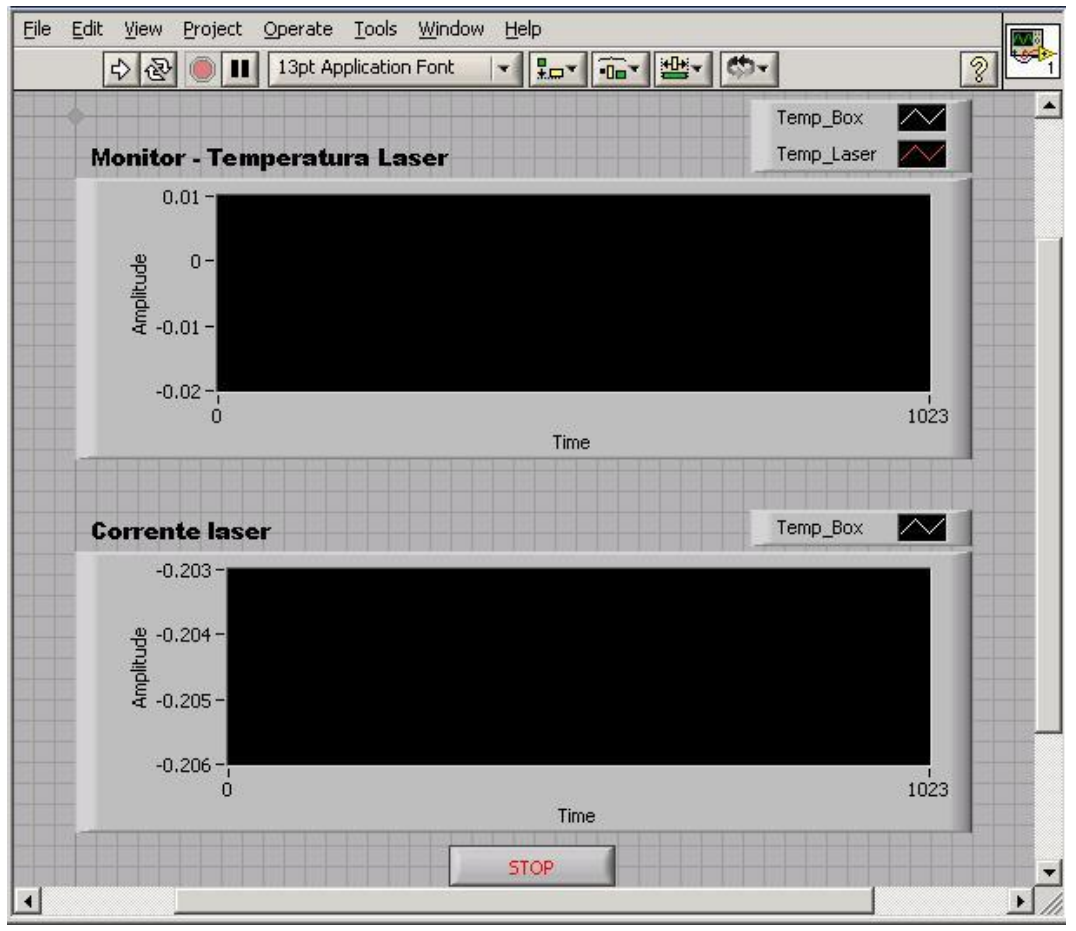

Painel Frontal do programa 